\title{
Lifting Analysis of Precast Prestressed Concrete Beams
}

\author{
Razvan Cojocaru
}

Thesis submitted to the faculty of the Virginia Polytechnic Institute and State University in partial fulfillment of the requirements for the degree of

\section{MASTER OF SCIENCE \\ in \\ Civil Engineering}

\author{
Cristopher D. Moen, Chair \\ Carin L. Roberts-Wollmann \\ William J. Wright
}

April 27, 2012

Blacksburg, VA

Keywords: precast prestressed concrete, lateral stability, sweep, lifting support eccentricity 


\title{
Lifting Analysis of Precast Prestressed Concrete Beams \\ Razvan Cojocaru
}

\begin{abstract}
Motivated by Robert Mast's original papers on lifting stability, this research study provides a method for predicting beam behavior during lifting, with application in the construction of bridges. A beam lifting cracking limit state is developed based on analytical equations for calculating the roll angle of the beam, the internal forces and moments, the weakaxis and strong-axis deflections, and the cross-sectional angle of twist. Finite element simulations are performed to investigate the behavior of concrete beams during lifting and to validate the proposed method. Additionally, a statistical characterization of beam imperfections is presented, based on recently conducted field measurements of beam lateral sweep and eccentricity of lift supports. Finally, numerical examples for two typical precast prestressed concrete beam cross-sections are included to demonstrate the proposed method.
\end{abstract}




\section{DEDICATION}

For my family, and my friend, Adrian Talapan, who offered me unconditional support throughout the course of this thesis. 


\section{ACKNOWLEDGEMENTS}

First and foremost, I would like to thank my friend Adrian Talapan to whom I am greatly indebted. Without his support I would have not been able to pursue my degree. Gratitude is also extended to my family for acting as my life support during this two year endeavor. I owe a special thank you to Dr. Cristopher D. Moen for providing me the opportunity to work on this project under his advisement. I have felt extremely honored to conduct research under him, as he served not only as an advisor, but a friend and mentor. My sincerest gratitude goes to Dr. Raymond Plaut, who repeatedly provided sound advice, answered questions and offered unquestioned expertise throughout my research. Thanks to Dr. Carin L. Roberts-Wollmann and Dr. William J. Wright for serving on my thesis committee.

The support of the members of the PCI Research and Development Committee and the project advisory members, Roger Becker, Robert Mast, Andy Osborn, Glenn Myers, and William Nickas is also gratefully acknowledged. In addition, I would like to recognize the support provided by: Richard Potts of Standard Concrete Products, Savannah, GA; Jason Moore of Tekna Corporation, Charleston, SC; Frankie Smith of Prestress of the Carolinas, Charlotte, NC; and Joe Rose of Coastal Precast Systems, Chesapeake, VA.

Finally, I would like to thank all my friends in the SEM family at Virginia Tech. 


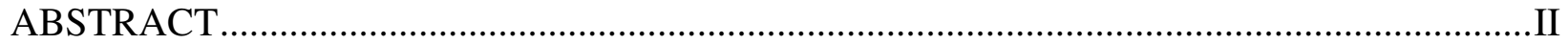

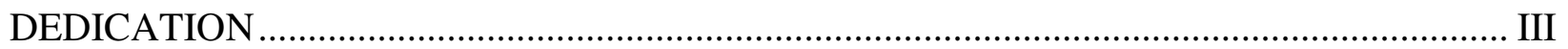

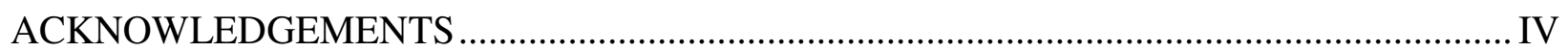

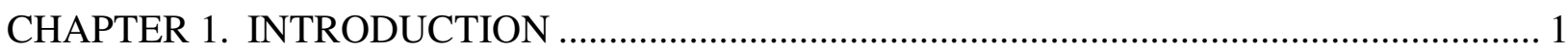

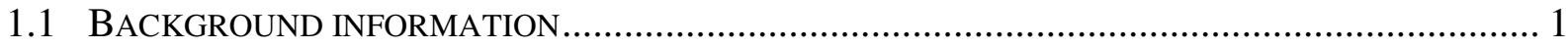

1.2 CODE PROVISIONS FOR STABILITY OF BEAMS DURING LIFTING ……….............................. 2

CHAPTER 2. LITERATURE REVIEW ....................................................................... 4

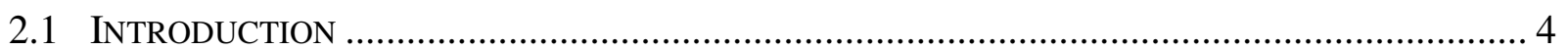

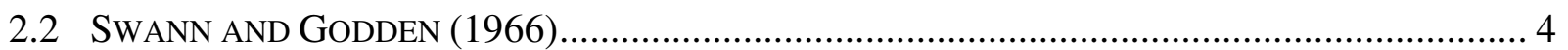

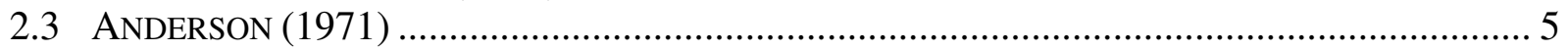

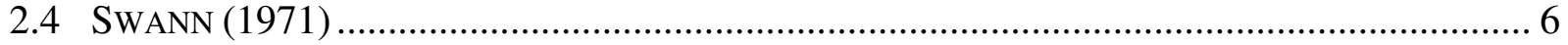

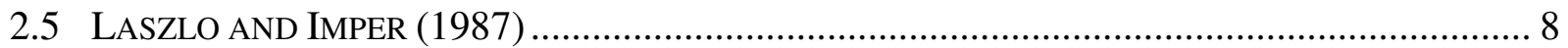

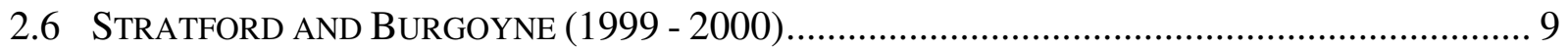

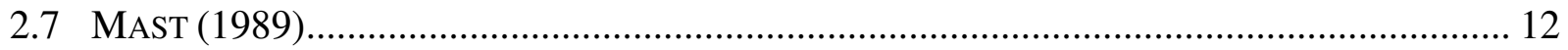

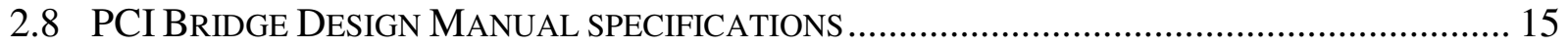

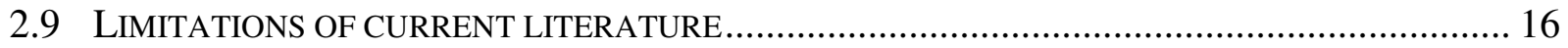

CHAPTER 3. PCI JOURNAL PAPER, Lifting Analysis of Precast Prestressed Concrete

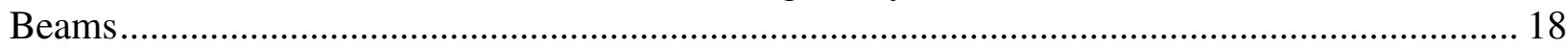

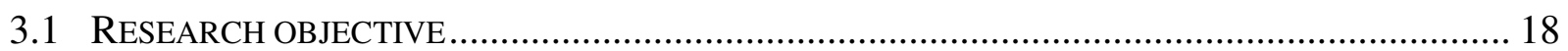

3.2 STUDY OF GEOMETRIC IMPERFECTIONS IN PRECAST PRESTRESSED CONCRETE BEAMS ......... 18



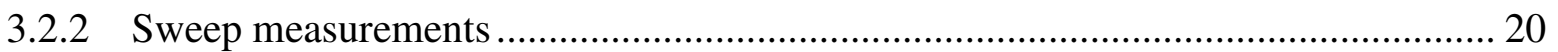

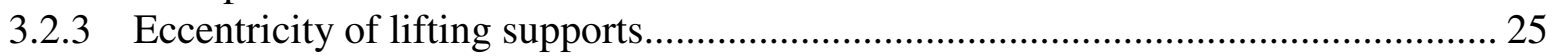

3.3 LIMIT STATE ANALYSIS OF CONCRETE BEAMS DURING LIFTING ……………………......... 28

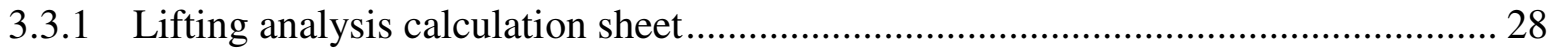



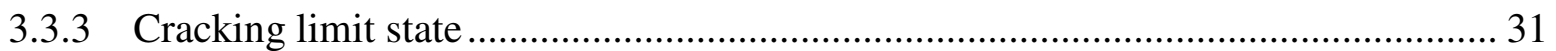

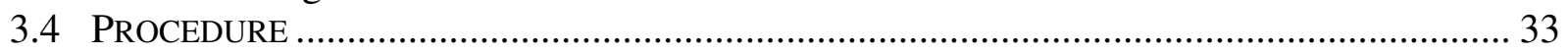

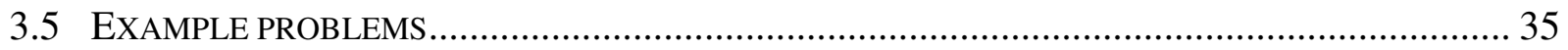

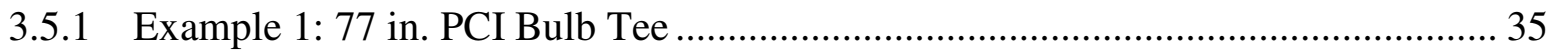



3.5.3 Comparison to Mast (1989) factor of safety approach .............................................. 45

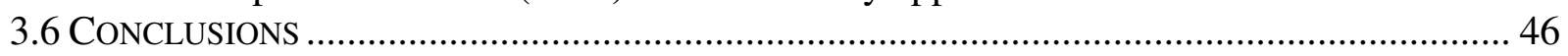

CHAPTER 4. VALIDATION OF PROPOSED MODEL ........................................................ 48

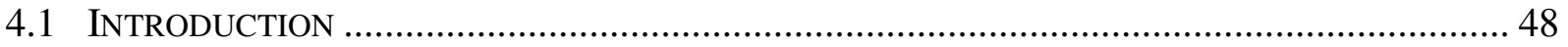

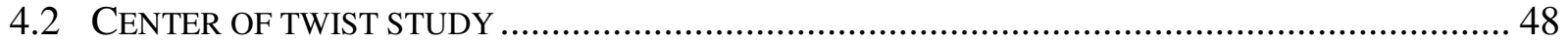

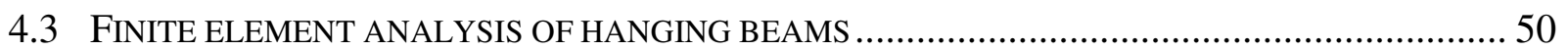

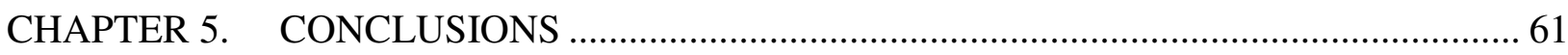

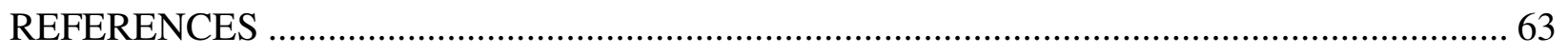




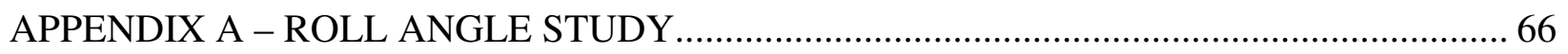

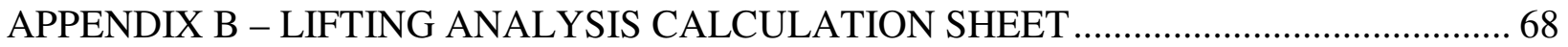

APPENDIX C - ABAQUS INPUT FILE - FE MODEL OF A HANGING BEAM .................. 73

APPENDIX D -MAST (1993) FS SAMPLE CALCULATIONS ........................................... 76

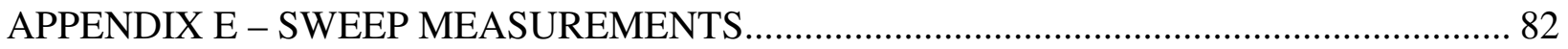




\section{LIST OF TABLES}

Table 1. Summary of beams measured for sweep ................................................................. 20

Table 2. Summary of beams measured for lifting support eccentricity .................................. 20

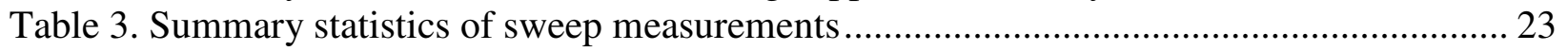

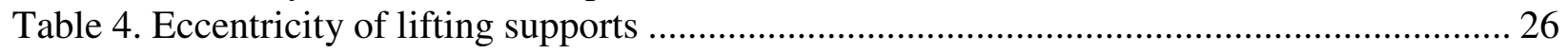

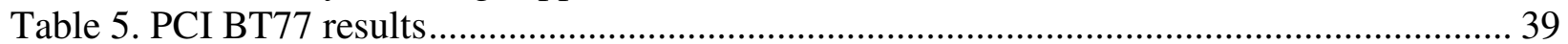

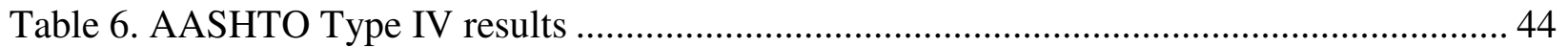

Table 7. FS against cracking approach for PCI BT77 ...................................................... 45

Table 8. FS against cracking approach for AASHTO Type IV .......................................... 45

Table 9. Center of twist location for common precast concrete beams .................................... 49

Table 10. Properties of Type IV AASHTO and PCI-BT-72 beams used for the FE model........ 52

Table 11. AASHTO Type IV beam: Plaut \& Moen/ABAQUS results ..................................... 53

Table 12. PCI-BT-72 beam: Plaut \& Moen/ABAQUS results ................................................. 54

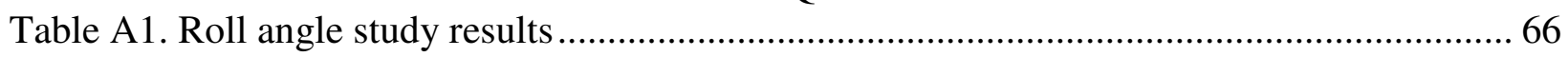

Table E1. Summary of sweep measurement results ......................................................... 82 


\section{LIST OF FIGURES}

Figure 1. Graphical representation of quantities defined in Swann (1971) ................................... 7

Figure 2. Tilted beam showing the location of the maximum tensile and compressive stresses



Figure 3. Stresses to be combined when assessing a beam during lifting ................................... 12

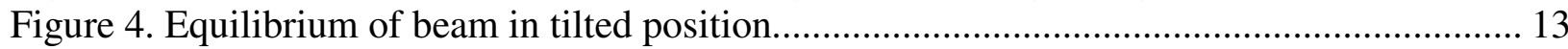

Figure 5. PCI tolerances for sweep and eccentricity of lift supports......................................... 19

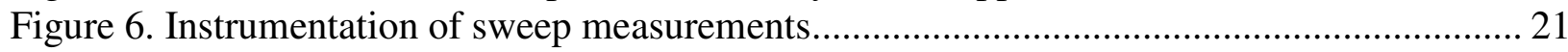

Figure 7. Shape of measured sweep for six random beams ..................................................... 22

Figure 8. Measured beams screened from direct sunlight exposure ............................................. 22

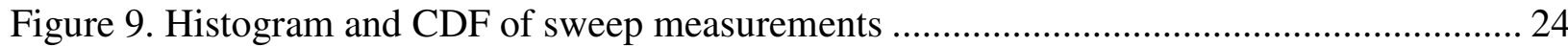

Figure 10. Lifting loops measured for eccentricity ................................................................. 25

Figure 11. Sign convention used for the lift support eccentricity measurements ......................... 26

Figure 12. Effect of eccentricity of lift supports is greatest when both lift loops are closer to





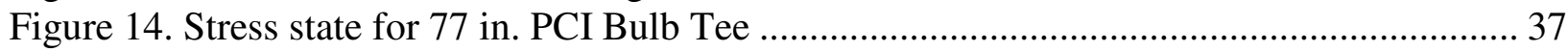

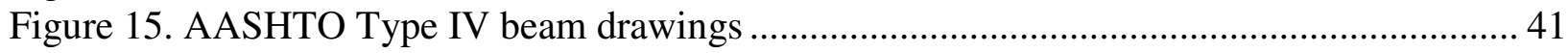

Figure 16. Stress state for AASHTO Type IV beam ................................................................ 43

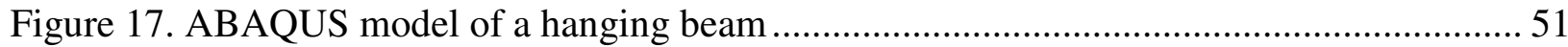

Figure 18. Strong-axis bending moment comparison for AASHTO type IV beam ......................5 54

Figure 19. Strong-axis bending moment comparison for PCI-BT-72 beam.................................. 55

Figure 20. Weak-axis bending moment comparison for AASHTO type IV beam........................ 55

Figure 21. Weak-axis bending moment comparison for PCI-BT-72 beam ................................... 56

Figure 22. Strong-axis shear comparison for AASHTO type IV beam .......................................... 56

Figure 23. Strong-axis shear comparison for PCI-BT-72 beam ………………………................ 57

Figure 24. Weak-axis shear comparison for AASHTO type IV beam ……………….................. 57

Figure 25. Weak-axis shear comparison for PCI-BT-72 beam..................................................... 58

Figure 26. Strong-axis displacement comparison for AASHTO type IV beam ........................... 58

Figure 27. Strong-axis displacement comparison for PCI-BT-72 beam......................................... 59

Figure 28. Weak-axis displacement comparison for AASHTO type IV beam............................... 59

Figure 29. Weak-axis displacement comparison for PCI-BT-72 beam .......................................... 60

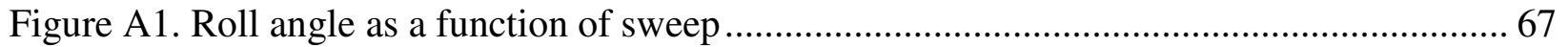

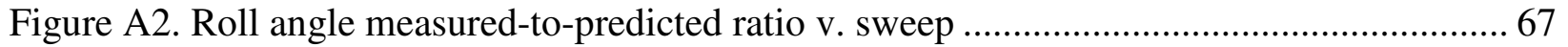



Figure B2. Graphical representation of quantities describing properties of lifting devices ......... 69

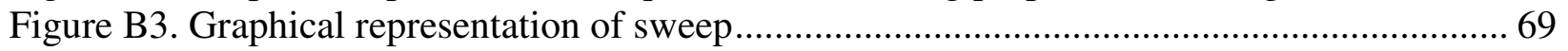

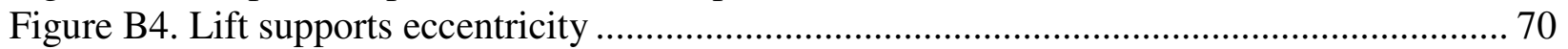

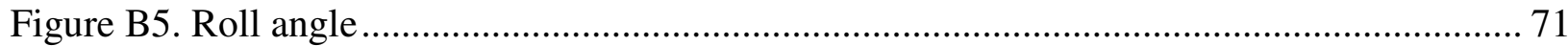






\section{CHAPTER 1. INTRODUCTION}

\subsection{Background information}

Precast prestressed concrete beams are widely used in today's bridge construction industry where speed and ease of erection are of paramount importance. Over the years, the precast prestressed concrete beam spans have increased due to improvements in material properties, the introduction of new girder shapes, larger prestressing strands, and advances in design methods (Castrodale and White 2004). Many states are currently utilizing long, globally slender girders exceeding $200 \mathrm{ft}$ with optimized section shapes, for example, the California Wide-Flange Girder (Pope and Holombo 2009) and the Nebraska University (NU) I-girder (Geren and Tadros 1994). The record length for a precast concrete plant-cast girder is currently held by a $213 \mathrm{ft}(65 \mathrm{~m})$ long, $19 \mathrm{ft} 3$ in. $(2.8 \mathrm{~m})$ deep spliced girder used for the Bow River Bridge near Calgary, Alberta, Canada. Nonetheless, there is an upper limit on precast prestressed concrete beam lengths because of size and weight limitations on beam shipping and handling (Castrodale and White 2004).

A consequence of the increase in beam spans is an increase in depth as well. Additionally, due to transportation and handling limitations, the weight is being kept to a minimum by reducing the width of the web and flanges. As a result, long span beams tend to have lower minor-axis and torsional stiffness compared to typical precast beams, making them more susceptible to lateral buckling and therefore increasing the likelihood of a stability failure (Hurff 2010). 
Many times, designers ignore the issue of lateral stability during lifting, only considering the stability of the finished structure and leaving any issues related to the construction and handling stage to the fabricators and contractors (Mast 1989). Several jobsites incidents have been reported involving excessive deformations and in some cases failure during the handling of long precast concrete beams. For this reason, it is important to understand the behavior of long concrete beams during lifting, which can be susceptible to stability failures. Lateral stability considerations must be taken into account during transportation, when beams are supported on trucks and trailers, and during the construction stages, when beams are resting on temporary supports. However, in a study performed by Stratford and Burgoyne (1999) using finite element techniques, it was found that the case of a prestressed concrete girder during lifting was the most critical condition when considering catastrophic failures. Accordingly, the analysis procedures described in the following sections focus on the behavior of precast prestressed concrete beams during lifting.

\subsection{Code provisions for stability of beams during lifting}

The PCI Design Handbook (6 ${ }^{\text {th }}$ Edition) highlights the issue of lateral stability in Section 5.4.1 and directs the reader to three articles published by Robert Mast $(1989,1993$, and 1994) for specific guidance. The PCI Bridge Design Manual (2003) addresses the lateral stability of slender members in Chapter 8.10 which outlines a procedure for calculating a factor of safety against cracking for a hanging beam. The described method is based on Robert Mast's paper published in 1989 in the PCI Journal titled Lateral Stability of Long Prestressed Concrete Beams, Part 1 .

The AASHTO LRFD Bridge Design Specifications (2007) and the AASHTO LRFD Bridge Construction Specifications (2004) do not provide specific guidelines for investigating 
lateral stability of beams when hanging. Section 5.14.1.2.1 of the AASHTO LRFD Bridge Design Specifications (2007) assigns the responsibility for safe shipping and erection to the contractor. Additionally, section 5.14.3.3 underscores the need for considering the possibility of buckling in tall thin web sections. Overall, the governing design codes include only very basic stability checks and lack sufficient guidance on the subject of stability of precast prestressed beams during lifting (Hurff 2010 and Stratford et al. 1999). 


\subsection{Introduction}

The importance of performing lateral stability checks on long slender beams was recognized many years before the boom of the precast prestressed concrete industry. It has always been customary to perform stability checks for curved steel beams. However, there are significant differences between the behavior of steel beams and concrete beams during lifting. For concrete beams self-weight is of greater importance and their minor axis stiffness is much lower compared to their torsional stiffness. For reasons such as these, temporary conditions for concrete beams under self-weight loading, such as during lifting, are much more critical than the final loading state when the top deck is in place preventing lateral instability (Stratford and Burgoyne 1999). For the purpose of this paper, the following section draws together the relevant literature and theory regarding the stability of precast prestressed concrete beams during lifting.

\subsection{Swann and Godden (1966)}

Swann and Godden (1966) provided a numerical method for calculating the elastic buckling load of a slender beam under vertical loading based on Newmark's procedure for determining the buckling load of struts. They simplified the lateral buckling problem of beams with a slight curvature (due to an initial imperfection) by dividing the beam into a small number of chords, and reducing a curved beam problem to an equivalent problem analyzing a number of straight beams joined end to end. Using this method, Swann and Godden then studied the selfweight buckling of long concrete beams during lifting. Their detailed derivation for calculating the buckling load of a beam supported by cables is given in reference 29 . 


\subsection{Anderson (1971)}

Anderson (1971) highlighted the need to pay more attention to temporary stresses and the lateral stability of precast prestressed concrete beams during transportation and erection. Anderson experienced firsthand the problem of lateral stability during the lifting of a $150 \mathrm{ft}$ long beam from the stressing bed. The beam started to tip and deflect laterally, at which point it was immediately lowered back and restored to its initial straight condition (Anderson 1971). In his paper, Anderson defined the factor of safety against lateral buckling for a beam that is lifted at the crane hooks as:

$$
\text { F.S. }=\frac{y_{t}}{\Delta_{y}}
$$

where

$y_{t}=$ distance from the beam top face to the beam centroid

$\Delta_{y}=$ mid-span deflection when the beam's self weight is applied in the weak-axis direction

In the case of a prismatic beam with a uniform weight and a constant moment of inertia, the deflection $\Delta_{y}$ can be calculated using the well-known deflection formula:

$$
\Delta_{y}=\frac{5}{384} \frac{w L^{4}}{E_{c} I_{y}}
$$

where

$w=$ self-weight of the beam

$L=$ length of the beam

$E_{c}=$ modulus of elasticity of concrete

$I_{y}=$ weak-axis moment of inertia 


\subsection{Swann (1971)}

Shortly after Anderson's publication, Swann (1971) proposed a new equation for the factor of safety against buckling:

$$
\text { F.S. }=\frac{y_{t}}{0.64 \Delta_{y}}
$$

He identified the term in the denominator to be the shift in the center of gravity of the mass of the beam after deflecting laterally, as opposed to the shift of the mid-span section. This agrees with Mast's findings (Mast 1989), where he calculated the lateral deflection of the center of gravity of a beam $\overline{z_{0}}$ supported at the ends as:

$$
\overline{z_{0}}=\frac{w L^{4}}{120 E_{c} I_{y}}=0.64 \Delta_{y}
$$

Additionally, Swann (1971) clarified that $y_{t}$ should be taken as the vertical distance between a line through the two lifting points and the center of gravity of the whole beam, rather than the distance between the top face of the beam and the center of gravity of the cross-sectional area. The reason is that when a beam has an initial camber due to the prestress, these two quantities are significantly different. A graphical representation of the above mentioned values is depicted in Figure 1. Furthermore, Swann (1971) also addressed the importance of initial imperfections. To illustrate the importance of considering geometric imperfections in stability calculations, he provided an equation for the weak axis bending moment $M_{y}$, which he surmised was the cause of failure in beams when hanging. He expressed $M_{y}$ as a function of $\theta_{0}$ :

$$
M_{y}=M_{x} \theta=M_{x} \theta_{0}\left(\frac{1}{1-\frac{1}{\text { F.S. }}}\right)
$$

where

$M_{x}=$ bending moment about the strong-axis due to self-weight 
$\theta=$ angle of tilt (in radians) of the member about a line through the lifting points (Figure 4)

$\theta_{0}=$ angle of tilt due to imperfections if the beam were rigid

Based on the above equation for weak-axis moment $\left(M_{y}\right)$, even with a large value for the factor of safety, $M_{y}$ can become large when $\theta_{0}$ is large. And since $\theta_{0}$ is directly proportional to the magnitude of the initial imperfections (which most of the time are unknown quantities), Swann (1971) concluded that a high factor of safety is not necessarily a guarantee against failure.

The two types of imperfections identified by him are lateral sweep and the transverse distance from the minor axis of the cross-section to where the lifting points are fixed.

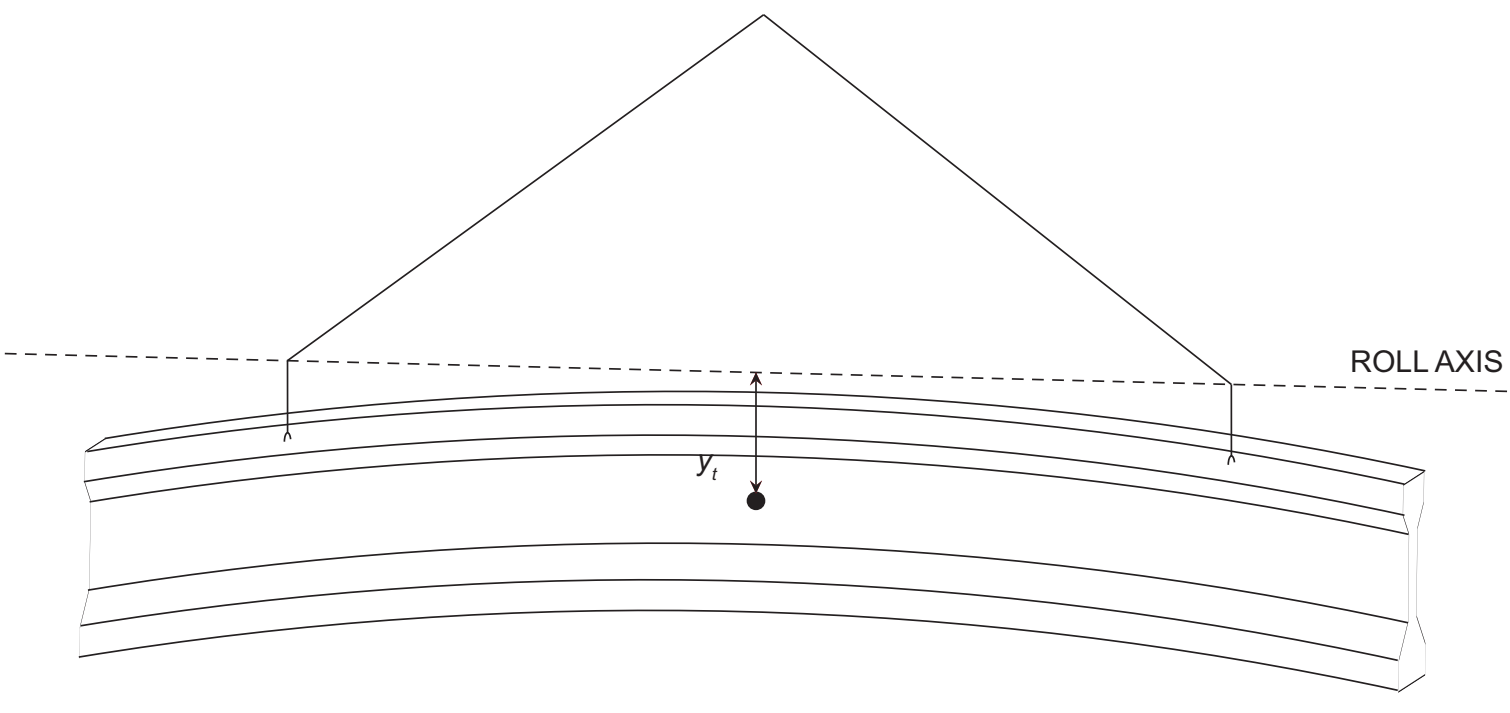

ISOMETRIC VIEW

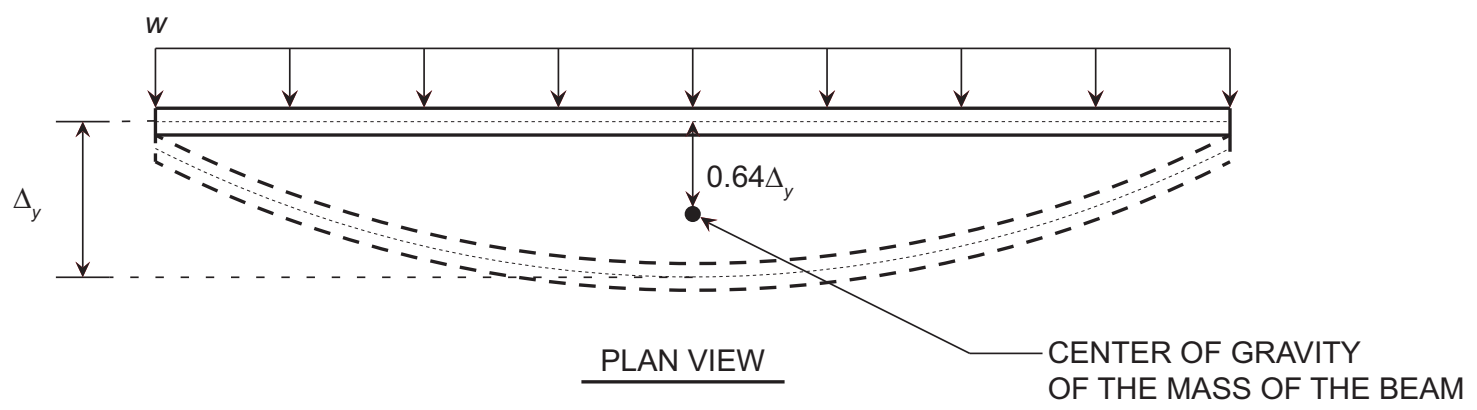

Figure 1. Graphical representation of quantities defined in Swann (1971): $y_{t}$ is the distance from the beam top face to the beam centroid, and it accounts for the shift in the location of the centroid due to camber. $\Delta_{y}$ is the midspan deflection when the beam's self weight is applied in the weak-axis direction. The shift in the center of mass of the deflected shape is $0.64 \Delta_{y}$. 
Furthermore, Swann (1971) emphasized that if a beam is allowed to crack when lifted, its weak-axis stiffness will decrease, magnifying the lateral deflection $\Delta_{y}$ and consequently decreasing the factor of safety. And from the above moment equation it can be observed that a reduction in the factor of safety increases the weak-axis bending which in turn leads to more cracking, etc. Therefore, according to him, cracking due to bending will most probably cause a catastrophic collapse with little or no warning (Swann 1971).

\subsection{Laszlo and Imper (1987)}

Laszlo and Imper (1987) suggested values for the factor of safety, based on plant and field experience: F.S. $>1.5$ for plant handling and F.S. $>1.75$ for field handling (erection). Furthermore, they proposed a seven step calculation method to carry out a stability check for the safe handling of long span bridge beams during lifting. The goal was to calculate the handling stresses of a laterally deflected beam at two critical points of the rotated cross-section: the downward top flange under high tension and the upward bottom flange under high compression at three critical locations along the length of the beam (midspan, pickup point, and at harping point), as depicted in Figure 2. The proposed seven step process is outlined in reference 11. 


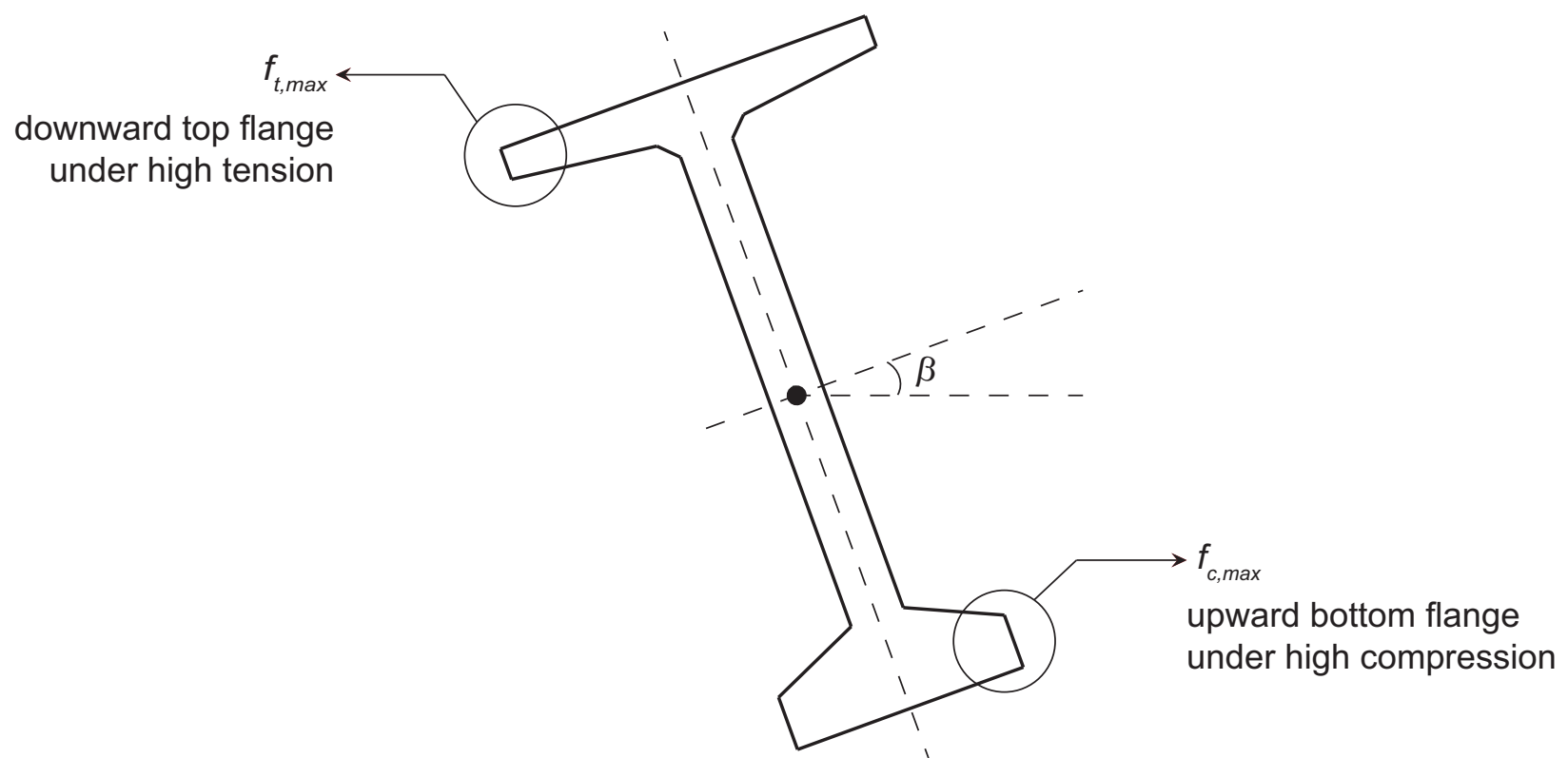

Figure 2. Tilted beam showing the location of the maximum tensile and compressive stresses during lifting. $f_{t, \max }=$ maximum tensile stress acting on the cross-section during lifting; $f_{c, \max }=$ maximum compressive stress acting on the cross-section during lifting; $\beta=$ roll angle.

\subsection{Stratford and Burgoyne (1999 - 2000)}

More recently, Stratford and Burgoyne $(1999,2000)$ derived a set of equations for hanging beams, presenting a detailed analysis for beams with inclined or vertical cables, with inclined or vertical yokes, with lateral loads (wind or inertia effects), and with initial imperfections. The authors provided solutions to critical quantities that are important when investigating the stability of long precast concrete beams: the critical load of a perfect beam $\left(w_{c r}\right)$, the load-deflection curve of the imperfect beam, the curvature associated with a given lateral deflection $(k)$, and the bending stresses which are additional to those due to the primary bending moment and the prestress $(\Delta \sigma)$. The authors derived separate equations for vertical cables and inclined cables. The equation for the beam midspan deflection $v_{m s}$ is the same for both cases:

$$
v_{m s}=\frac{\delta_{0}(1-\sin \pi a / L)}{\left(1-w / w_{c r}\right)}
$$


where

$\delta_{0}=$ sweep imperfection (it can be obtained by measuring a beam or by using a limiting value specified by existing codes)

$a=$ distance of yoke attachment point from end of beam

$L=$ length of beam

$w=$ self weight of beam per unit length

$w_{c r}=$ critical self weight of beam to cause buckling per unit length

Vertical cables:

For the case of vertical cables, the roll angle can be calculated by solving the following equation:

$$
v_{m s}=\frac{w \sin \theta}{384 E_{c} I_{y}}\left(5 L^{2}-20 a L-4 a^{2}\right)(2 a-L)^{2}+\delta_{0}\left(1-\sin \frac{\pi a}{L}\right)
$$

where

$v_{m s}=$ midspan deflection

$\theta=$ roll angle: rigid body rotation about the beam's axis

The midspan curvature $k_{m s}$ is evaluated using the following equation:

$$
k_{m s}=\frac{w \sin \theta}{8 E_{c} I_{y}}\left(L^{2}-4 a L\right)
$$

Inclined cables:

From the midspan deflection equation, the rigid body roll angle $\theta$ for the case of inclined cables can be calculated by substituting the appropriate values into the following equation:

$$
\begin{aligned}
v_{m s}= & \frac{w \sin \theta}{\mu^{4} E_{c} I_{y}}\left[\left(1-\frac{\mu^{2} a^{2}}{2}\right)(\cos \mu b+\tan \mu b \sin \mu b-1)-\frac{\mu^{2} b^{2}}{2}\right] \\
& +\frac{\pi^{2} \delta_{0}}{\pi^{2}-\mu^{2} L^{2}}\left[1-\sin \frac{\pi a}{L}(\cos \mu b+\tan \mu b \sin \mu b)\right]
\end{aligned}
$$

where 
$\mu=\sqrt{\left(\frac{w L}{2 E_{c} I_{y} \tan \alpha}\right)}$

$\alpha=$ cable inclination angle above the horizontal

$b=$ distance from the yoke attachment point to the center of the beam $(L / 2-a)$.

The midspan curvature is given by:

$$
k_{m s}=\mu^{2} v_{m s}+\frac{w \sin \theta}{2 E_{c} I_{y}}\left(b^{2}-a^{2}\right)
$$

The additional curvature at midspan, $k_{m s}$, is then used to determine the stress distribution across the beam. At a distance $X$ from the beam's major axis the change in the concrete stress $\Delta \sigma$ can be found from the following equation:

$$
\Delta \sigma=E_{c} k_{m s} X
$$

where

$X=$ distance from the beam's major axis

The change in stress must then be added to the major-axis stress distribution $\sigma_{y}$, which includes the effects of the self-weight bending moment in the strong-axis, the stress due to the prestress, and in the case of inclined cables, the additional force and bending moment resulting from the axial force in the cables (Figure 3). This allows the calculation of the stress at the two critical points of the cross-section, i.e., the two corners of the section with the largest tensile and compressive stresses, as shown previously in Figure 2. The full derivation of the equations developed by Stratford and Burgoyne (2000) is found in reference 27. 
STRESS DISTRIBUTION DUE TO BENDING ABOUT THE MINOR AXIS

Includes stresses due to:

- initial imperfection

- lateral stability effects, $\Delta \sigma=E k X$

(sign depends on direction of initial imperfection)



STRESS DISTRIBUTION DUE TO BENDING ABOUT THE MAJOR AXIS Includes the effects of:

- self-weight bending moment in the major-axis direction

- stress distribution due to the prestress

- additional force and bending moment from axial force due to inclined cables

Figure 3. Stresses to be combined when assessing a beam during lifting. Reprinted from Stratford et al. (1999) (adapted with permission).

\subsection{Mast (1989)}

As presented in the PCI Design Handbook ( $6^{\text {th }}$ Edition) and the PCI Bridge Design Manual (2003), the current standard for investigating the lateral stability of precast prestressed concrete members during lifting is based on Robert Mast's paper published in 1989 in the PCI Journal titled Lateral Stability of Long Prestressed Concrete Beams, Part 1. Mast used the assumption of torsional rigidity for the beam, transforming a lateral buckling problem into a simplified bending and equilibrium problem. According to him, in order for a beam to be stable, the height of the roll center $y_{r}$ must be greater than $\overline{z_{0}}$, and the ratio $y_{r} / \overline{z_{0}}$ may be thought of as the factor of safety against lateral buckling instability: 


$$
\mathrm{FS}=\frac{y_{r}}{\overline{z_{0}}}
$$

where

$y_{r}=$ the height of the roll axis above the center of gravity of the beam (measured along the original vertical axis of the beam)

$\overline{z_{0}}=$ the theoretical lateral deflection of the center of gravity of the beam, computed with the full dead weight applied laterally (Figure 4)



END VIEW EQUILIBRIUM DIAGRAM

Figure 4. Equilibrium of beam in tilted position. Reprinted from Mast (1989) (used with permission).

The above equation is the factor of safety for a perfectly straight beam with no initial geometric imperfection (sweep). However, there is a limit on the maximum tilt angle $\theta_{\max }$ that the lateral bending strength of the beam can tolerate. For this reason, imperfect beams could fail 
before total instability is reached. Using force equilibrium, Mast developed two equations to express the factors of safety against lateral instability for a hanging beam. The actual factor of safety is the minimum of the following two values:

$$
\begin{aligned}
& \mathrm{FS}=\frac{y_{r}}{\overline{z_{0}}}\left(1-\frac{\theta_{i}}{\theta_{\max }}\right) \\
& \mathrm{FS}=\frac{\theta_{\max }}{\theta_{i}}\left(1-\frac{\overline{z_{0}}}{y_{r}}\right)
\end{aligned}
$$

where

$\theta_{i}=$ initial roll angle of the beam due to initial imperfections

$\theta_{\max }=$ maximum permissible tilt angle of the beam

The initial roll angle is calculated as:

$$
\theta_{i}=\tan \left(e_{i} / y_{r}\right)\left(\text { small angle approximation } \theta_{i}=e_{i} / y_{r}\right)
$$

where

$e_{i}=$ initial eccentricity of the center of gravity of the beam from the roll axis (Figure 4)

The first factor of safety equation was derived assuming the important parameter to be the lateral elastic properties of the beam represented by $\overline{z_{0}}$. The effect of $\theta_{i}$ and $\theta_{\max }$ was taken to be a modifying effect on the basic stability represented by $y_{r} / \overline{z_{0}}$. The quantity $\left(1-\theta_{i} / \theta_{\max }\right)$ can be thought of as a reduction factor accounting for the effects of initial imperfections. The second factor of safety equation should be used when the beam is stiff laterally and thus $\overline{z_{0}}$ is small. In this case, the effect of initial imperfections would be the dominant effect, and it would be more logical to define the factor of safety as the ratio of $\theta_{\max } / \theta_{i}$. In the second factor of safety equation, $\theta_{\max } / \theta_{i}$ is the main parameter and the quantity $\left(1-\overline{z_{0}} / y_{r}\right)$ is the modifier. Mast provides the following equation for the quantity $\overline{z_{0}}$ : 


$$
\overline{z_{0}}=\frac{w}{12 E_{c} I_{y} L}\left(\frac{1}{10} L_{1}^{5}-a^{2} L_{1}^{3}+3 a^{4} L_{1}+\frac{6}{5} a^{5}\right)
$$

where

$w=$ self-weight of the beam

$E_{c}=$ modulus of elasticity of concrete

$I_{y}=$ weak-axis moment of inertia

$L=$ length of the beam

$L_{l}=$ distance between lifting points

$a=$ overhang (distance between lifting points and end of the beam)

In the Part 2 paper published four years later, Mast (1993) proposes a new equation for the calculation of the factor of safety against cracking:

$$
\mathrm{FS}=\frac{1}{\overline{z_{0}} / y_{r}+\theta_{i} / \theta_{\max }}
$$

The new equation was proposed to replace both Eqs. (1) and (2) given in Part 1. Equation (22) gives lower factors of safety when the ratios $\overline{z_{0}} / y_{r}$ and $\theta_{i} / \theta_{\max }$ are positive, since it considers the combined effect of the two ratios varying simultaneously, while Eqs. (1) and (2) consider the ratios varying one at a time (Mast 1993).

\subsection{PCI Bridge Design Manual specifications}

As mentioned above, the PCI Bridge Design Manual (2003) provisions are based on Robert Mast's paper published in 1989 described above. Section 8.10 suggests a value of 1.5 for the factor of safety against failure for hanging beams. Due to the possibility of a catastrophic failure, it is recommended that the factor of safety against failure to be conservatively taken as the factor of safety against cracking. However, the manual states that the necessary factors of 
safety cannot be determined scientifically, and that they must be determined from experience by employing sound engineering judgment. For the initial lateral eccentricity of the center of gravity with respect to the roll axis, $e_{i}$, the manual recommends a value of $1 / 4$ in. plus one-half the PCI tolerance for sweep, which is $1 / 8$ in. per $10 \mathrm{ft}$ of member length.

\subsection{Limitations of current literature}

All of the above presented methods are useful tools for investigating beam stability during lifting; nonetheless, they all have limitations to their applicability. For instance, although presented in a very easy to follow seven-step process, the method outlined by Laszlo and Imper (1987) does not consider the effect of initial imperfections. The influence of initial lateral (sweep) imperfections on beam deformation during lifting is discussed in Mast (1989, 1993), Stratford et al. (1999), and Plaut and Moen (2012), and is further investigated in the following sections of this paper.

Next, in Mast's proposed method, the computation of a net factor of safety requires actual knowledge of $e_{i}$ and $\theta_{\max }$. Most of the time, the initial lateral eccentricity $e_{i}$ is unknown, therefore it is usually assumed or taken as the PCI recommended value of 1/4 in. plus L/960. Additionally, as stated by Mast, the determination of $\theta_{\max }$ involves some difficulties, requiring the computation of the ultimate strength of the beam subjected to biaxial bending. An exact solution is not provided. Mast's recommended method for approximating $\theta_{\max }$ is a conservative one, suggesting that $\theta_{\max }$ could be expressed as the ratio of the weak axis bending moment that causes the tensile stress in the top corner to reach the modulus of rupture to the strong axis selfweight moment (Mast 1989). Lastly, Mast's procedure does not treat the case of inclined cables in detail, which is common practice during field handling when using single cranes. To account for the effects of inclined cables, Mast (1989) modified the $\overline{z_{0}}$ equation by the factor: 


$$
\left(1-H / P_{c r}\right)
$$

where

$H=$ axial compression in the beam due to inclined cables

$P_{c r}=$ Euler Buckling load of the beam

Finally, Stratford and Burgoyne (2000) provided useful equations for calculating the stresses in beams during lifting. They offered equations for midspan deflections, midspan curvature, and roll angle, and provided explicit numeric solutions, but only to specific particular cases.

Overall, the existing papers on the subject of lifting stability of precast prestressed concrete beams do not offer explicit and easy to use formulas for calculating displacements, forces, and moments during lifting that could readily be utilized in practice. 


\title{
Lifting Analysis of Precast Prestressed Concrete Beams
}

\author{
Razvan Cojocaru ${ }^{1}$ and Cristopher D. Moen ${ }^{2}$
}

\subsection{Research objective}

The goal of this paper is to eliminate the unknowns related to the stability calculations of long concrete beams and provide the precast community with an accurate, accessible method for predicting behavior during lifting. There are two tasks supporting the abovementioned objective. The first task is to quantify geometric imperfections (sweep and eccentricity of lift supports) in long precast prestressed concrete beams and provide a statistical characterization. The second task is to present a new method for predicting the behavior of beams during lifting. To achieve this task, the authors incorporate recently derived equations (Plaut and Moen 2012) that calculate beam deflections and internal forces and moments in a beam during lifting with a freely available Microsoft Excel (Lifting Analysis 2012) calculation sheet. The internal forces can then be used to calculate demand stresses on the beam during lifting, which can then be checked against existing stress limits in tension and compression.

\subsection{Study of geometric imperfections in precast prestressed concrete beams}

\subsubsection{Introduction}

In order to ensure safety during lifting, it is important to be aware of the magnitudes of beam sweep and support eccentricities and their effects on lateral stability. Particular attention

\footnotetext{
${ }^{1}$ Graduate Research Assistant, Virginia Tech, Blacksburg, VA, 24061, USA. (cojocaru@ vt.edu)

${ }^{2}$ Assistant Professor, Virginia Tech, Blacksburg, VA, 24061, USA. (cmoen@ vt.edu)
} 
should be paid to long slender beams, as the effects of initial imperfections on stability during lifting are amplified in such members (Hill 2009).

There is no current study quantifying typical values of geometric sweep imperfections in long precast prestressed concrete beams. When performing stability checks, these values are usually assumed. The urgency to document such imperfections was emphasized recently by a Georgia Department of Transportation funded study on girder rollover (Hurff 2010). Therefore, due to the lack of current information, a study was conducted to quantify the values of sweep and eccentricity of lifting supports in long prestressed precast concrete beams. A graphical representation of the two types of imperfections and their maximum allowed values as defined by the PCI Tolerance Manual for Precast and Prestressed Concrete Construction are depicted in Figure 5.

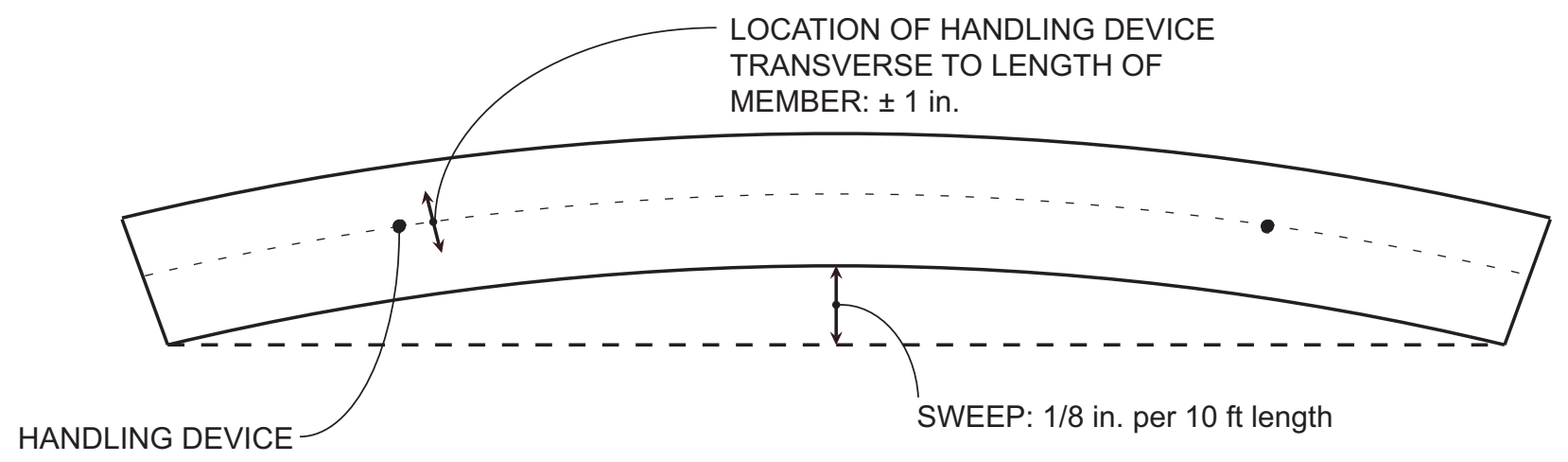

PLAN VIEW

Figure 5. PCI tolerances for sweep and eccentricity of lift supports.

The geometric imperfections study was conducted at four different PCI certified plants in the United States, and a total of 128 beams between $121 \mathrm{ft}$ and $139 \mathrm{ft}$ were measured to quantify sweep. Eccentricities of lifting supports were measured for ten different beams. A detailed 
summary of the type and number of beams measured for sweep and lifting support eccentricities is reported in Table 1 and Table 2, and individual member measurements are provided in Appendix E.

Table 1. Summary of beams measured for sweep

\begin{tabular}{l|cccc}
\hline \multicolumn{1}{c|}{ Beam Type } & Length $L, \mathrm{ft}$ & Count & $\begin{array}{c}\text { Average } \\
\text { sweep, } \delta / L\end{array}$ & COV \\
\hline 77 in. Bulb Tee & 139 & 6 & $L / 2282$ & 0.49 \\
74 in. Bulb Tee (Modified) & 124 & 10 & $L / 1762$ & 0.67 \\
\hline & 122 & 6 & & \\
72 in. Bulb Tee & 124 & 1 & & 0.68 \\
& 127 & 3 & $L / 2063$ & \\
& 129 & 28 & & 0.39 \\
\hline 72 in. Bulb Tee (Modified) & 139 & 56 & & \\
\hline
\end{tabular}

Note: $1 \mathrm{ft}=30.48 \mathrm{~cm}$; COV = Coefficient of Variation.

Table 2. Summary of beams measured for lifting support eccentricity

\begin{tabular}{ccccccc}
\hline $\begin{array}{c}\text { Beam } \\
\text { Type }\end{array}$ & $\begin{array}{c}\text { Length } L, \\
\mathrm{ft}\end{array}$ & $\begin{array}{c}\text { Number of lifting } \\
\text { loops at each end }\end{array}$ & $\begin{array}{c}\text { Overhang } a, \\
\text { in. }\end{array}$ & Count & $\begin{array}{c}\text { Average } q, \\
\text { in. } \dagger\end{array}$ & COV \\
\hline 72 in. & 139 & 2 & 119 & 5 & 0.40 & 0.52 \\
Bulb Tee & 129 & 1 & 90 & 5 & 0.25 & 0.89 \\
\hline
\end{tabular}

Note: $a=$ distance from the edge of the beam to the centroid of the lifting support group;

$q=$ eccentricity of the centroid of the handling device relative to the centerline of the top flange at each end; $1 \mathrm{ft}=$ $30.48 \mathrm{~cm}$; 1 in. $=25.4 \mathrm{~mm} ; \mathrm{COV}=$ Coefficient of Variation; $\uparrow$ denotes the average of the absolute values of lift support eccentricity.

\subsubsection{Sweep measurements}

A special jig consisting of a tensioned line with anchors that clamp to the ends of a beam was used to measure sweep imperfections, as shown in Figure 6. Measurements of sweep were made with a digital caliper while the beams were sitting on rigid supports. Measurements were taken at $10 \mathrm{ft}$ increments along the length of the beam at the top flange, bottom flange, and the mid-height of the web. 




Figure 6. Instrumentation of sweep measurements

For the majority of the beams, the value of the sweep at the top and bottom flanges coincided with the value of the sweep at the mid-height of the web. Additionally, for the majority of the beams, the value of the sweep at midspan coincides with the maximum lateral deflection of the beam (Figure 7). As a result, the initial midspan lateral deflection measured at the mid-height of the web was reported as the beam's initial sweep imperfection. 


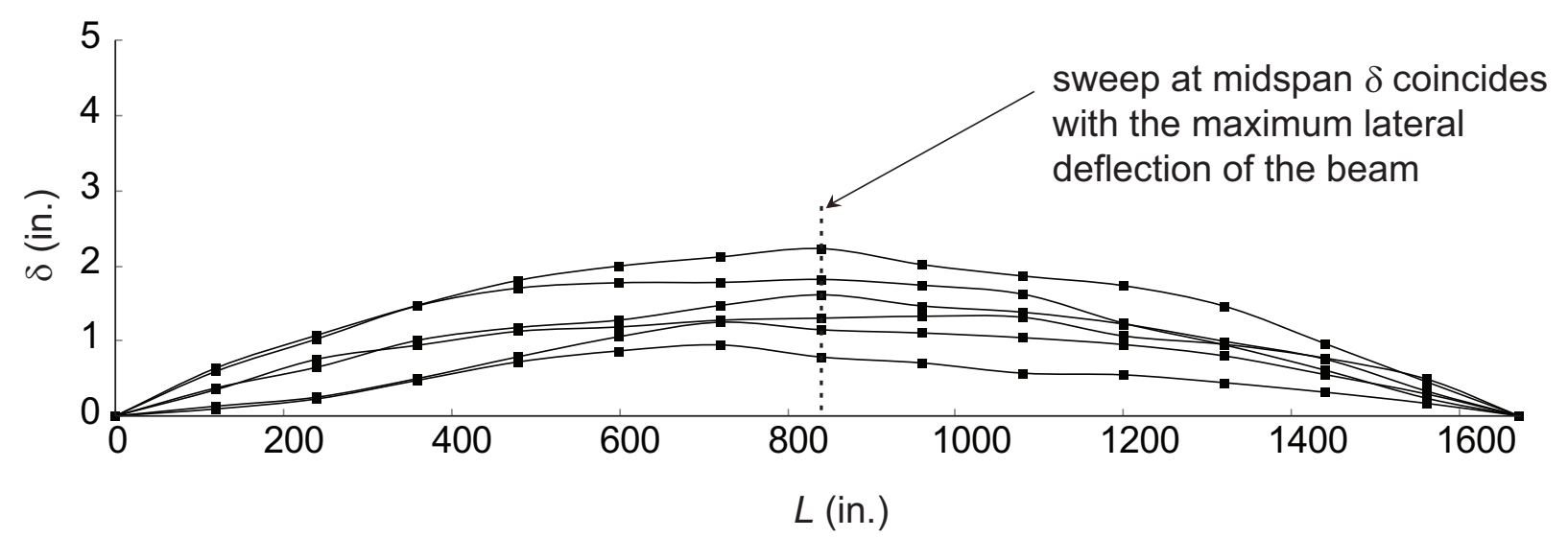

Figure 7. Shape of measured sweep for six random beams. The sweep at midspan coincides with the maximum lateral deflection of the beam

The influence of temperature gradient played a small role in the variability of the measured sweep. This is because in the plants visited, the beams sitting in storage were placed very close to each other. For that reason, as illustrated in Figure 8, only the interior beams were investigated because their sides were screened from direct sunlight exposure.



Figure 8. Measured beams screened from direct sunlight exposure 
Hence, by taking the effect of the temperature gradient out of the equation, it is believed that the measured sweep was caused primarily by the combination of three factors: eccentricity of the prestressing strands, differences in the forces in the prestressing strands, and by the variations of the elastic modulus within the concrete (Stratford and Burgoyne 1999). However, thermal gradient has been proven to have a significant impact on the magnitude of sweep in long bridge girders. In a recent experimental study performed by Hurff (2008) on a $101 \mathrm{ft}$ PCI BT-54, it was shown that initial sweep increased up to $40 \%$ due to the effect of solar radiation.

For statistical purposes, the sweep imperfection magnitude at midspan $\delta_{0}$ for each beam is normalized to the beam length $L$, and reported as $\delta / L$. Similarly, the PCI tolerance for sweep (1/8 in. per $10 \mathrm{ft}$ of beam length) is expressed as L/960. Numerically estimated cumulative distribution function (CDF) values and the summary statistics of the aggregated data is provided in Table 3. The mean of the reported sweep values is $L / 1500$ and the Coefficient of Variance $(\mathrm{COV})$ is 0.61 .

Table 3. Summary statistics of sweep measurements

\begin{tabular}{cc}
\hline $\mathrm{P}\left(\delta<\delta_{o}\right)$ & Normalized sweep, $\delta / L$ \\
\hline 0.25 & $\mathrm{~L} / 3125$ \\
0.50 & $\mathrm{~L} / 1508$ \\
0.75 & $\mathrm{~L} / 1111$ \\
0.95 & $\mathrm{~L} / 575$ \\
0.99 & $\mathrm{~L} / 472$ \\
\hline Number of measurements & 128 \\
Minimum & $\mathrm{L} / 6667$ \\
Maximum & $\mathrm{L} / 470$ \\
Mean & $\mathrm{L} / 1500$ \\
Standard deviation & $\mathrm{L} / 2500$ \\
COV & 0.61 \\
\hline
\end{tabular}

Note: $\mathrm{CDF}=$ Cumulative Distribution Function; $\mathrm{P}\left(\delta<\delta_{o}\right)$ indicates the probability that a randomly selected imperfection value, $\delta$, is less than a discrete deterministic imperfection, $\delta_{o}$; $\mathrm{COV}=$ Coefficient of Variation. 
The CDF values reported in Table 3 can be used to define a probability of occurrence for a particular sweep imperfection magnitude. A CDF value is written as $\mathrm{P}\left(\delta<\delta_{o}\right)$ and indicates the probability that a beam's measured sweep imperfection, $\delta$, is less than $\delta_{o}$ (Schafer and Pekoz 1998). For example, the probability $\mathrm{P}\left(\delta<\delta_{o}=L / 1111\right)=0.75$ which means that a precast beam is expected to have a maximum sweep imperfection less than $L / 111175 \%$ of the time.

Further, to provide a better sense of the full range of measurements recorded, a histogram is shown in Figure 9. Only 18 percent of the beams measured exceed the PCI tolerance for sweep, as represented by the values to the right of the red vertical line on the histogram. No sweep measurements exceed L/470.

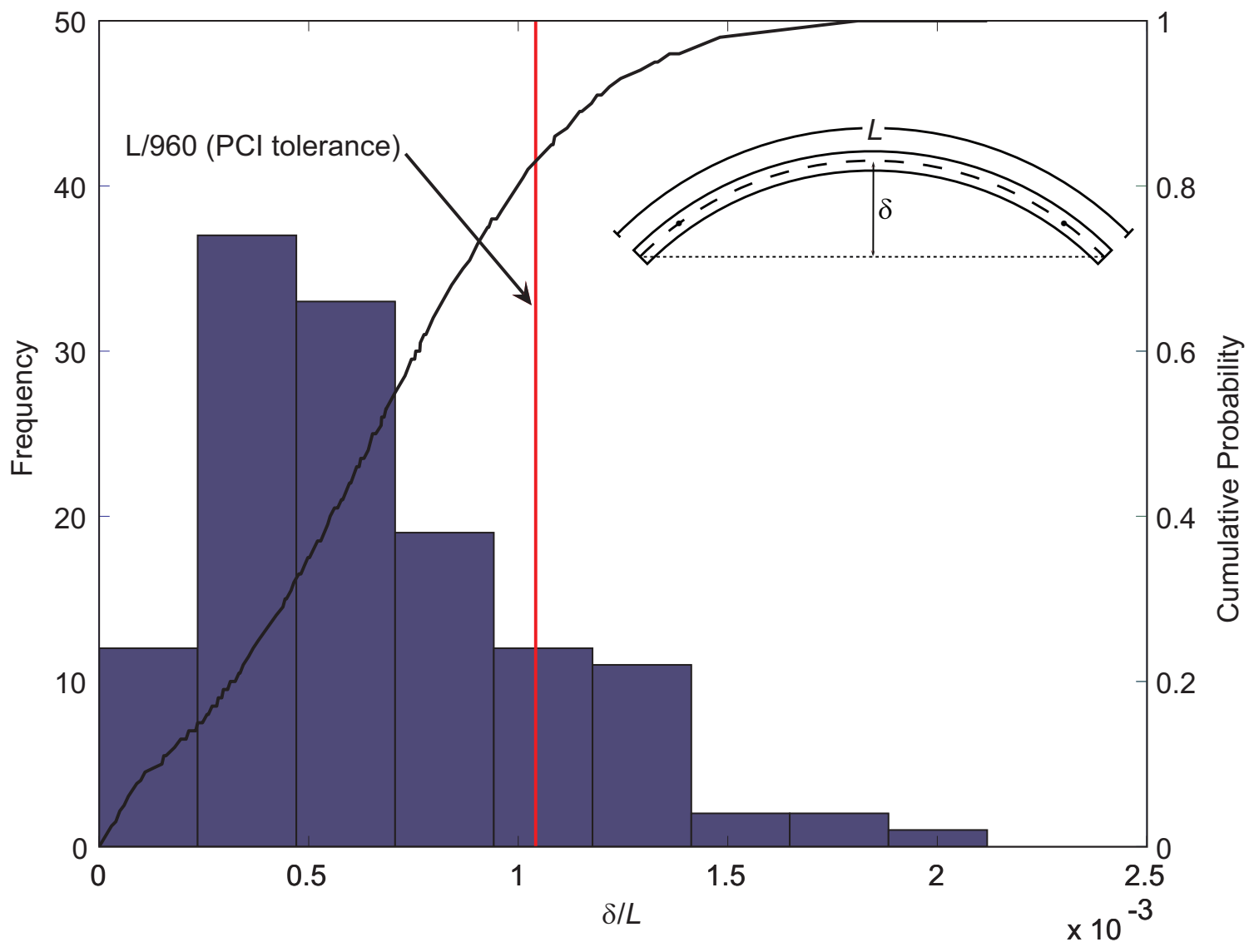

Figure 9. Histogram and CDF of sweep measurements 
Based on the sweep measurement results presented above it can be concluded that the PCI limit is reasonable for the beams considered in this study. Nonetheless, although not typical, it is also shown that sweep magnitudes exceeding the PCI tolerance can be encountered. In cases such as these, the likelihood that a stability failure would occur increases greatly. For this reason, it is important that accurate sweep imperfection magnitudes be considered in stability checks whenever possible, and especially for very long beams. Additionally, for more realistic magnitudes of sweep imperfections, the sweep values presented in this study could be increased by $40 \%$ to account for temperature effects (Hurff 2008).

\subsubsection{Eccentricity of lifting supports}

The lifting support eccentricity of 10 - 72 in. PCI Bulb Tee beams was studied. The investigated lifting loops were composed of five prestressing strands bundled together. Half of the beams had two lifting loops at each end, and half just one, as shown in Figure 10.

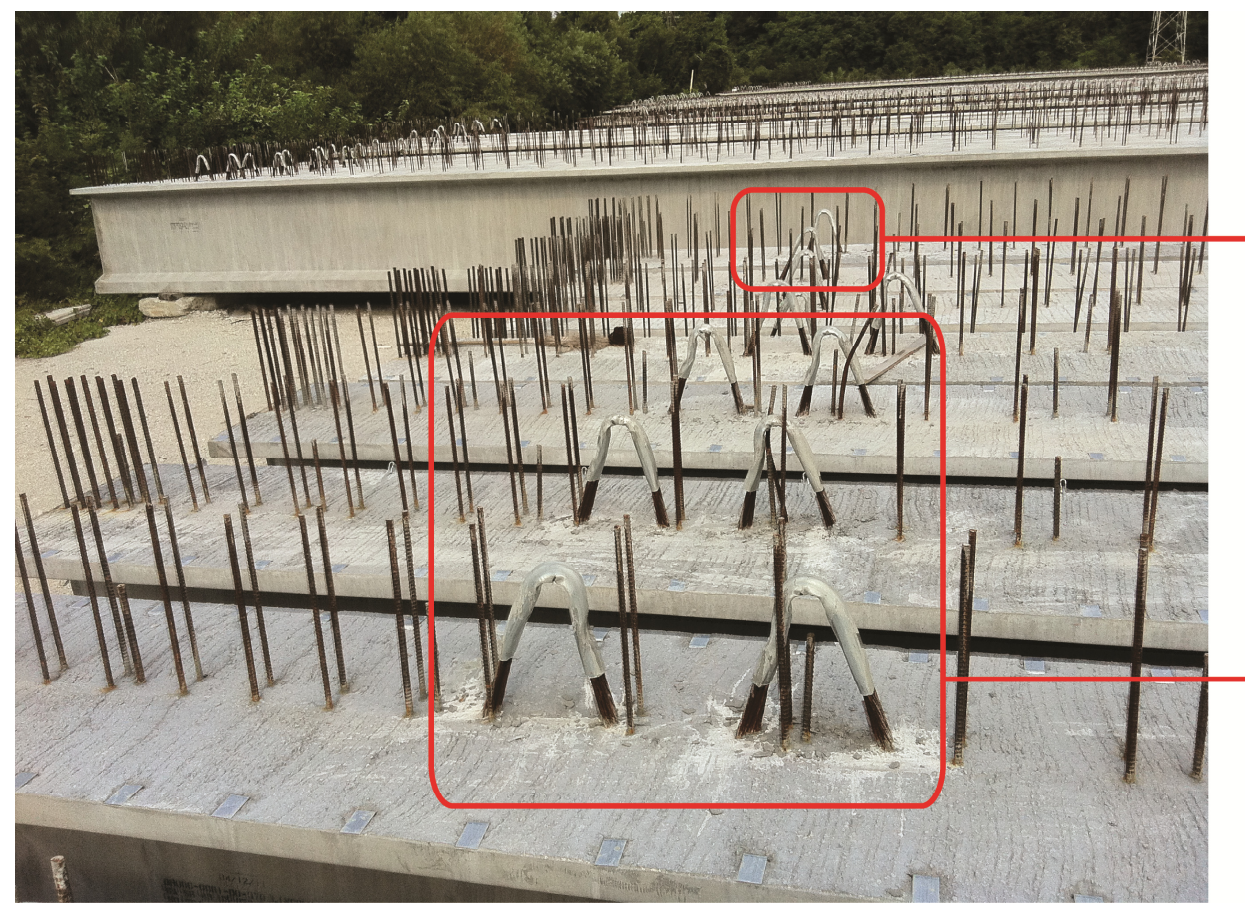

BEAMS WITH ONE LIFTING LOOP AT EACH END

Figure 10. Lifting loops measured for eccentricity 
In both cases, the reported value for the individual lifting support eccentricity $q$, is the distance from the vertical midplane of the web to the centroid of the prestressing strand bundles. The lift support eccentricity results are presented in Table 4, and an explanation of the measurements is provided in Figure 11.

Table 4. Eccentricity of lifting supports

\begin{tabular}{ccc}
\hline \multirow{2}{*}{ Beam } & \multicolumn{2}{c}{ Individual lifting support eccentricity $q$, in. } \\
\cline { 2 - 3 } & Left end & Right end \\
\hline 1 & 0.06 & -0.19 \\
2 & 0.06 & 0.13 \\
3 & -0.13 & -0.13 \\
4 & -0.19 & -0.38 \\
5 & -0.50 & -0.75 \\
6 & 0.38 & 0.25 \\
7 & 0.25 & 0.63 \\
8 & 0.38 & 0.56 \\
9 & -0.25 & -0.81 \\
10 & $0.25 \quad$ Average $=0.32$ in. $\dagger$ \\
\hline \multicolumn{2}{c}{ COV $=0.69$} \\
\hline
\end{tabular}

Note: $q=$ eccentricity of the centroid of the handling device relative to the centerline of the top flange at each end; 1in. $=25.4 \mathrm{~mm} ; \mathrm{COV}=$ Coefficient of Variation; $\uparrow$ denotes the average of the absolute values of lift support eccentricity.

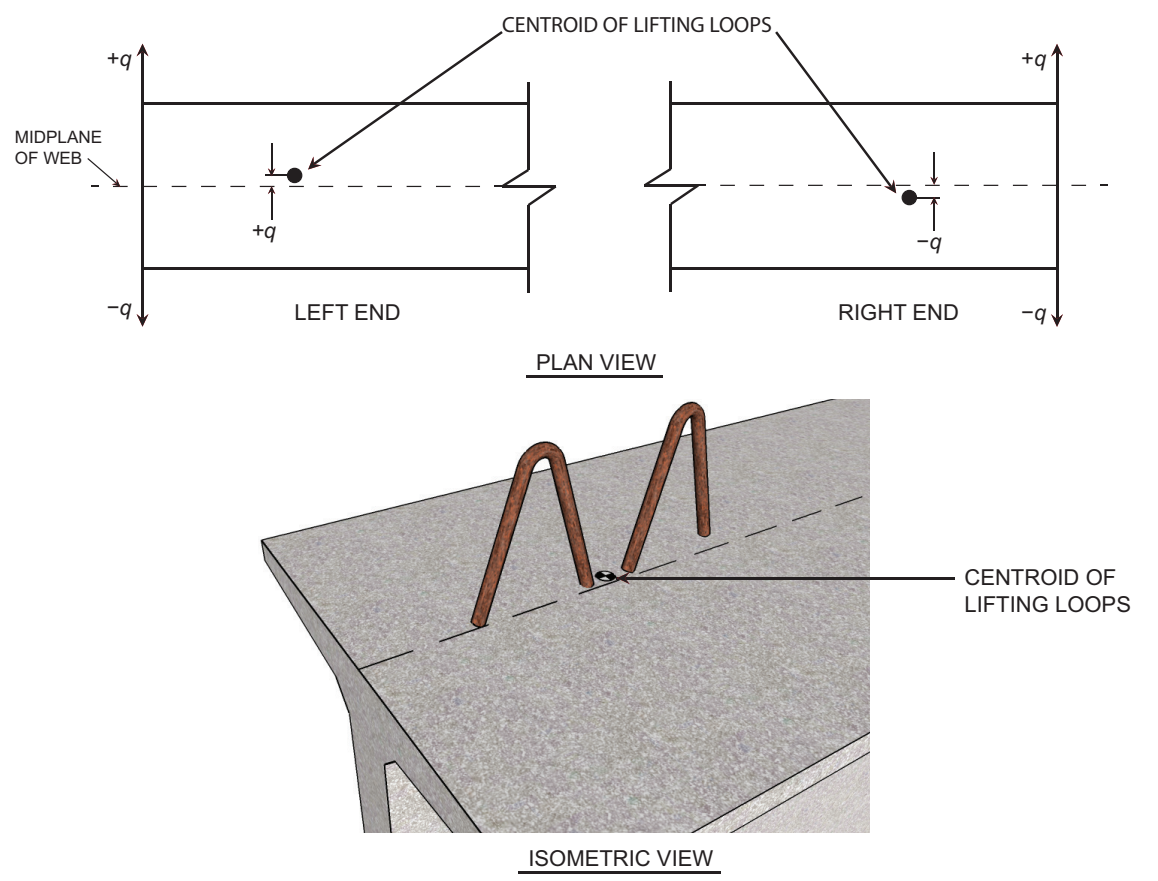

Figure 11. Sign convention used for the lift support eccentricity measurements 
The tolerance for the location of the handling device transverse to the length of the member is \pm 1 in., as reported by the PCI Tolerance Manual for Precast and Prestressed Concrete Construction. None of the measured eccentricities exceed this limit. The average of the lift support eccentricities is 0.32 in., and the COV is 0.69 .

Lifting loop eccentricities can influence the stability of beams during lifting. If the lifting devices are slightly eccentric relative to the vertical centerline of the beam, an otherwise straight girder will twist or roll and deform laterally (Hill 2009). The effect is greatest when both individual lifting support eccentricities $q$ are on the same side of the midplane of the web, i.e., both $q$ values have the same sign, and are closer to the center of curvature of the beam than the midplane of the web (Figure 12).

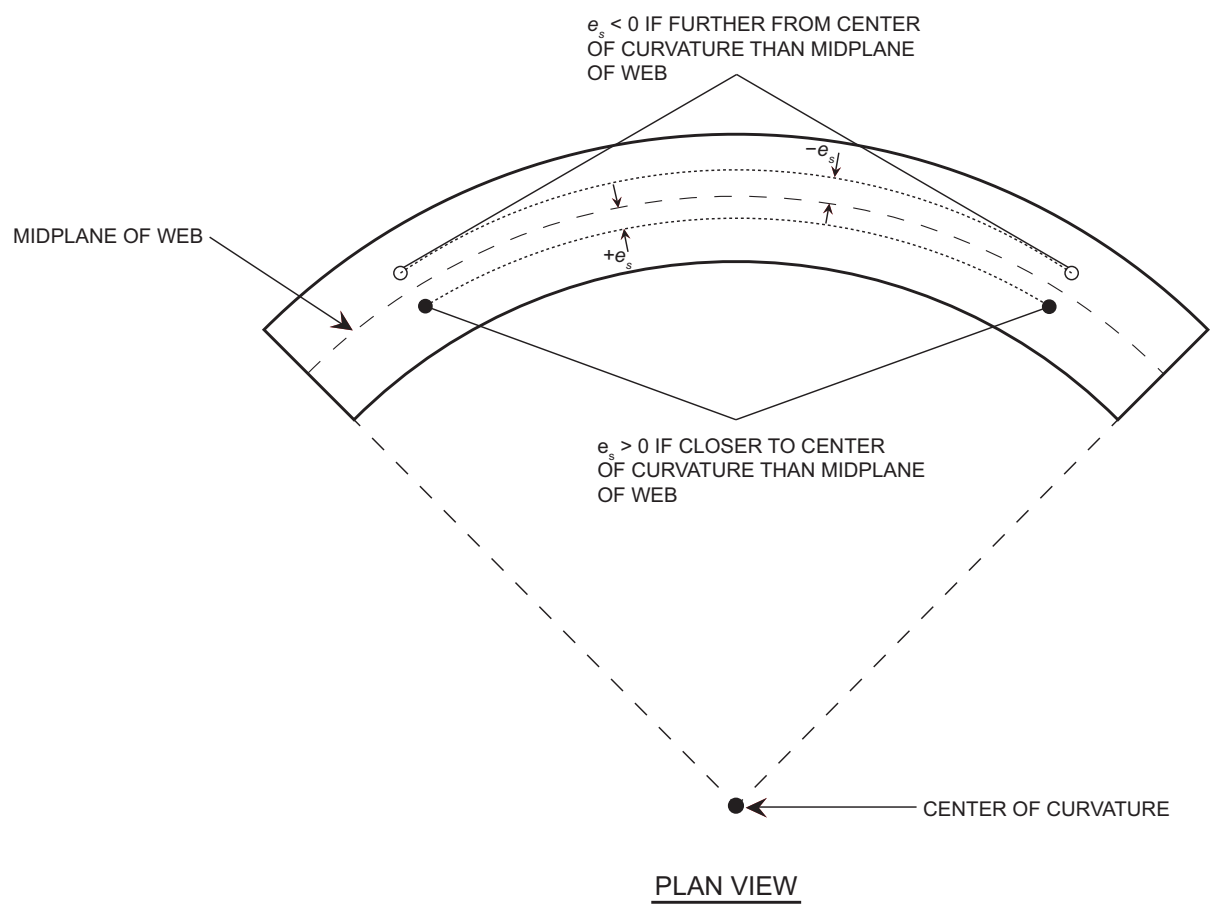

Figure 12. Effect of eccentricity of lift supports is greatest when both lift loops are closer to center of curvature than midplane of web.

It is important that both types of imperfections are considered when predicting the behavior of precast concrete girders during lifting. The sweep and lifting eccentricity 
measurements results discussed above provide valuable information that will be used with the (Plaut and Moen 2012) lifting analysis method outlined in the following section.

\subsection{Limit state analysis of concrete beams during lifting}

\subsubsection{Lifting analysis calculation sheet}

A new method for investigating the behavior of beams during lifting was recently developed to calculate roll angle, twist, displacements, internal forces, internal moments, and stresses in a doubly symmetric curved beam during lifting by two cables. The formulas derived by Plaut and Moen for a circularly curved beam can readily be used in practice, offering engineers a means of determining the resulting stresses that will occur in beams during lifting, and allowing them to prevent damage and failure. The equations are valid for both steel (Plaut et al. 2011) and concrete beams. However, for the purpose of this paper, the applicability to concrete beams where the initial curvature corresponds to a small imperfection is considered. The complete derivation of the equations can be found in reference 20 .

For convenience, the equations derived in Plaut and Moen (2012) are organized in a user friendly calculation sheet (Lifting Analysis 2012), which is available to the precast community in both U.S. and metric units. The calculation sheet can accommodate beams with vertical and inclined cables, with an initial curvature due to sweep, and with eccentric lifting supports.

The calculation sheet requires the following inputs:

- Material properties: modulus of elasticity $E_{c}$, specific gravity $S G$, and modulus of rigidity G.

- Beam properties and dimensions: beam length $L$, cross-sectional-area $A$, strong-axis and weak-axis moments of inertia $I_{z}$ and $I_{y}$, torsion constant $J$, and self-weight $w$. (A method 
for computing $J$ for typical prestressed concrete girders is presented in reference 30 , or it can be calculated using cross-section analysis computer programs).

- Lifting device information: location of lifting device $a$ from the ends of the beam, height of yoke to cable attachment points above the centroid of the beam $H$, global eccentricity of lift supports $e_{s}$, and the inclination angle of the cables $\psi$.

- Initial normalized sweep imperfection $\delta_{0} / L$.

Based on the received input, the calculation sheets compute the following values at any location along the length of the beam:

- Roll angle

- Twist angle

- Internal forces (weak-axis shear, strong-axis shear, and longitudinal axial force)

- Internal moments (twisting moment, weak-axis bending, and strong-axis bending)

- Deflections (weak-axis and strong-axis)

A detailed explanation of the use of the spreadsheet is given in Appendix B of this paper.

\subsubsection{Calculation sheet limitations}

The analytical solutions derived by Plaut and Moen (2012) used in the calculation sheet are for the case of doubly-symmetric cross sections. However, the case of beams with a doublysymmetric cross section is not common in bridge construction, since typical precast prestressed concrete beam shapes are singly-symmetric. The main difference in behavior of a singlysymmetric concrete cross-section during lifting is due to the offset of the center of twist (shear center) relative to the cross-section centroid. For a singly-symmetric beam for which the center of twist is very close to the centroid of the beam, the results should be close to those presented in this paper. 
Schuh (2008) also investigated the effect of cross-section symmetry of steel I-girders on lifting stability and stated that a singly-symmetric girder with a larger bottom flange than top flange exhibits slightly less rotation than a doubly-symmetric girder. The reason is that as the center of twist moves farther down the section, the rotation required to align the center of twist of the girder with the roll axis decreases. Therefore, girders which have a center of twist below the centroid will rotate less, thus providing conservative estimates for the internal forces, moments, weak-axis deformation, and cross-sectional twist (Plaut and Moen 2012). Vice versa, a singlysymmetric girder with the center of twist above the centroid will rotate more, and yielding slightly non-conservative results for the weak-axis moment and displacement.

To address this issue, a study investigating the location of the center of twist of most common precast prestressed concrete beam shapes was performed in Section 3 of Chapter 4. Finite element simulations were performed to investigate the behavior of singly-symmetric concrete beams during lifting. Internal forces, internal moments, and deflections were calculated, and the finite element simulation results were compared to the prediction method developed by Plaut and Moen (2012). The results presented in Section 1 of Chapter 4 show small differences, no more than \pm 5 percent, between the Plaut and Moen (2012) method and the finite element simulation.

Additionally, the equations derived by Plaut and Moen (2012) do not include the influence of camber. The influence of camber was considered in Peart et al. (2002), and it was concluded that it reduces the buckling load for a straight beam, but may not have a large influence on the roll angle and deformations of a curved beam during lifting (Plaut and Moen 2012). According to Mast (1989), it is sufficiently accurate to assume that the centroid of the mass is shifted upward by $2 / 3$ of the midspan camber. Additionally, Section 8.10.7.1 of the PCI 
Bridge Design Manual (2003) offers an equation for calculating the height of the center of gravity of the cambered arc. However, it also states that camber has only a small effect on the shift of the height of the roll axis, $H$, and that one may simply subtract an estimate of one or two inches from the value of $H$.

\subsubsection{Cracking limit state}

In 1991, Mast conducted a lateral bending test on a $149 \mathrm{ft}$ long prestressed concrete Ibeam to investigate the cracked section behavior of beams subjected to lateral loads (Mast 1994). According to his findings, the test beam tolerated lateral loads in excess of the theoretical cracking load, without any visible sign of damage once the lateral load was removed (Mast 1994). However, as emphasized by Swann and Godden (1966), if a cracked section is allowed during lifting there will be a reduction in the beam's stiffness, resulting in increased deflections and consequently increasing the possibility of a self-propagating catastrophic stability failure which would occur with little or no warning (Swann and Godden 1966). Therefore, as recommended by Stratford et al. (1999), for safety considerations it is advised that a cracked section is not allowed during lifting.

With this in mind, a tensile concrete stress limit is proposed, meaning the goal is to limit tensile stresses in the corner of the top flange (as seen in Figure 2) to the modulus of rupture of the concrete. In order to control cracking in a beam during lifting, the following limit state is recommended:

$$
f_{t, \max } \leq f_{t}
$$

where

$f_{t}=$ allowable tension stress at the time of lifting

$f_{t, \max }=$ maximum tensile stress acting on the cross-section during lifting 
It is also recommended to check the bottom flange of the rotated section for high compression as well:

$$
f_{c, \max } \leq f_{c}
$$

where

$f_{c}=$ allowable compression stress at the time of lifting

$f_{c, \max }=$ maximum compressive stress acting on the cross-section during lifting

\section{Capacity:}

The values $f_{t}$ and $f_{c}$ should be taken as the appropriate allowable concrete stresses at the time of lifting as per code specifications. For example, AASHTO Standard Specifications for Highway Bridges (17th Edition), specifies $7.5 \sqrt{f_{c}^{\prime}}$ for the allowable tensile stresses ("Cracking Stresses" [STD Art. 9.15.2.3]), and $0.60 f_{c i}^{\prime}$ for allowable compressive stresses ("Temporary Stresses before Losses due to Creep and Shrinkage” [STD Art. 9.15.2.1]).

where

$f_{c}^{\prime}=$ specified compressive strength of concrete, psi

$f_{c i}^{\prime}=$ specified compressive strength of concrete at time of initial prestress, psi

Additionally, as referenced in Appendix D of the PCI Bridge Design Manual (2003), the Washington Department of Transportation outlines specific "criteria for checking girder stresses at the time of lifting or transporting and erecting," as follows:

Allowable compression stress:

$f_{c}=0.60 f_{c m}^{\prime}$

Allowable tension stress:

$f_{t}=3 \sqrt{f_{c m}^{\prime}}$, with no bonded reinforcement 
$f_{t}=7.5 \sqrt{f_{c m}^{\prime}}$, with bonded reinforcement to resist total tension force in the concrete computed on the basis of an uncracked section

where

$f^{\prime}{ }_{c m}=$ compressive strength at time of lifting or transporting verified by test but shall not exceed design compressive strength $\left(f_{c}^{\prime}\right)$ at 28 days in psi $+1,000$ psi

Overall, beams are usually lifted at a very young age. It is common practice to strip the forms and lift the beams from the casting bed within one day. For this reason, it is recommended that engineers rely on cylinder test results to determine the concrete strength at the time of lifting.

\section{Demand:}

The values $f_{t, \max }$ and $f_{c, \max }$ include the combined effect of the stresses induced on the cross-section due to the self-weight weak-axis and strong-axis bending during lifting, the stresses due to the prestress, and in the case of inclined cables, the additional normal stresses resulting from the axial force in the cables. For a beam that is being lifted, the maximum tensile stress typically occurs at the harp points in the corner of the downward top flange of the rotated crosssection, and the maximum compressive stress occurs in the corner of the bottom flange, as shown in Figure 2.

\subsection{Procedure}

During lifting, the beam is under combined biaxial bending and axial force, and therefore the proposed procedure requires the use of a structural cross-section analysis program capable of performing biaxial moment - axial load interaction analysis. This paper incorporates the use of the biaxial nonlinear fiber element sectional analysis software XTRACT by TRC software, 
which is the commercial version of the University of Berkeley program UCFyber (Chadwell and TRC software 2002).

Detailed below is the proposed procedure for performing a stability check for precast prestressed concrete beams during lifting:

Step 1: Input material properties (modulus of elasticity $E_{c}$, specific gravity $S G$, and modulus of rigidity $G$ ), beam properties (beam length $L$, cross-sectional-area $A$, strong-axis and weak-axis moments of inertia $I_{z}$ and $I_{y}$, torsion constant $J$, and self-weight $w$ ), lifting device information (location of lifting device $a$ from the ends of the beam, height of yoke to cable attachment points above the centroid of the beam $H$, global eccentricity of lift supports $e_{s}$, and the inclination angle of the cables $\psi$ ), and initial sweep imperfection $\left(\delta_{0} / L\right)$ in the Lifting Analysis calculation sheet. Collect axial force and weak-axis and strong-axis bending moments acting on the cross-section at critical locations along the length of the beam (midspan, harp points, and lift points).

Step 2: Using a cross-sections analysis program (e.g., XTRACT), apply the resulting axial force and weak-axis and strong-axis bending moments on the beam's cross-section. Add the effect of the prestress. Record the resulting maximum tensile and compressive stresses acting on the cross-section.

Step 3: Check the resulting lifting stresses at the two critical locations of the rotated cross-section: the corner of the downward top flange in tension and the corner of the upward bottom flange in compression. Compare these values with the maximum allowable stresses as per code specifications to ensure cracking does not occur. Perform this check at critical locations along the length of the beam: midspan, at the harp points, and at the lifting points. 
The above outlined procedure for investigating the stability of precast prestressed concrete beams during lifting is applied in the following section of this paper to obtain numerical results for two examples.

\subsection{Example problems}

\subsubsection{Example 1: 77 in. PCI Bulb Tee}

The first example is a PCI-BT-77 beam that was cast in 2011 for the North Carolina Department of Transportation. The beam has $L=139 \mathrm{ft}, A=970.7 \mathrm{in}^{2}$, strong-axis moment of inertia $I_{z}=789,500 \mathrm{in}^{4}$, weak-axis moment of inertia $I_{y}=63,600 \mathrm{in}^{4}$, torsion constant $J=34,560$ in $^{4}$, and self-weight $w=0.084 \mathrm{kip} / \mathrm{in}$. The lift point location is $a=90 \mathrm{in}$. at each end. The beam is assumed to be lifted by inclined cables $\left(\psi=45^{\circ}\right)$, and the roll axis height is $H=39 \mathrm{in}$. above the shear center. The lifting loops are located on the vertical centerline of the beam, i.e., the lifting supports have zero eccentricity with respect to the midplane of the web; $e_{s}=0$. The specified 28-day strength of the concrete is ${f^{\prime}}_{c}=8,000 \mathrm{psi}$, and the release strength is $f^{\prime}{ }_{c i}=6,500$ psi. The unit weight of the concrete is $150 \mathrm{pcf}$. The beam is prestressed using 56 Grade 270 low-relaxation prestressing strands with a 0.60 in. diameter. The strands are harped at $5 \mathrm{ft}$ from midspan. The initial jacking force is 43.90 kip per strand. Strands are released one day after casting. Assume 7 percent losses at the time of strand release (equivalent stress in the strands after release is $0.7 f_{p u}$ ). The beam has six draped strands, and the harp points are located $5 \mathrm{ft}$ from midspan in both directions. Figure 13 presents detailed drawings for the beam dimensions and the location of the prestressing strands at the three critical locations: midspan, harp points, and lift points. 


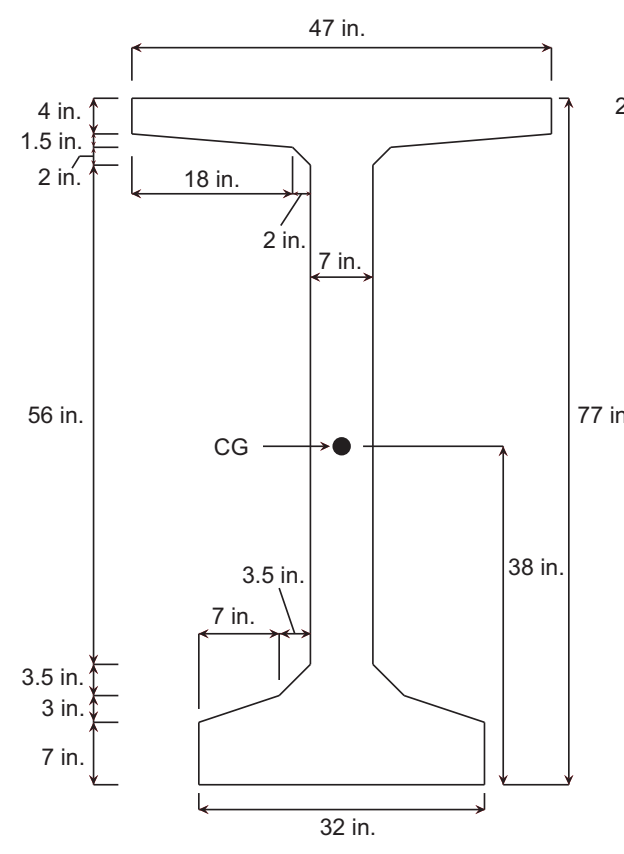

BEAM DIMENSIONS

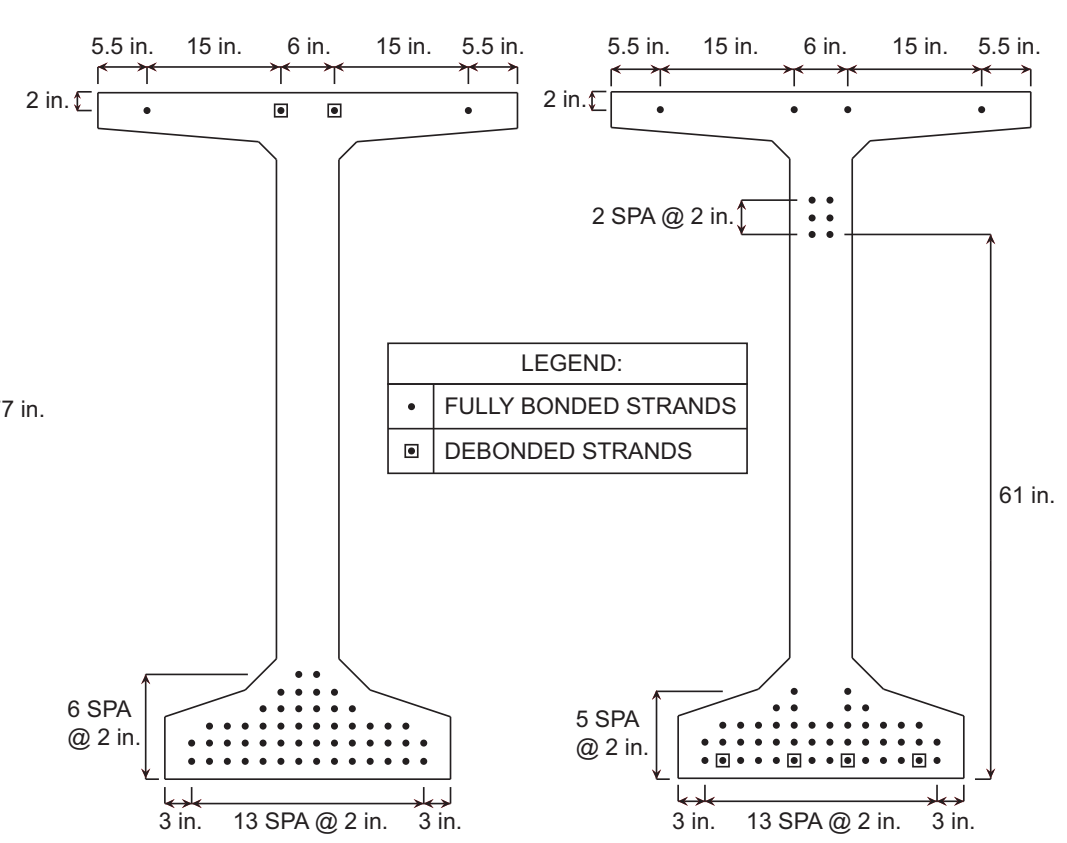

STRANDS AT MIDSPAN AND HARP POINTS

Figure 13. 77 in. PCI Bulb Tee drawings.

Procedure:

Step 1: Using the Lifting Analysis calculation sheet and the beam information given above, the axial force and the weak-axis and strong-axis moments acting on the cross-section due to lifting are determined. Three different sweep magnitudes are investigated: the PCI limit of L/960, the $99^{\text {th }}$ percentile sweep imperfection according to the histogram in Figure 9 (L/472), and the sweep magnitude at which cracking first occurs for this particular beam (L/320).

The compressive axial force in the beam due to the prestress is 2,205 kip at midspan and harp points, and 2,123 kip at the lift points. The moment due to the prestress is 66,027 kip-in. at midspan and harp points, and 44,168 kip-in. at the lift points. The resultant compressive axial force due to the inclined cables is $70 \mathrm{kip}$, which is the same at midspan, harp points, and lift points. The calculated weak-axis and strong-axis moments due to lifting for all three sweep 
magnitudes are recorded in Table 5. Results are presented at midspan, harp points, and lift points. Additionally, the roll angle of the beam for the three imperfection magnitudes is presented.



"ON THE GROUND" STRESS STATE

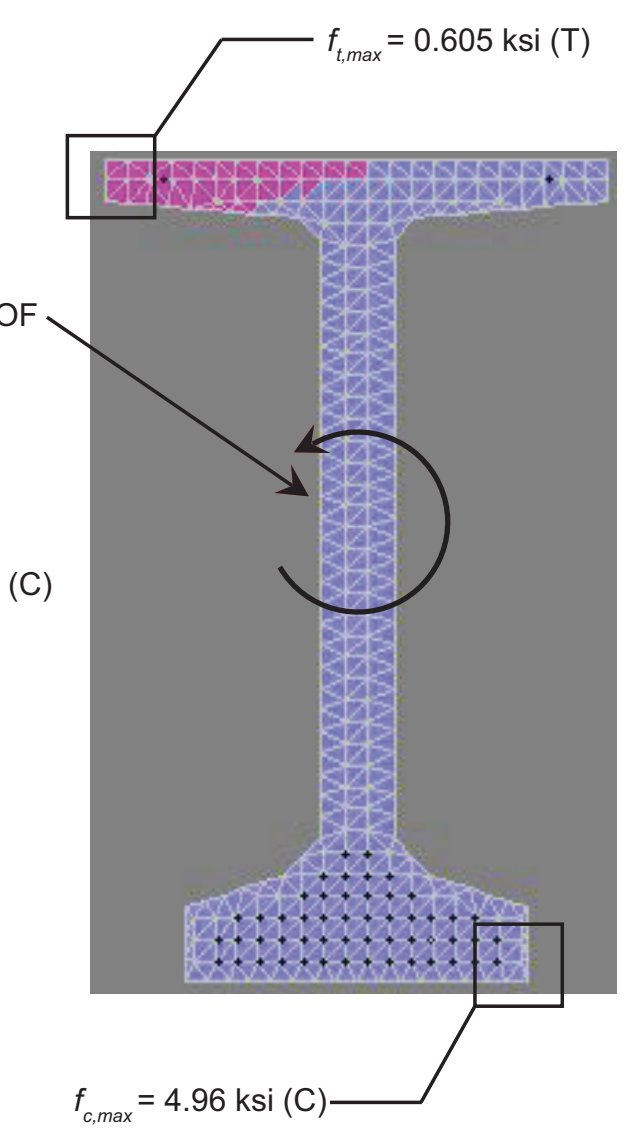

“IN THE AIR" STRESS STATE (L/320)

Figure 14. Stress state for $77 \mathrm{in.} \mathrm{PCI} \mathrm{Bulb} \mathrm{Tee.} \mathrm{The} \mathrm{figure} \mathrm{on} \mathrm{the} \mathrm{left} \mathrm{depicts} \mathrm{the} \mathrm{stress} \mathrm{state} \mathrm{of} \mathrm{the} \mathrm{beam}$ at harp points when resting on the ground. The figure on the right depicts the state of stress of the beam at harp points during lifting.

Step 2: Apply the resulting axial force and weak-axis and strong-axis bending moments on the beam's cross-section. Add the effect of the prestress.

Using the cross-sections analysis program XTRACT, the moments due to lifting and the axial compressive force due to the inclined cables calculated in step 1 are applied to the beam. Additionally, the effect of the prestress is applied automatically in XTRACT. The resulting 
maximum tensile and compressive stresses acting on the cross-section are recorded in Table 5. To illustrate the change in the stress state of the beam when lifted, Figure 14 above depicts the stress distribution on the cross-section at the harp points for the beam when resting on the ground (supported at its ends) and when hanging. The lifting stresses illustrated in Figure 14 (right side) are for the case when the beam reaches its cracking limit, which occurs at a sweep magnitude of L/320.

Step 3: Compare the resulting lifting stresses with the maximum allowable stresses as per code specifications to ensure cracking does not occur. For the purpose of this example problem, the allowable stresses are computed in accordance to the Washington Department of Transportation specifications as outlined in Appendix D of the PCI Bridge Design Manual (2003).

It is assumed that the beam is lifted from the casting bed within one day of casting. Therefore, the compressive strength at the time of lifting $f^{\prime}{ }_{c m}$ is taken as the release strength $f_{c i}^{\prime}=$ 6,500 psi.

Allowable tension stress:

$$
f_{t}=7.5 \sqrt{f_{c m}^{\prime}}=7.5 \sqrt{6500}=605 \mathrm{psi}
$$

Allowable compression stress:

$$
f_{c}=0.60 f_{c m}^{\prime}=0.60 \cdot 6500=3900 \mathrm{psi}
$$


Table 5. PCI BT77 results

\begin{tabular}{|c|c|c|c|c|c|c|}
\hline \multirow{2}{*}{$\begin{array}{l}\text { Normalized } \\
\text { sweep } \delta / L \\
\quad \text { (Actual } \\
\text { sweep } \delta, \text { in.) }\end{array}$} & \multirow[b]{2}{*}{ Location } & \multicolumn{2}{|c|}{ Lifting moments } & \multicolumn{2}{|c|}{ Maximum stresses } & \multirow[b]{2}{*}{$\begin{array}{c}\text { Roll angle } \\
\quad \beta \text {, deg }\end{array}$} \\
\hline & & $\begin{array}{l}\text { Strong-axis } \\
M_{z}, \text { kip-in. }\end{array}$ & $\begin{array}{l}\text { Weak-axis } \\
M_{y}, \text { kip-in. }\end{array}$ & $\begin{array}{l}\text { Tension: } \\
f_{t, \text { max }}, \mathrm{ksi}\end{array}$ & $\begin{array}{l}\text { Compression: } \\
f_{c, \max }, \mathrm{ksi}\end{array}$ & \\
\hline \multirow{3}{*}{$\begin{array}{c}L / 960 \\
(1.7)\end{array}$} & Midspan & $-24,897$ & 754 & 0.048 & $4.67 \ddagger$ & \multirow{3}{*}{1.6} \\
\hline & Harp point & $-24,746$ & 749 & 0.054 & $4.67 \div$ & \\
\hline & Lift point & 340 & -9.7 & n.a. & $4.38 \div$ & \\
\hline \multirow{3}{*}{$\begin{array}{c}L / 472 \\
(3.6)\end{array}$} & Midspan & $-24,866$ & 1533 & 0.330 & $4.82 \div$ & \multirow{3}{*}{3.3} \\
\hline & Harp point & $-24,715$ & 1523 & 0.334 & $4.82 \ddagger$ & \\
\hline & Lift point & 340 & -19.8 & n.a. & $4.39 \ddagger$ & \\
\hline \multirow{3}{*}{$\begin{array}{c}L / 320 \\
(5.2)\end{array}$} & Midspan & $-24,817$ & 2,260 & 0.595 & $4.95 \ddagger$ & \multirow{3}{*}{4.9} \\
\hline & Harp point & $-24,660$ & 2,250 & $0.605 \dagger$ & $4.96 \div$ & \\
\hline & Lift point & 339 & -30 & n.a. & $4.39 \ddagger$ & \\
\hline
\end{tabular}

Note: $\dagger$ denotes a tensile stress value greater than $7.5 \mathrm{~V} f_{c m}^{\prime} ; \$$ denotes a compressive stress value greater than 0.60 $f^{\prime}{ }^{\prime} ; f^{\prime}{ }^{\prime}{ }^{\prime}=$ compressive strength at time of lifting or transporting verified by test but shall not exceed design compressive strength $\left(f^{\prime}{ }_{c}\right)$ at 28 days in psi $+1,000$ psi; positive strong-axis bending moment produces tension in the top fibers and compression in the bottom fibers of the beam; positive weak-axis bending moment produces tension in the face farther to the center of curvature and compression in the face closer to the center of curvature; 1 in. $=25.4$ $\mathrm{mm} ; 1$ kip-in $=0.113 \mathrm{kN}-\mathrm{m} ; 1 \mathrm{ksi}=6.895 \mathrm{MPa}$.

As seen in Table 5, for a sweep imperfection magnitude of L/320, the maximum tensile stress in the beam at the harp points reaches the modulus of rupture. Additionally, for all three sweep magnitudes, the maximum allowable compression stress is exceeded at midspan, harp points, and lift points. However, practitioners suggest that the $0.6 f^{\prime}{ }_{c i}$ limit for compressive stress is artificial and that a beam's performance is not reduced by exceeding the compressive stress limit at release (Hale and Russell 2006). Moreover, the PCI Standard Design practice reports that "no problems have been reported by allowing compression as high as $0.75 f$ " ci" (PCI Standard Design Practice). Therefore, the maximum allowable compression stress for the PCI BT77 beam can be permitted to reach:

$$
f_{c}=0.75 f_{c m}^{\prime}=0.75 \cdot 6500=4875 \mathrm{psi}
$$

Accounting for the increase in allowable compression stress and the based on the results presented above, it is concluded that the beam does not exceed the tensile and compressive stress limits within the PCI tolerance for sweep (L/960). Nonetheless, cracking in tension or crushing 
in compression can occur at sweep imperfection values greater than L/320 (5.2 in.). However, based on the geometric imperfections study presented in Section 3.2, such sweep magnitudes are unlikely.

\subsubsection{Example 2: Type IV AASHTO beam}

The second example is a Type IV AASHTO beam that was cast in 2010 for the North Carolina Department of Transportation. The beam has $L=104 \mathrm{ft}, A=789 \mathrm{in}^{2}$, strong-axis moment of inertia $I_{z}=260,741 \mathrm{in}^{4}$, weak-axis moment of inertia $I_{y}=24,374 \mathrm{in}^{4}$, torsion constant $J=32,924 \mathrm{in}^{4}$, and self-weight $w=0.07 \mathrm{kip} / \mathrm{in}$. The lift point location is $a=48$ in. at each end. The beam is assumed to be lifted by vertical cables $\left(\psi=0^{\circ}\right)$, and the roll axis height is $H=29.3$ in. above the shear center. The lifting supports have an eccentricity $e_{s}=+0.5$ in. The eccentricity is assumed to be positive, meaning that the lifting loops are closer to the center of curvature than the midplane of the web. The specified 28-day strength of the concrete is $f^{\prime}{ }_{c}=$ $10,000 \mathrm{psi}$, and the release strength is $f^{\prime}{ }_{c i}=8,000$ psi. The unit weight of the concrete is 150 pcf. The beam is prestressed using 46 Grade 270 low-relaxation prestressing strands with a 0.60 in. diameter. The strands are harped at $5 \mathrm{ft}$ from midspan. The applied prestress is 43.95 kip per strand. Similarly to the first example, the strands are released one day after casting. Assume 7 percent losses at the time of strand release (equivalent stress in the strands after release is $0.7 f_{p u}$ ). The beam has eight draped strands, and the harp points are located $5 \mathrm{ft}$ from midspan in both directions. Figure 15 presents detailed drawings for the beam dimensions and the location of the prestressing strands at the three critical locations: midspan, harp points, and lift points. 


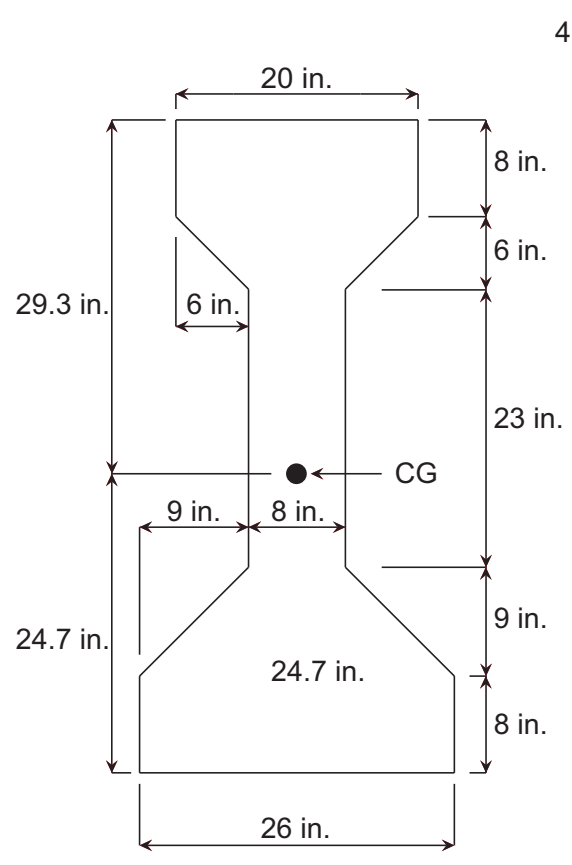

BEAM DIMENSIONS

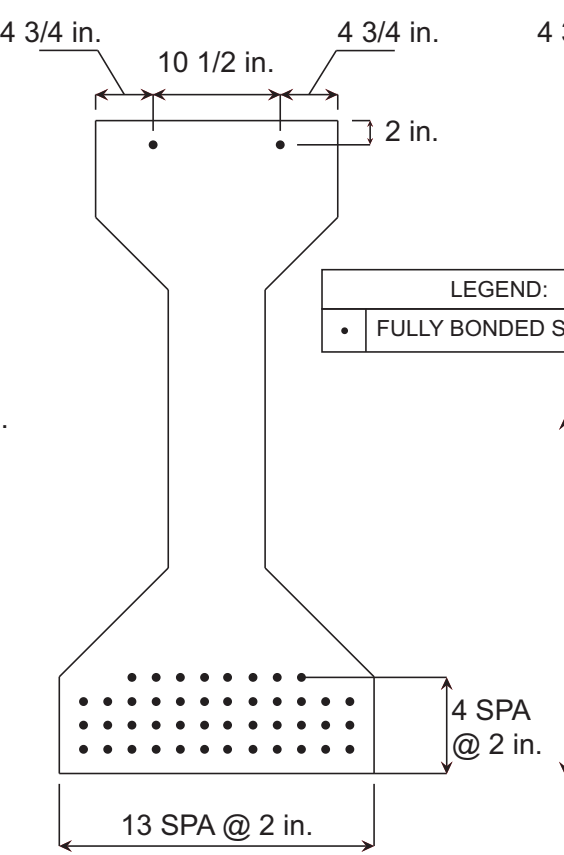

STRANDS AT MIDSPAN

AND HARP POINTS

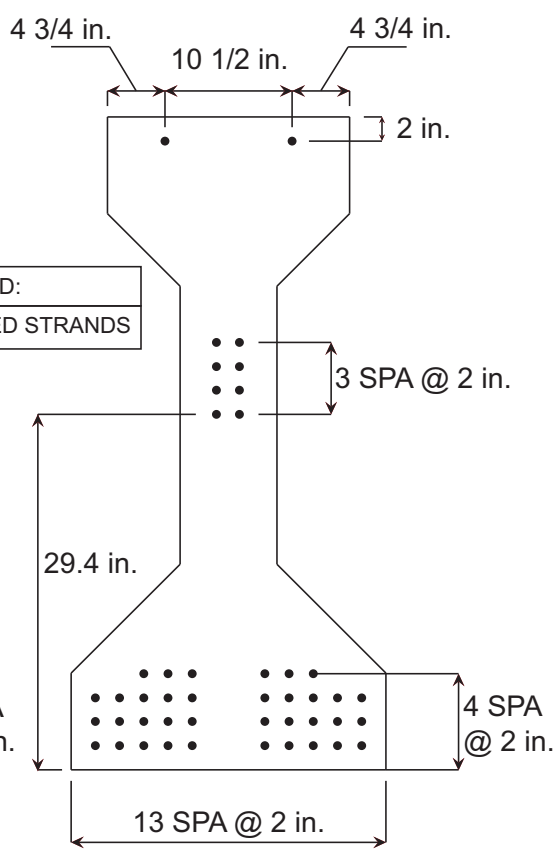

STRANDS AT LIFT POINT

Figure 15. AASHTO Type IV beam drawings

Procedure:

Step 1: Using the Lifting Analysis calculation sheet and the beam information given above, the weak-axis and strong-axis moments acting on the cross-section due to lifting are determined. Since the cables are vertical, there is no additional axial force in the beam. Three different sweep magnitudes are investigated: the PCI limit of L/960, the $99^{\text {th }}$ percentile imperfection according to the histogram in Figure 9 (L/472), and the sweep magnitude at which cracking first occurs $(\mathrm{L} / 300)$.

The compressive axial force in the beam due to the prestress is 1880 kip at midspan, harp points, and lift points. The moment due to the prestress is 33,787 kip-in. at midspan and harp points, and 24,826 kip-in. at the lift points. The calculated weak-axis and strong-axis moments due to lifting for all three sweep magnitudes are recorded in Table 6. Results are presented at 
midspan, harp points, and lift points. Additionally, the roll angle of the beam for the three imperfection magnitudes is presented.

Step 2: Apply the resulting axial force and weak-axis and strong-axis bending moments on the beam's cross-section. Add the effect of the prestress.

Using the cross-sections analysis program XTRACT, the moments due to lifting calculated in step 1 are applied to the beam. Additionally, the effect of the prestress is applied automatically in XTRACT. The resulting maximum tensile and compressive stresses acting on the cross-section are recorded in Table 6. To illustrate the change in the stress state of the beam when lifted, Figure 16 depicts the stress distribution on the cross-section at the harp points for the beam when resting on the ground (supported at the ends) and when hanging. The lifting stresses illustrated in Figure 16 (right side) are for the case when the beam reaches its cracking limit, which occurs at a sweep magnitude of L/300. 


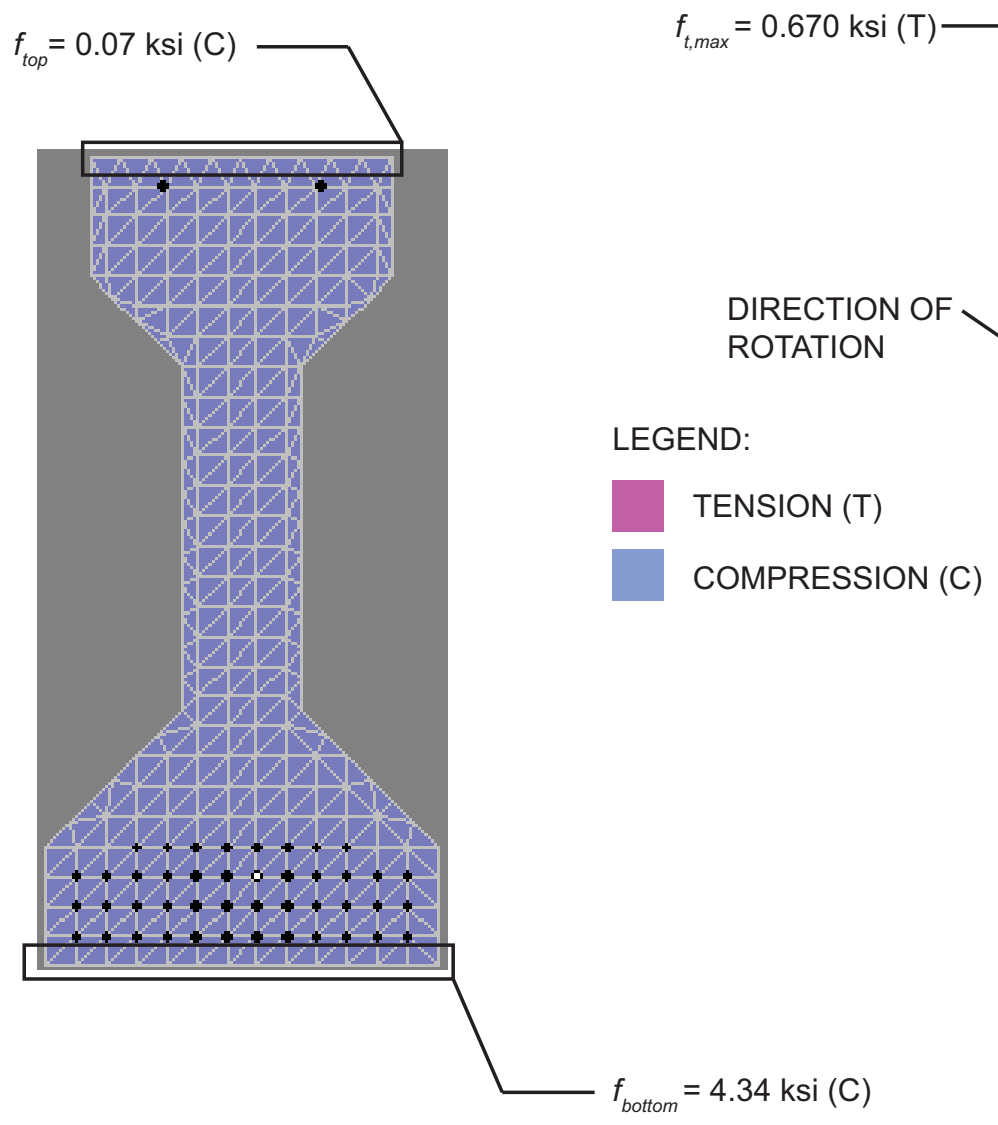

“ON THE GROUND” STRESS STATE

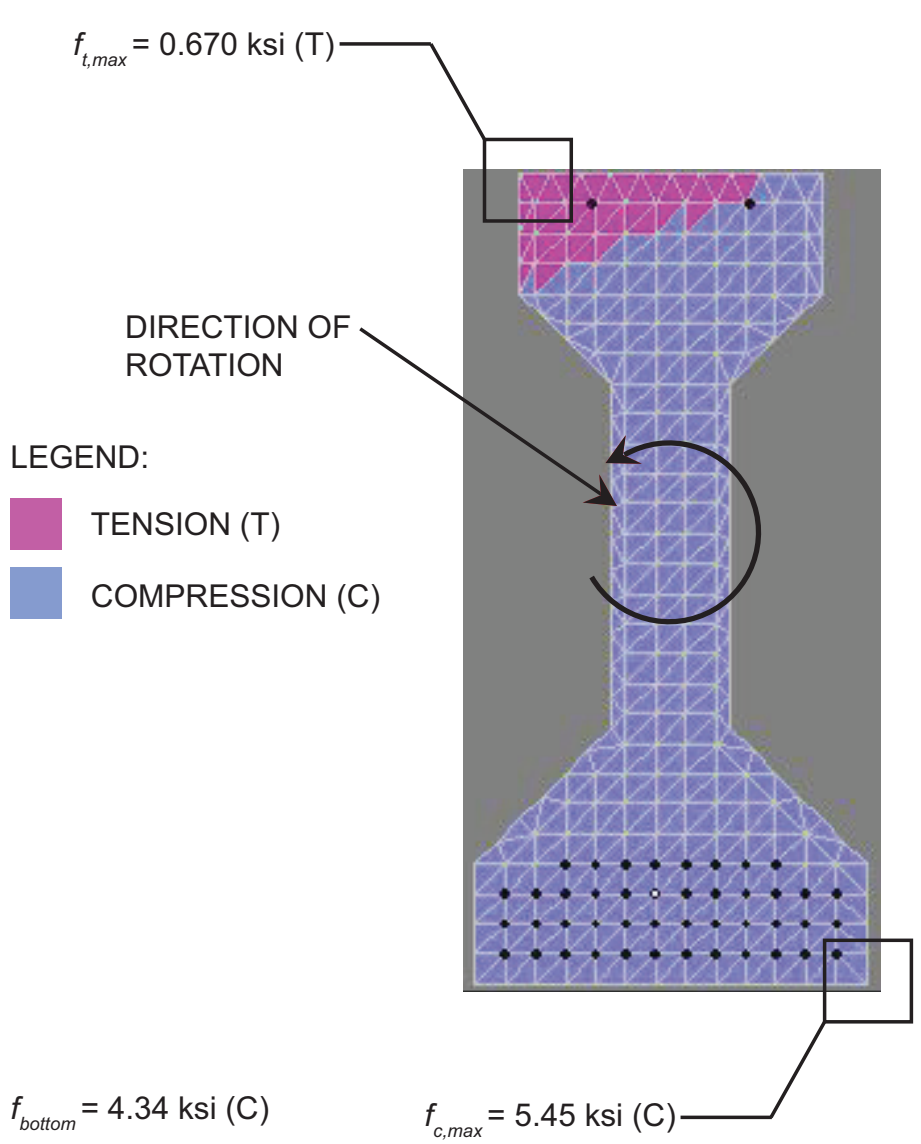

“IN THE AIR" STRESS STATE (L/300)

Figure 16. Stress state for AASHTO Type IV beam. The figure on the left depicts the stress state of the beam at harp points when resting on the ground. The figure on the right depicts the state of stress of the beam at harp points during lifting.

Step 3: Compare the resulting lifting stresses with the maximum allowable stresses as per code specifications to ensure cracking does not occur. Similar to the previous example, the allowable stresses are computed in accordance with the Washington Department of Transportation specifications. It is assumed that the beam is lifted from the casting bed within one day of casting. Therefore, the compressive strength at the time of lifting $f^{\prime}{ }_{\mathrm{cm}}$ is taken as the release strength $f^{\prime}{ }_{c i}=8,000$ psi. 
Allowable tension stress:

$$
f_{t}=7.5 \sqrt{f_{c m}^{\prime}}=7.5 \sqrt{8000}=670 \mathrm{psi}
$$

Allowable compression stress:

$$
f_{c}=0.60 f_{c m}^{\prime}=0.60 \cdot 8000=4800 \mathrm{psi}
$$

\begin{tabular}{|c|c|c|c|c|c|c|}
\hline \multirow{2}{*}{$\begin{array}{l}\text { Normalized } \\
\text { sweep } \delta / L \\
\quad \text { (Actual } \\
\text { sweep } \delta, \text { in.) }\end{array}$} & \multirow[b]{2}{*}{ Location } & \multicolumn{2}{|c|}{ Lifting moments } & \multicolumn{2}{|c|}{ Maximum stresses } & \multirow[b]{2}{*}{$\begin{array}{c}\text { Roll angle } \\
\quad \beta \text {, deg }\end{array}$} \\
\hline & & $\begin{array}{l}\text { Strong-axis } \\
M_{z}, \text { kip-in. }\end{array}$ & $\begin{array}{l}\text { Weak-axis } \\
M_{y}, \text { kip-in. }\end{array}$ & $\begin{array}{l}\text { Tension: } \\
f_{t, \max } \text {, ksi }\end{array}$ & $\begin{array}{l}\text { Compression: } \\
f_{c, \max }, \mathrm{ksi}\end{array}$ & \\
\hline \multirow{3}{*}{$\begin{array}{c}L / 960 \\
(1.3)\end{array}$} & Midspan & $-11,515$ & 610 & 0.368 & $4.95 \ddagger$ & \multirow{3}{*}{3.0} \\
\hline & Harp point & $-11,389$ & 603 & 0.380 & $4.96 \ddagger$ & \\
\hline & Lift point & 81 & -4 & 0.384 & 4.78 & \\
\hline \multirow{3}{*}{$\begin{array}{c}L / 472 \\
(2.7)\end{array}$} & Midspan & $-11,490$ & 971 & 0.498 & $5.11 \ddagger$ & \multirow{3}{*}{4.8} \\
\hline & Harp point & $-11,365$ & 960 & 0.507 & $5.12 \ddagger$ & \\
\hline & Lift point & 80 & -7 & 0.385 & 4.78 & \\
\hline \multirow{3}{*}{$\begin{array}{c}L / 300 \\
(4.2)\end{array}$} & Midspan & $-11,448$ & 1,377 & 0.660 & $5.43 \ddagger$ & \multirow{3}{*}{6.9} \\
\hline & Harp point & $-11,323$ & 1,362 & $0.670 \dagger$ & $5.45 \div$ & \\
\hline & Lift point & 80 & -10 & 0.386 & 4.78 & \\
\hline
\end{tabular}

Table 6. AASHTO Type IV results

Note: $\dagger$ denotes a tensile stress value greater than $7.5 \mathrm{~V} f_{\mathrm{cm}}^{\prime} ; \sharp$ denotes a compressive stress value greater than 0.60 $f_{c m}^{\prime} ; f^{\prime}{ }_{c m}^{\prime}=$ compressive strength at time of lifting or transporting verified by test but shall not exceed design compressive strength $\left(f_{c}^{\prime}\right)$ at 28 days in psi $+1,000$ psi; positive strong-axis bending moment produces tension in the top fibers and compression in the bottom fibers of the beam; positive weak-axis bending moment produces tension in the face farther to the center of curvature and compression in the face closer to the center of curvature; 1 in. $=25.4$ $\mathrm{mm} ; 1$ kip-in $=0.113 \mathrm{kN}-\mathrm{m} ; 1 \mathrm{ksi}=6.895 \mathrm{MPa}$.

As seen in Table 6, for a sweep imperfection magnitude of L/300, the maximum tensile stress in the beam at the harp points reaches the modulus of rupture. Additionally, for all three sweep magnitudes, the maximum allowable compression stress is exceeded at midspan and the harp points. Similar to the previous example, if the maximum allowable compression stress is increased to $0.75 f^{\prime}{ }_{c i}(6,000 \mathrm{psi})$, the Type IV AASHTO beam does not exceed the stress limits within the PCI tolerance for sweep (L/960). However, it is shown that cracking can occur for sweep imperfection values greater than L/300 (4.2 in.), though, such sweep magnitudes are unlikely. 


\subsubsection{Comparison to Mast (1989) factor of safety approach}

The factors of safety against cracking were calculated for the PCI BT77 beam and AASHTO Type IV beam using Mast's approach to investigating lateral stability during lifting. The factors of safety obtained using Mast's procedure were then compared to the ratio of the allowable tension stress to the actual tension stress calculated using the Plaut and Moen (2012) method. For comparison purposes, since Mast's procedure does not account for inclination of cables or the eccentricity of the lift supports, both beams were assumed to be lifted by vertical cables and the eccentricity of the lift supports was assumed to be 0 in. All other properties were identical to the beams presented in Examples 1 and 2. Three sweep magnitudes were investigated for each beam: the PCI sweep limit of $L / 960$, the sweep at which cracking first occurs according to the Plaut and Moen (2012) method, and the sweep magnitude at which the Mast (1993) factor of safety against cracking is 1.0. The results are presented in Table 7 and Table 8 .

Table 7. FS against cracking approach for PCI BT77

\begin{tabular}{ccccc}
\hline \multirow{2}{*}{$\begin{array}{c}\text { Normalized } \\
\text { sweep } \delta / L\end{array}$} & $\begin{array}{c}\mathrm{FS}_{c} \\
\text { (Mast 1993) }\end{array}$ & $\begin{array}{c}\text { Allowable tension } \\
\text { stress } f_{t}, \text { ksi }\end{array}$ & $\begin{array}{c}\text { Actual tension } \\
\text { stress } f_{t, \text { max }}, \text { ksi }\end{array}$ & $\begin{array}{c}\text { Allowable stress/ } \\
\text { Actual stress }\end{array}$ \\
\hline$L / 960$ & 2.2 & 0.605 & 0.171 & 3.5 \\
$L / 330$ & 1.2 & 0.605 & 0.605 & 1.0 \\
$L / 270$ & 1.0 & 0.605 & 0.745 & 0.8 \\
\hline
\end{tabular}

Table 8. FS against cracking approach for AASHTO Type IV

\begin{tabular}{ccccc}
\hline \multirow{2}{*}{$\begin{array}{c}\text { Normalized } \\
\text { sweep } \delta / L\end{array}$} & \multirow{2}{*}{$\begin{array}{c}\mathrm{FS}_{c} \\
\text { (Mast 1993) }\end{array}$} & $\begin{array}{c}\text { Allowable tension } \\
\text { stress } f_{t}, \text { ksi }\end{array}$ & $\begin{array}{c}\text { Actual tension } \\
\text { stress } f_{t, \max }, \mathrm{ksi}\end{array}$ & $\begin{array}{c}\text { Allowable stress/ } \\
\text { Actual stress }\end{array}$ \\
\hline$L / 960$ & 2.5 & 0.670 & 0.289 & 2.3 \\
$L / 240$ & 1.1 & 0.670 & 0.670 & 1.0 \\
$L / 210$ & 1.0 & 0.670 & 0.731 & 0.9 \\
\hline
\end{tabular}


According to Mast (1993), the necessary factor of safety cannot be determined from scientific laws, however, it must be determined from experience. Tentatively, Mast (1993) recommends using a factor of safety of 1.0 against cracking and 1.5 against failure. For the two example beams, the equations developed by Plaut and Moen (2012) yield more conservative results compared to the factor of safety approach recommended by Mast (1993). As seen in Table 7 and Table 8, using the Plaut and Moen (2012) method, both beams are predicted to reach their tensile capacities at sweep magnitudes lower than the sweep magnitudes at which Mast's factor of safety against cracking is 1.0. The detailed calculation steps used for the computation of the Mast (1993) factors of safety are presented in Appendix D.

\subsection{Conclusions}

A new method for the analysis of precast prestressed concrete beams during lifting has been presented. Using the procedure outlined in this paper, one has the ability to determine roll angle, twist, moments, forces, deflections, and most importantly the maximum stresses acting on a beam during lifting.

Accounting for sweep and eccentricity of lift supports is important for predicting the behavior of beams during lifting. Quantifying these geometric imperfections in precast prestressed concrete beams is possible, and the presented data on imperfections provides useful characterization of typical magnitudes that could be expanded to more cross-section types and precast plants in the future. The PCI limits of L/960 for sweep and \pm 1 in. for lifting support eccentricity are consistent with measurement statistics presented in this study.

The proposed method for checking stresses during lifting involves the use of the freely available Lifting Analysis calculation sheet and an additional cross-section analysis program which can perform biaxial moment - axial load interaction analysis. Performing this type of 
study can involve difficulties, since not all engineers have access to such software, or the tools to perform cross-sectional analysis. For this reason, an open source tool for performing biaxial moment - axial load interaction analysis is needed. Alternatively, the development of combined biaxial bending and axial force interaction curves and tables for commonly used precast prestressed concrete beam sections would be very beneficial. 
CHAPTER 4. VALIDATION OF PROPOSED MODEL

\subsection{Introduction}

The equations proposed by Plaut and Moen (2012), on which the Lifting Analysis calculation sheet is based, are for doubly-symmetric beams. However, most precast prestressed concrete beams have singly-symmetric cross-sections. For this reason, in order to validate the proposed model, this chapter investigates the applicability of the Lifting Analysis sheet to singlysymmetric concrete beam cross-sections. Since the difference in behavior of a singly-symmetric concrete beam during lifting is due to the offset of the center of twist relative to the centroid, a study investigating the location of the center of twist of common precast prestressed concrete beams is presented in Section 4.2. Additionally, finite element models are developed in Section 4.2 to investigate the behavior of singly-symmetric concrete beams sections during lifting. Internal forces, internal moments, and deflections are calculated, and the results of the finite element models are compared to the prediction method developed by Plaut and Moen (2012).

\subsection{Center of twist study}

The main difference in behavior of a singly-symmetric concrete cross-section during lifting is due to the offset of the center of twist relative to the centroid. For a beam with the center of twist below the centroid, the equations developed by Plaut and Moen (2012) offer conservative estimates for weak-axis shear force, moment, and deformation. On the other hand, the case of a beam with the center of twist above the centroid is of concern, since the equations developed by Plaut and Moen (2012) would offer non-conservative results. For this reason, a study is conducted to investigate the location of the center of twist of typical precast prestressed 
concrete beams. The advanced general beam section calculator, ShapeDesigner SaaS by MechaTools Technologies (Shape Designer SaaS 2012), was used to find the centroid and center of twist (shear center) location of 13 precast beam shapes. The results are presented in Table 9 below.

Table 9. Center of twist location for common precast concrete beams

\begin{tabular}{l|cccc}
\hline \multicolumn{1}{c|}{ Beam type } & Depth, in. & $y_{c}$, in. & $y_{s}$, in. & $e_{c t}$, in. \\
\hline AASHTO modified type I beam & 28 & 12.83 & 10.94 & -1.89 \\
AASHTO type I beam & 28 & 12.59 & 10.22 & -2.37 \\
AASHTO type II beam & 36 & 15.83 & 11.76 & -4.07 \\
AASHTO type III beam & 45 & 20.27 & 15.91 & -4.36 \\
AASHTO type IV beam & 54 & 24.73 & 20.20 & -4.53 \\
AASHTO type V beam & 63 & 31.96 & 40.49 & 8.53 \\
AASHTO type VI beam & 72 & 36.39 & 46.30 & 9.91 \\
PCI-BT-54 & 54 & 27.63 & 37.16 & 9.53 \\
PCI-BT-56 & 56 & 27.54 & 34.52 & 6.98 \\
PCI-BT-63 & 63 & 32.12 & 43.44 & 11.32 \\
PCI-BT-65 & 65 & 31.87 & 42.35 & 10.48 \\
PCI-BT-72 & 72 & 36.60 & 49.69 & 13.09 \\
PCI-BT-74 & 74 & 36.22 & 48.17 & 11.95 \\
\hline
\end{tabular}

Note: $y_{c}=$ distance from centroid to the extreme bottom fiber; $y_{s}=$ distance from center of twist to the extreme bottom fiber; $e_{c t}=$ distance from centroid to center of twist (a positive value denotes a center of twist above the centroid)

From Table 9 above, it can be observed that the location of the center of twist for typical precast concrete beams varies, based on the shape of the beam. For beams with narrow top flanges, such as the smaller AASHTO beams, the center of twist is located below the centroid. On the other hand, for beams with wider top flanges, such as type V and VI, and the PCI bulb tee beams, the center of twist is above the centroid.

In a recent study by Schuh (2008), it was shown that a singly-symmetric beam with a larger bottom flange than top flange exhibits slightly less rotation than a doubly symmetric 
beam. Hence, if a singly-symmetric beam with a center of twist below the centroid rotates less than a doubly-symmetric beam, it will have less weight applied in the weak-axis direction, thus yielding a smaller weak-axis moment and displacement. Vice versa, a singly-symmetric beam with the center of twist above the centroid will rotate more, therefore yielding a greater weakaxis moment and displacement.

In order to investigate the behavior during lifting of beams with singly-symmetric cross sections, two finite element models were created for the beams with the greatest eccentricities of the center of twist relative to the centroid. The first model was created for the AASHTO type IV beam, for which the center of twist is $4.53 \mathrm{in}$. below the centroid. The second finite element model is for the PCI-BT-72 beam, which has a center of twist 13.09 in. above the centroid. The results of the finite element models are then compared to the prediction method developed by Plaut and Moen (2012), which is based on the assumption of a doubly-symmetric cross section.

\subsection{Finite element analysis of hanging beams}

The two finite element models (Type IV AASHTO and PCI-BT-72) were developed in ABAQUS v6.10 based on a previous study of Stratford and Burgoyne (1999), where finite element eigenvalue analyses and non-linear analyses were performed for hanging beams. Using B31OS beam elements in ABAQUS, the beams were divided into 50 elements, aligned with their centroid. The B31OS element in ABAQUS is a three-dimensional 2-node linear beam element that uses interpolation to determine the stress results for the entire cross section (ABAQUS 6.10). The B31OS element is able to account for the position of the center of twist relative to the centroid, which is necessary when modeling singly-symmetric cross sections. The beams are assumed to be lifted by vertical cables, which were modeled using T3D2 truss elements. The

cables were connected to the beam using rigid elements attached to the centroid. A distributed 
load equal to the beam's self weight was applied in the negative z-direction along the beam's length. For the purpose of the analysis, prestressing was not considered. Figure 17 below shows a graphical representation of the ABAQUS beam model. The AASHTO type IV and PCI-BT-72 beam properties are shown in Table 10.

In order for the solution to converge in Abaqus, it was required to restrain the beam in the y-direction at the cable attachment points. This condition does not accurately reflect the actual behavior of a hanging beam. However, the influence of this imposed boundary condition had a small impact on the results, as the reaction forces developed at the cable attachment points in the y-direction were small.

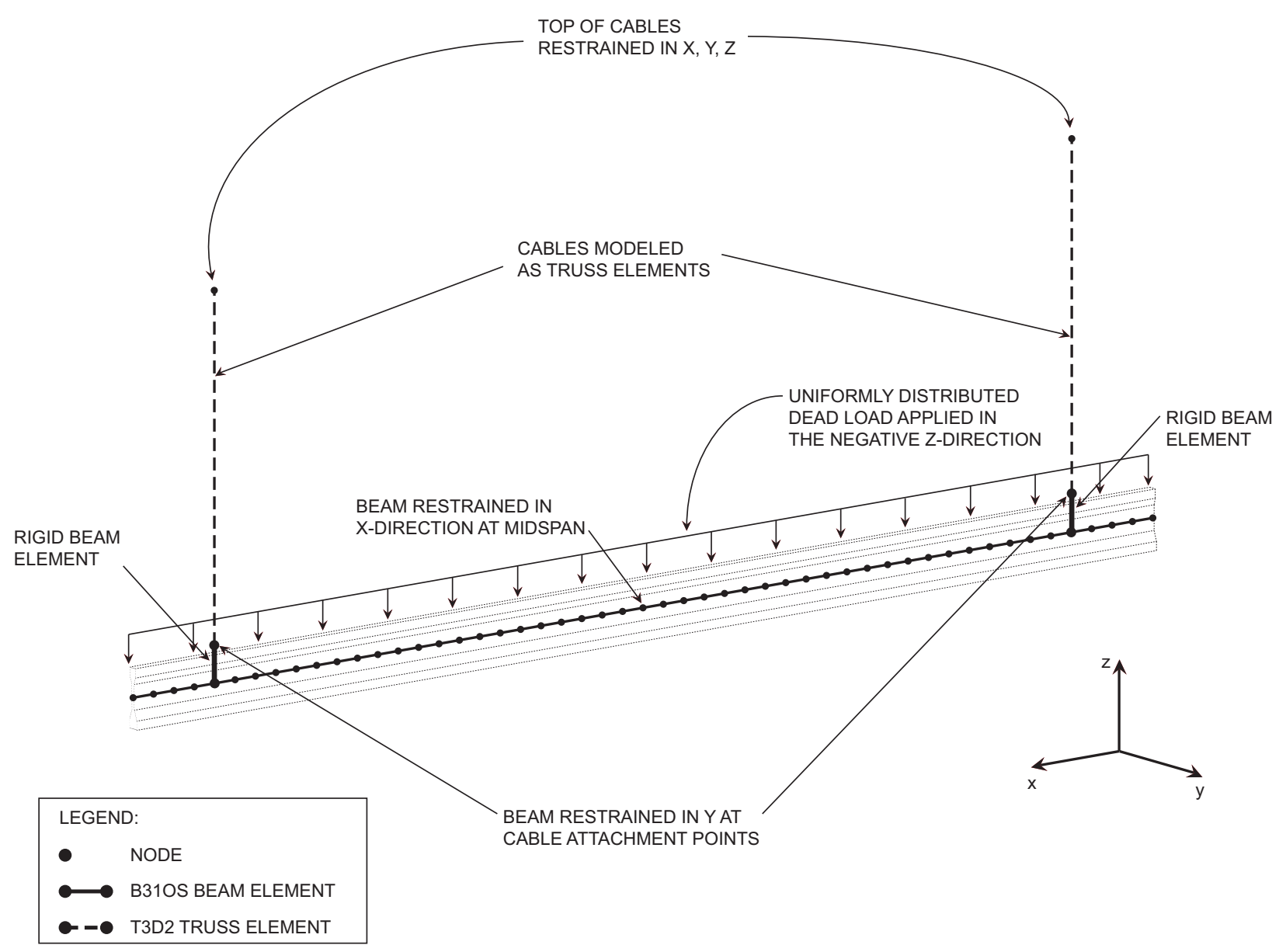

Figure 17. ABAQUS model of a hanging beam 
To investigate the applicability of the new method proposed in this paper (Plaut and Moen 2012) to singly-symmetric beams, internal forces, moments, and displacements were first calculated using the Lifting Analysis calculation sheet for both beams. The results were then compared to the values obtained from the ABAQUS finite element models. A comparison of the maximum resulting forces, moments and displacements is provided in Table 11 and Table 12. Additionally, a graphical representation of the results for both beams is offered in Figures 18-29. The results are plotted on the right half of the beam. The moments and displacements are symmetric with respect to the midspan, whereas the internal shear forces are anti-symmetric about midspan.

Table 10. Properties of Type IV AASHTO and PCI-BT-72 beams used for the FE model

\begin{tabular}{|c|c|c|}
\hline & $\begin{array}{l}\text { AASHTO } \\
\text { Type IV }\end{array}$ & PCI-BT-72 \\
\hline Beam length, in. & 1248 & 1248 \\
\hline Inclination of lifting cables from vertical, deg. & 0 & 0 \\
\hline Location of lift points from ends, in. & 31.2 & 31.2 \\
\hline Sweep at midspan & $L / 960$ & $L / 960$ \\
\hline Overall beam height, in. & 54 & 72 \\
\hline Height of centroid from bottom fiber, in. & 24.7 & 36.6 \\
\hline Height of center of twist from bottom fiber, in. & 20.2 & 49.7 \\
\hline Cross-sectional area, in. ${ }^{2}$ & 789 & 766 \\
\hline Strong-axis moment of inertia, in. ${ }^{4}$ & 260,741 & 545,857 \\
\hline Weak-axis moment of inertia, in. ${ }^{4}$ & 24,374 & 37,634 \\
\hline St. Venant's torsion constant, in. ${ }^{4}$ & 32,924 & 12,258 \\
\hline Warping constant, in. ${ }^{6}$ & $7,225,000$ & $30,850,000$ \\
\hline Self-weight, kip/in. & 0.08 & 0.06 \\
\hline Young's modulus, ksi & 5422 & 5422 \\
\hline Torsional shear modulus, ksi & 2259 & 2259 \\
\hline
\end{tabular}


The equations developed by Plaut and Moen (2012) yield similar results to the ABAQUS finite element model. As shown in Table 11 and Table 12, the results obtained using the Plaut and Moen (2012) equations are within \pm 5 percent of the finite element analysis results. Slightly conservative results are obtained for weak-axis moment and weak-axis displacement using the Plaut and Moen (2012) equations for the AASHTO type IV beam. The reason for this is because singly-symmetric beams with the center of twist below the centroid exhibit a slightly smaller rotation than doubly-symmetric beams (Schuh 2008), which also means that less weight is applied in the weak-axis direction, thus yielding a smaller weak-axis moment and displacement. Conversely, for the PCI-BT-72 beam which has a center of twist above the centroid, the Plaut and Moen (2012) equations yield non-conservative results for the weak-axis moment and displacement.

Table 11. AASHTO Type IV beam: Plaut \& Moen/ABAQUS results

\begin{tabular}{l|lccc}
\hline & Location & $\begin{array}{c}\text { Plaut \& Moen } \\
\text { model }\end{array}$ & $\begin{array}{c}\text { ABAQUS } \\
\text { model }\end{array}$ & $\begin{array}{c}\text { Plaut \& } \\
\text { Moen/ } \\
\text { ABAQUS }\end{array}$ \\
\hline Strong-axis moment $M_{z}$, kip-in. & Midspan & 14,270 & 14,263 & 1.00 \\
Weak-axis moment $M_{y}$, kip-in. & Midspan & 537 & 523 & 1.03 \\
Strong-axis shear $N_{y}$, kip & Lift points & 48.3 & 48.3 & 1.00 \\
Weak-axis shear $N_{z}$, kip & Lift points & 1.8 & 1.8 & 1.00 \\
Strong-axis displacement $V$, in. & Midspan & 1.48 & 1.51 & 0.98 \\
Weak-axis displacement $W$, in. & Midspan & 0.59 & 0.56 & 1.05 \\
\hline
\end{tabular}


Table 12. PCI-BT-72 beam: Plaut \& Moen/ABAQUS results

\begin{tabular}{l|lccc}
\hline & Location & $\begin{array}{c}\text { Plaut \& Moen } \\
\text { model }\end{array}$ & $\begin{array}{c}\text { ABAQUS } \\
\text { model }\end{array}$ & $\begin{array}{c}\text { Plaut \& } \\
\text { Moen/ } \\
\text { ABAQUS }\end{array}$ \\
\hline Strong-axis moment $M_{z}$, kip-in. & Midspan & 10,913 & 10,907 & 1.00 \\
Weak-axis moment $M_{y}$, kip-in. & Midspan & 263 & 269 & 0.98 \\
Strong-axis shear $N_{y}$, kip & Lift points & 36.9 & 36.9 & 1.00 \\
Weak-axis shear $N_{z}$, kip & Lift points & 0.89 & 0.89 & 1.00 \\
Strong-axis displacement $V$, in. & Midspan & 0.54 & 0.55 & 0.98 \\
Weak-axis displacement $W$, in. & Midspan & 0.19 & 0.20 & 0.95 \\
\hline
\end{tabular}

Overall, the finite element analysis results are consistent with the previous study performed by Schuh (2008) investigating the effects of cross section symmetry during lifting. The prediction method (Plaut and Moen 2012) offers conservative results for weak-axis moment and displacement for beams with the center of twist below the centroid, and non-conservative results for beams with the center of twist above the centroid. However, the difference in results between the FE model and the Plaut and Moen (2012) method is small, not exceeding \pm 5 percent.

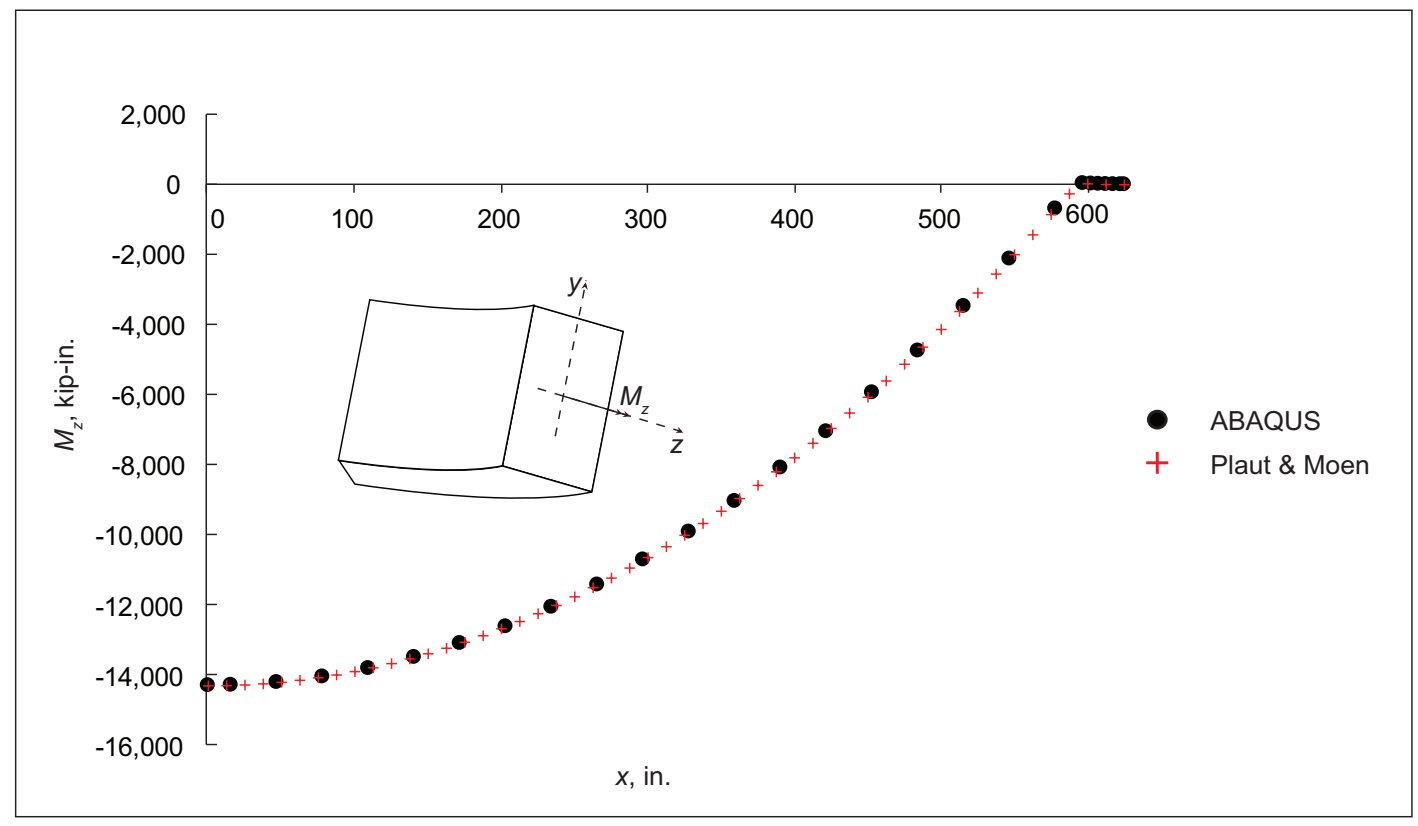

Figure 18. Strong-axis bending moment comparison for AASHTO type IV beam 


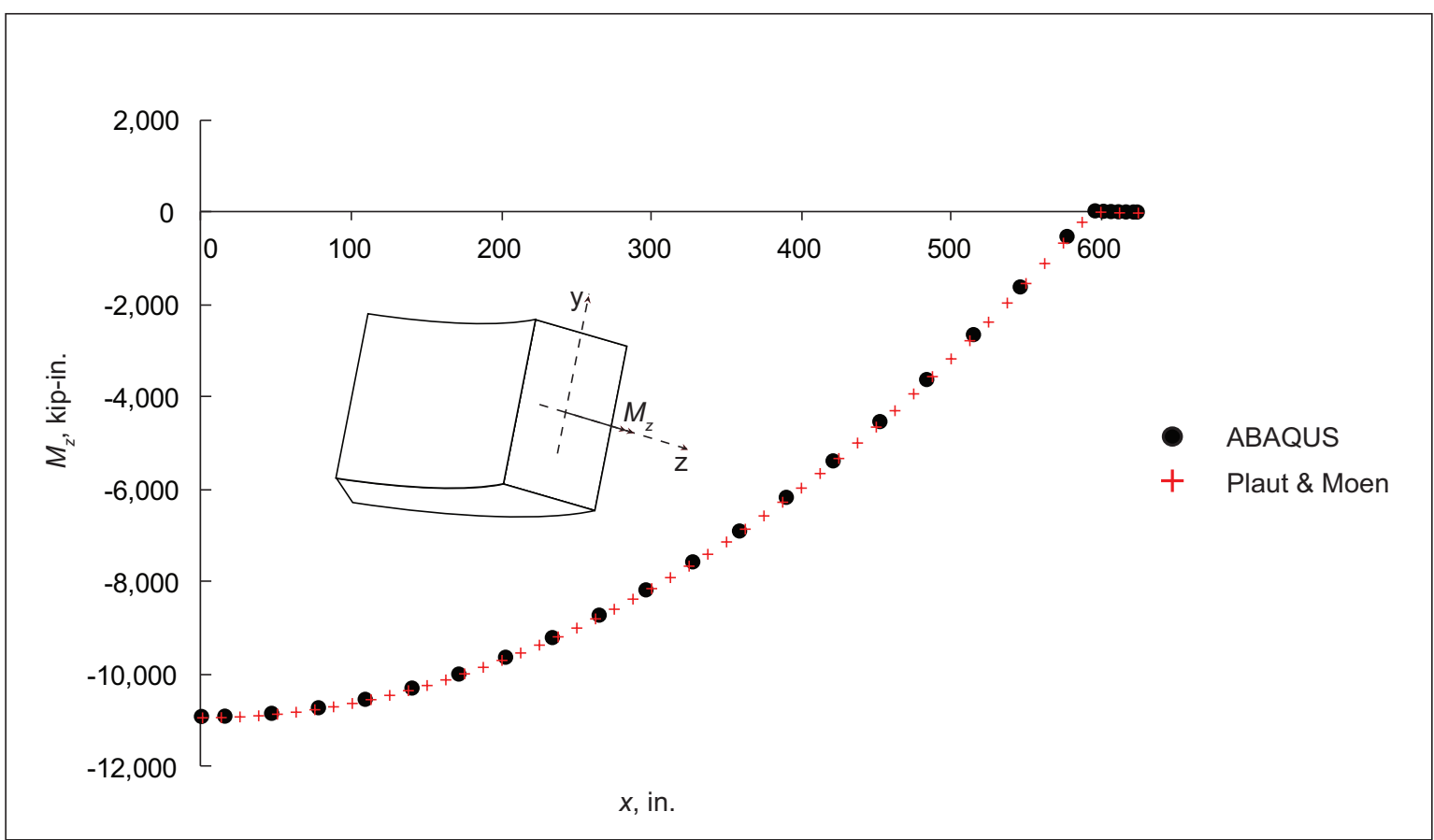

Figure 19. Strong-axis bending moment comparison for PCI-BT-72 beam

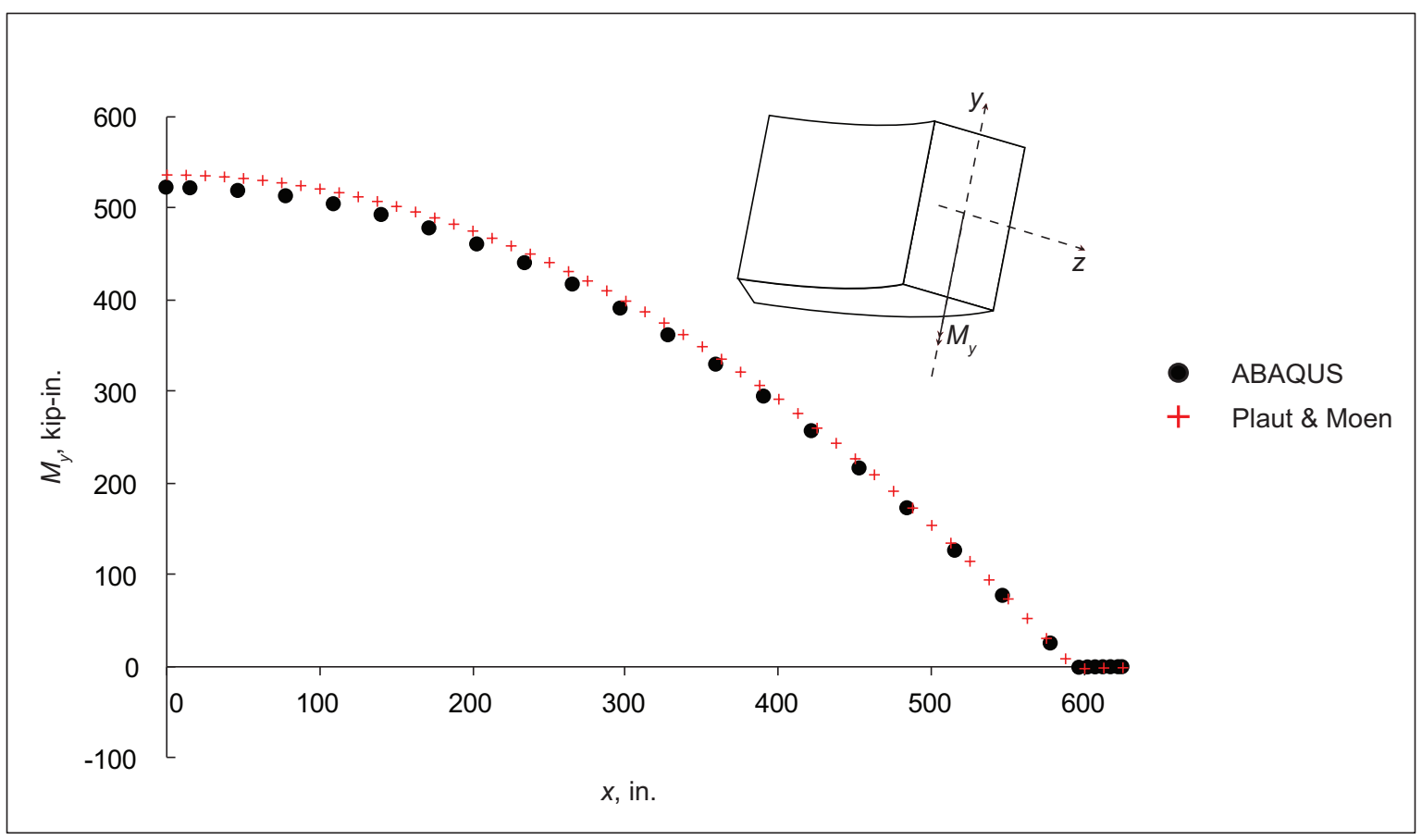

Figure 20. Weak-axis bending moment comparison for AASHTO type IV beam 




Figure 21. Weak-axis bending moment comparison for PCI-BT-72 beam



Figure 22. Strong-axis shear comparison for AASHTO type IV beam 


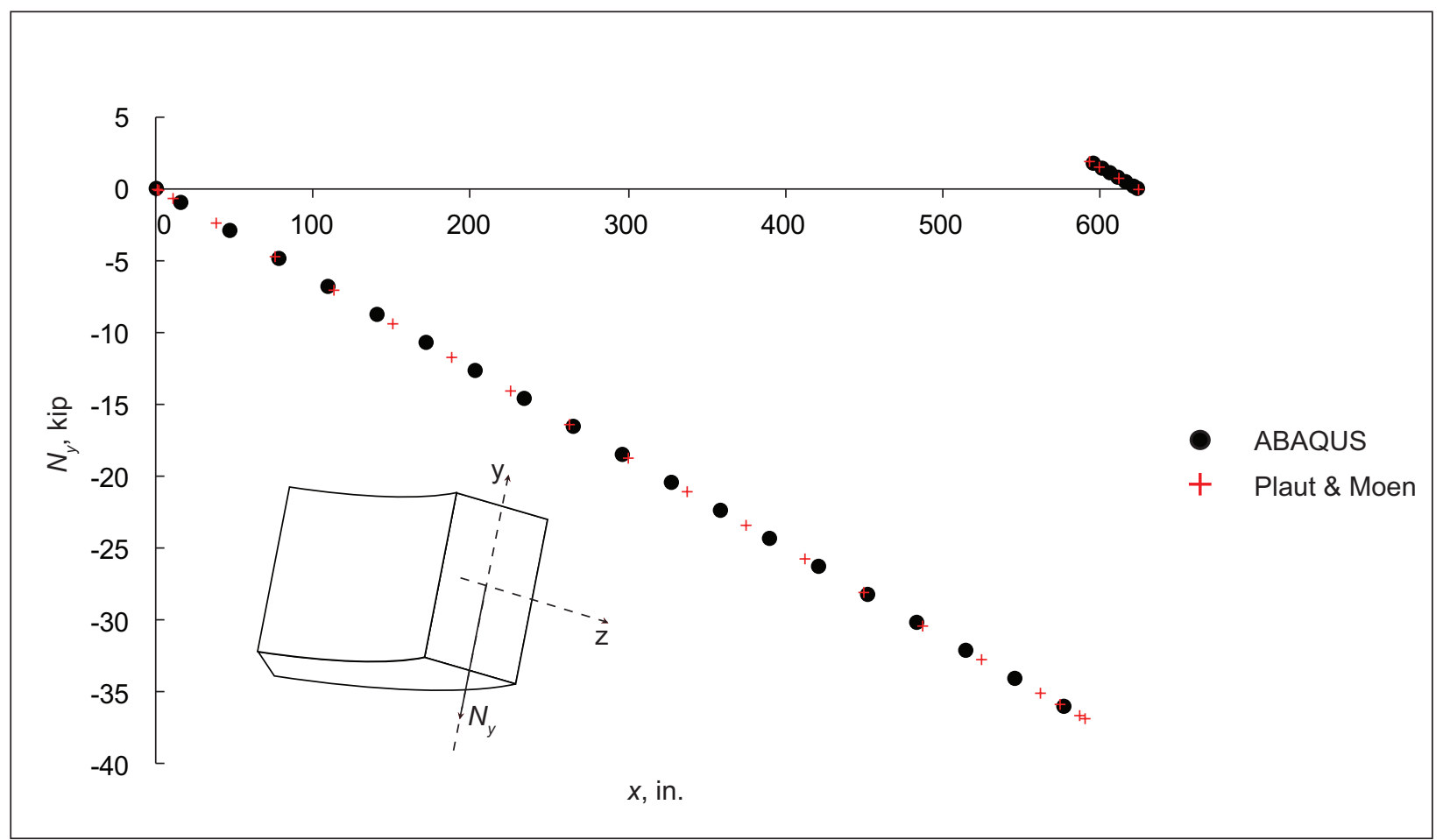

Figure 23. Strong-axis shear comparison for PCI-BT-72 beam

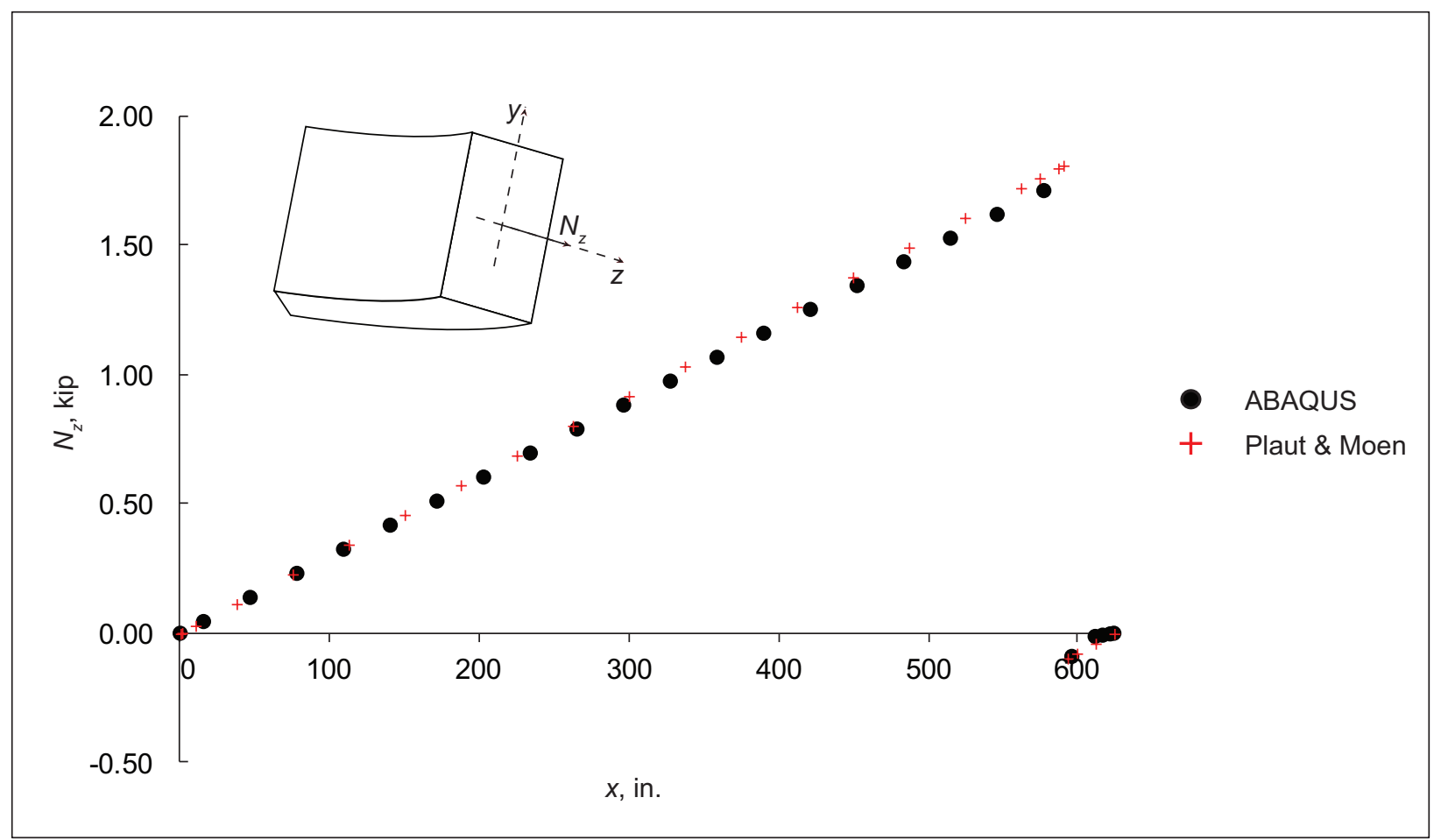

Figure 24. Weak-axis shear comparison for AASHTO type IV beam 




Figure 25. Weak-axis shear comparison for PCI-BT-72 beam



Figure 26. Strong-axis displacement comparison for AASHTO type IV beam 




Figure 27. Strong-axis displacement comparison for PCI-BT-72 beam



Figure 28. Weak-axis displacement comparison for AASHTO type IV beam 


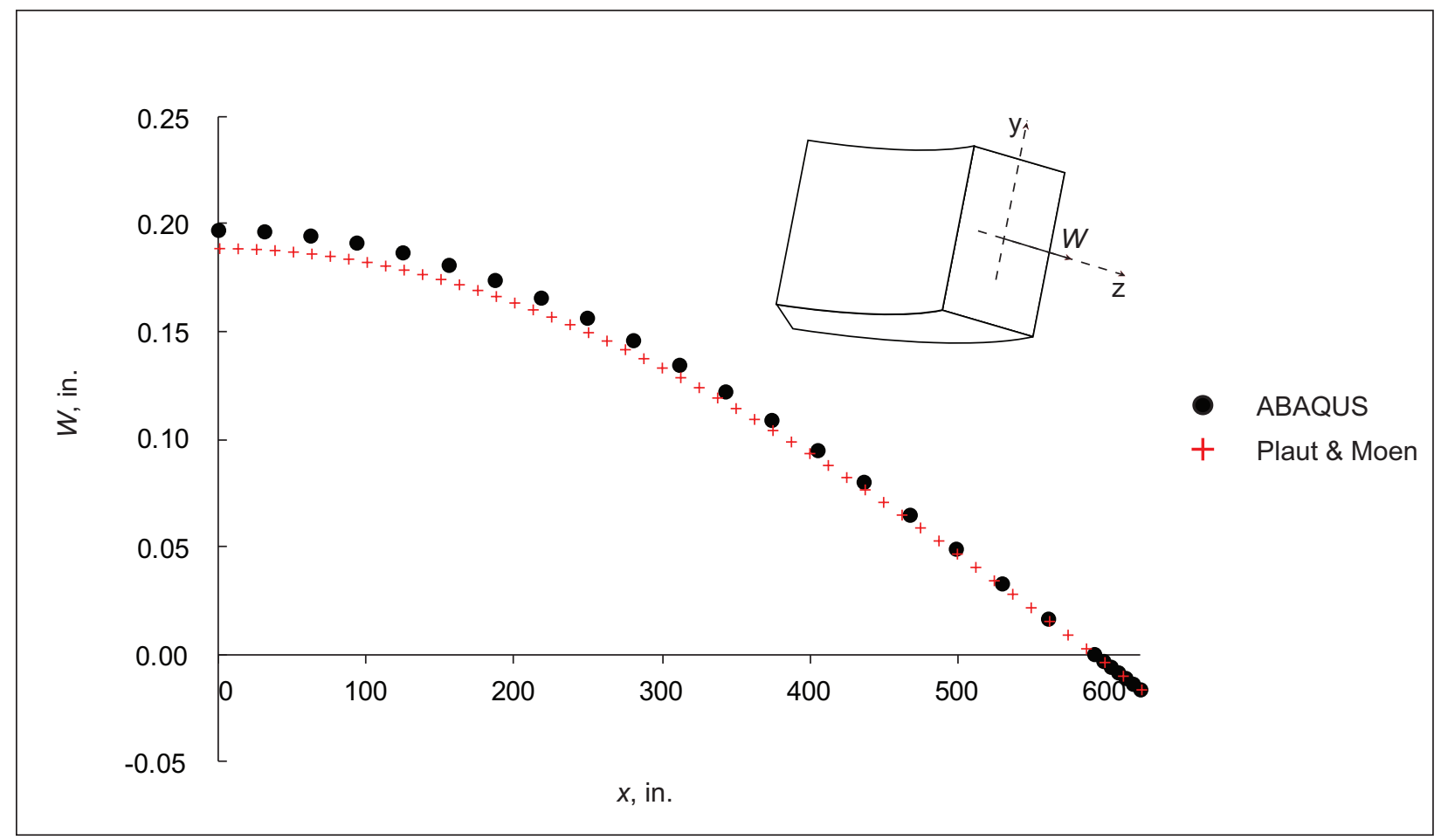

Figure 29. Weak-axis displacement comparison for PCI-BT-72 beam 


\section{CHAPTER 5. CONCLUSIONS}

A new method for predicting the behavior of precast prestressed concrete beams during lifting was presented. Based on the equations developed by Plaut and Moen (2012), an easy to use free calculation sheet was created in Excel which allows the determination of the roll angle, twist, moments, forces, and deflections for a beam during lifting. Although derived for doublysymmetric beams, using finite element simulations it was shown that the equations can be applied to typical precast concrete beams with singly-symmetric cross-sections. The difference in results between the FE model and the Plaut and Moen (2012) method is small, not exceeding \pm 5 percent.

Additionally, a tensile concrete stress limit was proposed, in which the goal was to limit tensile stresses in the corner of the top flange to the modulus of rupture of the concrete. The proposed method for checking stresses during lifting involves the use of the Lifting Analysis calculation sheet and an additional cross-sections analysis program which can perform biaxial moment - axial load interaction analysis. Performing this type of study can involve difficulties, since not all engineers have access to such software, or the tools to perform cross-sectional analysis. For this reason, an open source tool for performing biaxial moment - axial load interaction analysis is needed. Alternatively, the development of combined biaxial bending and axial force interaction curves and tables for commonly used precast prestressed concrete beam sections would be very beneficial.

Finally, this study outlined that accounting for sweep and eccentricity of lift supports is important for predicting the behavior of beams during lifting. Quantifying these geometric imperfections in precast prestressed concrete beams is possible, and the presented data on 
imperfections provided useful characterization of typical magnitudes that could be expanded to more cross-section types and precast plants in the future. The PCI limits of L/960 for sweep and \pm 1 in. for lifting support eccentricity are consistent with measurement statistics presented in this study. 
1. AASHTO LRFD Bridge Design Specifications (2007), 4th ed., American Association of State Highway and Transportation Officials, Washington, DC.

2. AASHTO LRFD Bridge Construction Specifications (2004), $2^{\text {nd }}$ ed. with 2006 and 2007 Interim Revisions, American Association of State Highway and Transportation Officials, Washington, DC.

3. AASHTO Standard Specifications for Highway Bridges (2002), $17^{\text {th }}$ ed., American Association of State Highway and Transportation Officials, Washington, DC.

4. Anderson, A. R. (1971). "Lateral stability of long prestressed concrete beams." PCI Journal, 16(3), 7-9. Discussion by R. A. Swann, PCI Journal, 16(6), 85-86. Closure, PCI Journal, 16(6), 86-87.

5. Castrodale, R. W. and White, C. D. (2004). Extending span ranges of precast prestressed concrete girders. National Cooperative Highway Research Program Report 517.

6. Chadwell, C.B. and TRC software. 2002. XTRACT: cross-sectional X sTRuctural Analysis of ComponenTs.

7. Geren, K. L. and Tadros, M. K. (1994). "The NU precast/prestressed concrete bridge Igirder series.” PCI Journal, May-June, 26-32.

8. Hale, W. M. and Russell, B. W. (2006). "Effect of allowable compressive stress at release on prestress losses and on the performance of precast, prestressed concrete bridge girders.” PCI Journal, March-April, 14-25.

9. Hill, C. D., Dick, J. S. and Tadros M. K. (2009). " PCI advisory on I-girder stability during handling and construction." Aspire, The Concrete Bridge Magazine, 38-40.

10. Hurff, J. B. (2010). "Stability of precast prestressed concrete bridge girders considering imperfections and thermal effects." PhD thesis, Georgia Institute of Technology, Atlanta, GA.

11. Laszlo, G., and Imper, R. R. (1987). "Handling and shipping of long span bridge beams." PCI Journal, 32(6), 86-101. Discussion by A. R. Anderson, PCI Journal, 34(1), 164-167. Closure, PCI Journal, 34(1), 167-168.

12. Mast, R. F. (1989). "Lateral stability of long prestressed concrete beams, Part 1." PCI Journal, 34(1), 34-53.

13. Mast, R. F. (1993). "Lateral stability of long prestressed concrete beams, Part 2." PCI Journal, 38(1), 70-88. 
14. Mast, R. F. (1994). "Lateral bending test to destruction of a $149 \mathrm{ft}$ prestressed concrete Ibeam." PCI Journal, 39(1), 54-62.

15. PCI Bridge Design Manual (2003), $2^{\text {nd }}$ ed., Prestressed Concrete Institute, Chicago, IL.

16. PCI Design Handbook, $6^{\text {th }}$ ed., Prestressed Concrete Institute, Chicago, IL.

17. PCI Committee on Tolerances. 2000. PCI Tolerance Manual for Precast and Prestressed Concrete Construction. $1^{\text {st }}$ ed. Chicago, IL: PCI.

18. PCI Technical Activities Council and PCI Committee on Building Code, July-August 1996, “PCI Standard Design Practice,” PCI Journal, V. 41, No. 4, pp. 31-43.

19. Peart, W. L., Rhomberg, E. J., and James, R. W. (1992). "Buckling of suspended cambered girders." Journal of Structural Engineering, 118(2), 505-528.

20. Plaut, R. H., and Moen, C. D. (2012). "Analysis of elastic, doubly symmetric, horizontally curved beams during lifting." Journal of Structural Engineering.

21. Plaut, R. H., Moen, C. D., and Cojocaru, R. (2011). "Beam deflections and stresses during lifting." Proc., SSRC 2011 Annual Stability Conference, Pittsburgh, Pa.

22. Pope, M and Holombo, Jay. (2009). "The new California wide-flange girder. A super girder for California bridges.” Western Bridge Engineers' Seminar, Sacramento, California.

23. Schafer, B.W. and Peköz, T. (1998). "Computational modeling of cold-formed steel: characterizing geometric imperfections and residual stresses." Journal of Constructional Steel Research, 47(3), 193-210.

24. Schuh, A. C. (2008). "Behavior of horizontally curved steel I-girders during lifting." MS thesis, University of Texas at Austin, Austin, Texas.

25. ShapeDesigner Saas. Advanced general beam section calculator. MechaTools Technologies, 2012.

26. Stratford, T. J. and Burgoyne, C. J. (1999). "Lateral stability of long precast concrete beams." Proc. Instn. Civ. Engrs. Structs. \& Bldgs., 124(2), 169-180.

27. Stratford, T. J., and Burgoyne, C. J. (2000). "The toppling of hanging beams." Int. J. Solids Struct., 27(26), 3569-3589.

28. Stratford, T. J., Burgoyne, C. J., and Taylor, H. P. J. (1999). "Stability design of long precast concrete beams." Proc. Instn. Civ. Engrs. Structs. \& Bldgs., 134(2), 159-168. 
29. Swann, R. A. and Godden, W. G. (1966). "The lateral buckling of concrete beams lifted by cables." The Structural Engineer, 44(1), 21-33.

30. Yoo, C. H. (2000). "Torsional and other properties of prestressed concrete sections." PCI Journal, May-June, 66-72.

31. Zeinoddini-Meimand, V. (2011). "Geometric imperfections in cold-formed steel members." PhD thesis, Johns Hopkins University, Baltimore, MD. 


\section{APPENDIX A - ROLL ANGLE STUDY}

An experimental study was conducted to investigate the rotation of six 77 in. PCI Bulb Tee bridge girders during lifting. The motivation of this study was to confirm the accuracy of the roll angle prediction using three theoretical methods: Mast (1989), Plaut and Moen (2012), and Stratford et al. (1999). The six girders were lifted by vertical cables, and "in the air" measurements were taken using SBS1U inclinometers attached at the ends and the midspan of the girders. Additionally, the sweep of each girder was measured, based on which the theoretical values of the roll angle were computed. The properties of the girders can be found in Section 3.5.1, as they are the same girders used in example problem 1. The results of the study are presented in Table A1.

Table A1. Roll angle study results

\begin{tabular}{ccc|cc|cc|cc}
\hline \multirow{2}{*}{ Beam } & \multirow{2}{*}{, in. $\begin{array}{c}\beta \text { measured, } \\
\text { deg. }\end{array}$} & \multicolumn{2}{|c|}{$\begin{array}{c}\text { Mast }(1989) \\
\text { predicted, }\end{array}$} & $\beta$ measured/ & \multicolumn{2}{c|}{ Stratford et al (1999) } & \multicolumn{2}{c}{ Plaut and Moen (2012) } \\
\hline 1 & 0.73 & 0.50 & 0.64 & $\beta$ predicted & $\beta$ measured/ & $\beta$ predicted, & $\beta$ measured/ \\
deg. & $\beta$ predicted & $\begin{array}{c}\beta \text { predicted } \\
\text { deg. }\end{array}$ \\
\hline 2 & 0.38 & 0.37 & 0.33 & 0.8 & 0.64 & 0.8 & 0.64 & 0.8 \\
3 & 1.25 & 1.03 & 1.09 & 0.9 & 0.33 & 1.1 & 0.33 & 1.1 \\
4 & 1.12 & 1.29 & 0.98 & 1.3 & 0.98 & 0.9 & 1.09 & 0.9 \\
5 & 0.83 & 0.49 & 0.72 & 0.7 & 0.73 & 0.7 & 0.97 & 1.3 \\
6 & 0.77 & 0.62 & 0.67 & 0.9 & 0.68 & 0.9 & 0.72 & 0.7 \\
\hline
\end{tabular}

The results show that the three theoretical methods used to predict the value of the roll angle of the beam during lifting yield identical results. Additionally, the theoretical prediction methods offer good estimates of the actual measured roll angle. The differences in results between the measured and predicted values are within 70 percent. A linear relation is observed between the magnitude of the sweep imperfection and the magnitude of the measured roll angle, as depicted in Figure A1. 


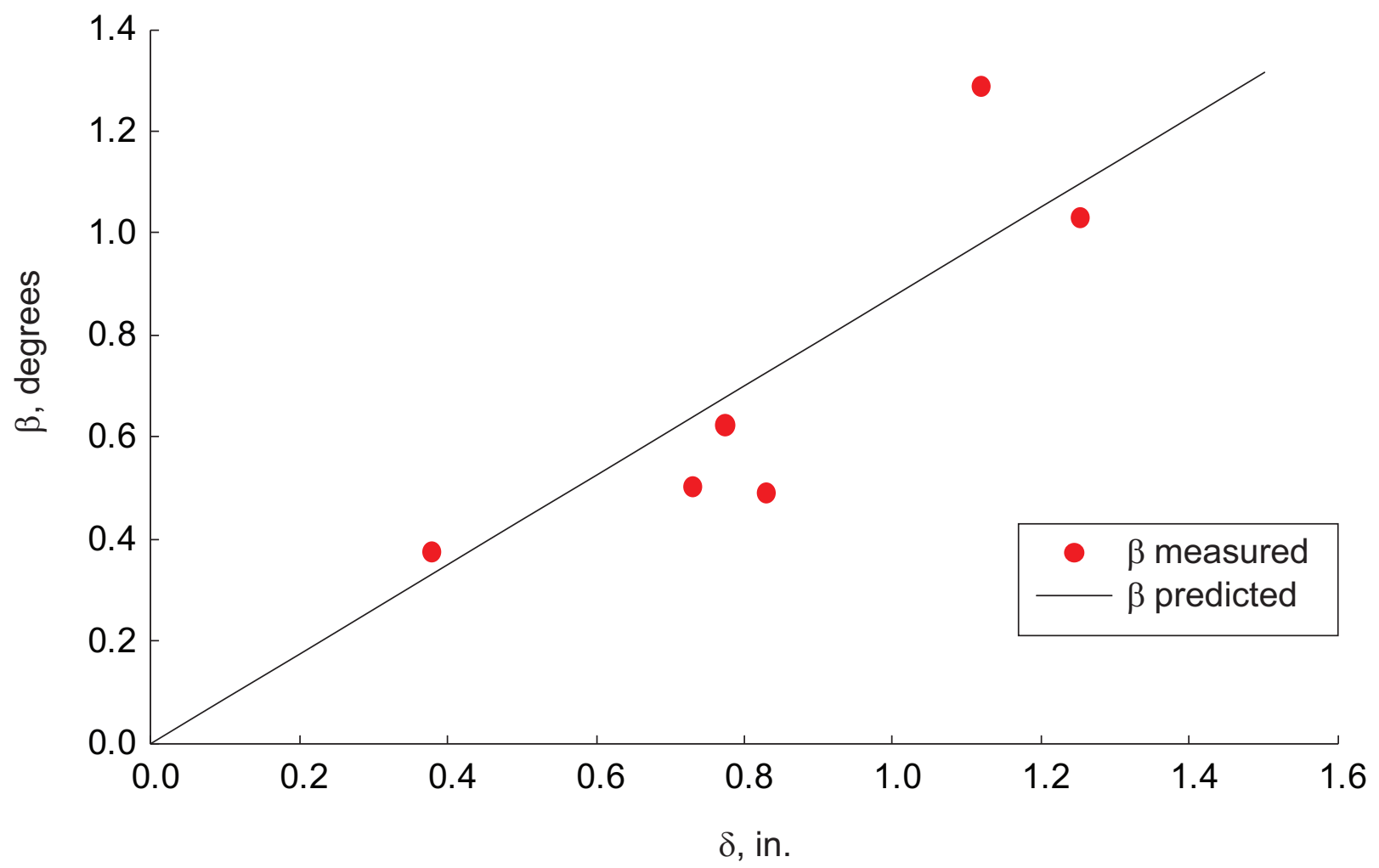

Figure A1. Roll angle as a function of sweep



Figure A2. Roll angle measured-to-predicted ratio v. sweep 
The Lifting Analysis calculation sheet has been created at Virginia Tech by Razvan Cojocaru and Dr. Cristopher Moen (cojocaru@vt.edu, cmoen@vt.edu). The equations used in this spreadsheet are based on the prediction method in Plaut, R. H., and Moen, C. D. (2012). "Analysis of elastic, doubly symmetric, horizontally curved beams during lifting." J. Struct. Eng.

An explanation of the quantities used in the calculation sheet is provided below:

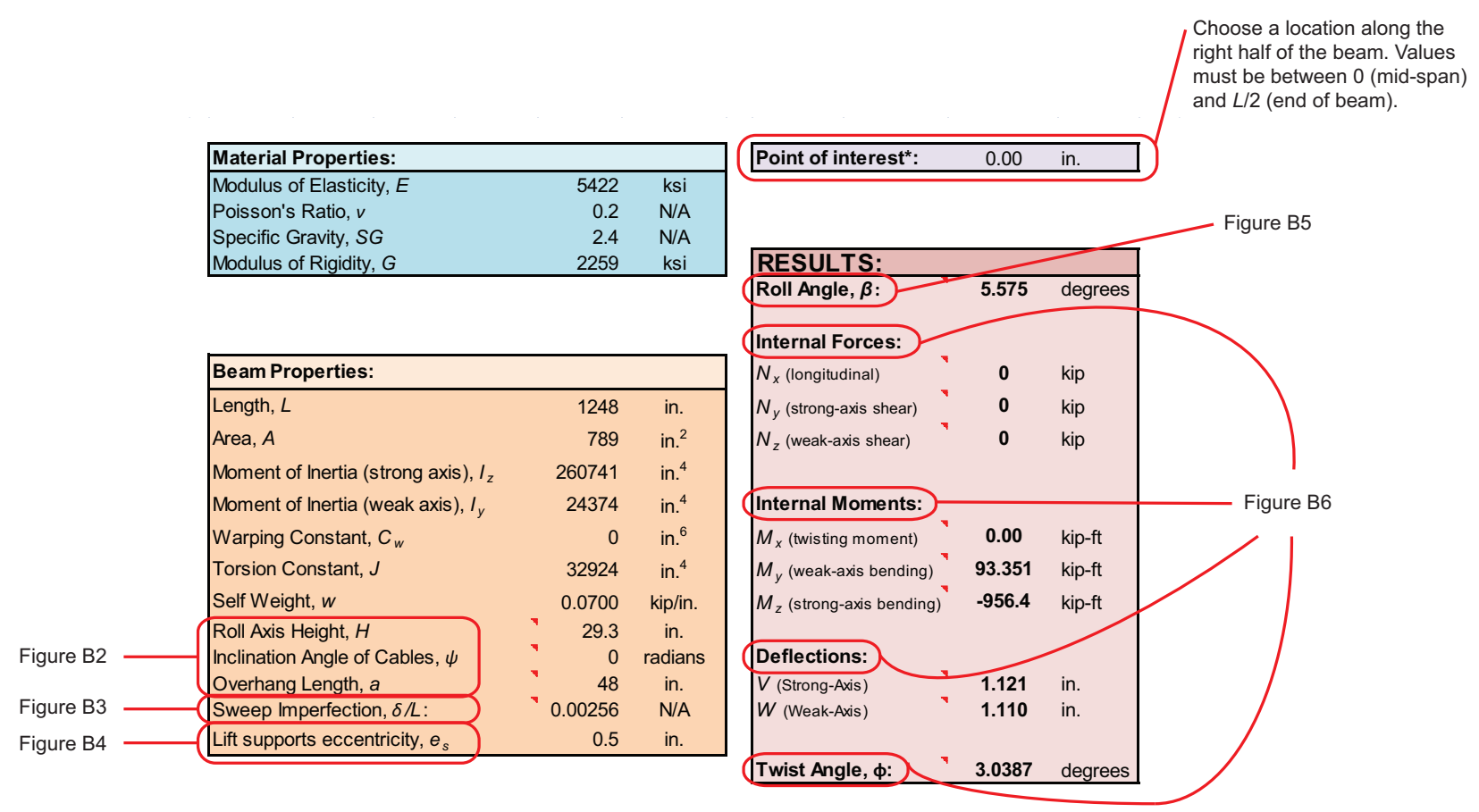

Figure B1. Lifting Analysis calculation sheet 




ELEVATION VIEW

Figure B2. Graphical representation of quantities describing properties of lifting devices

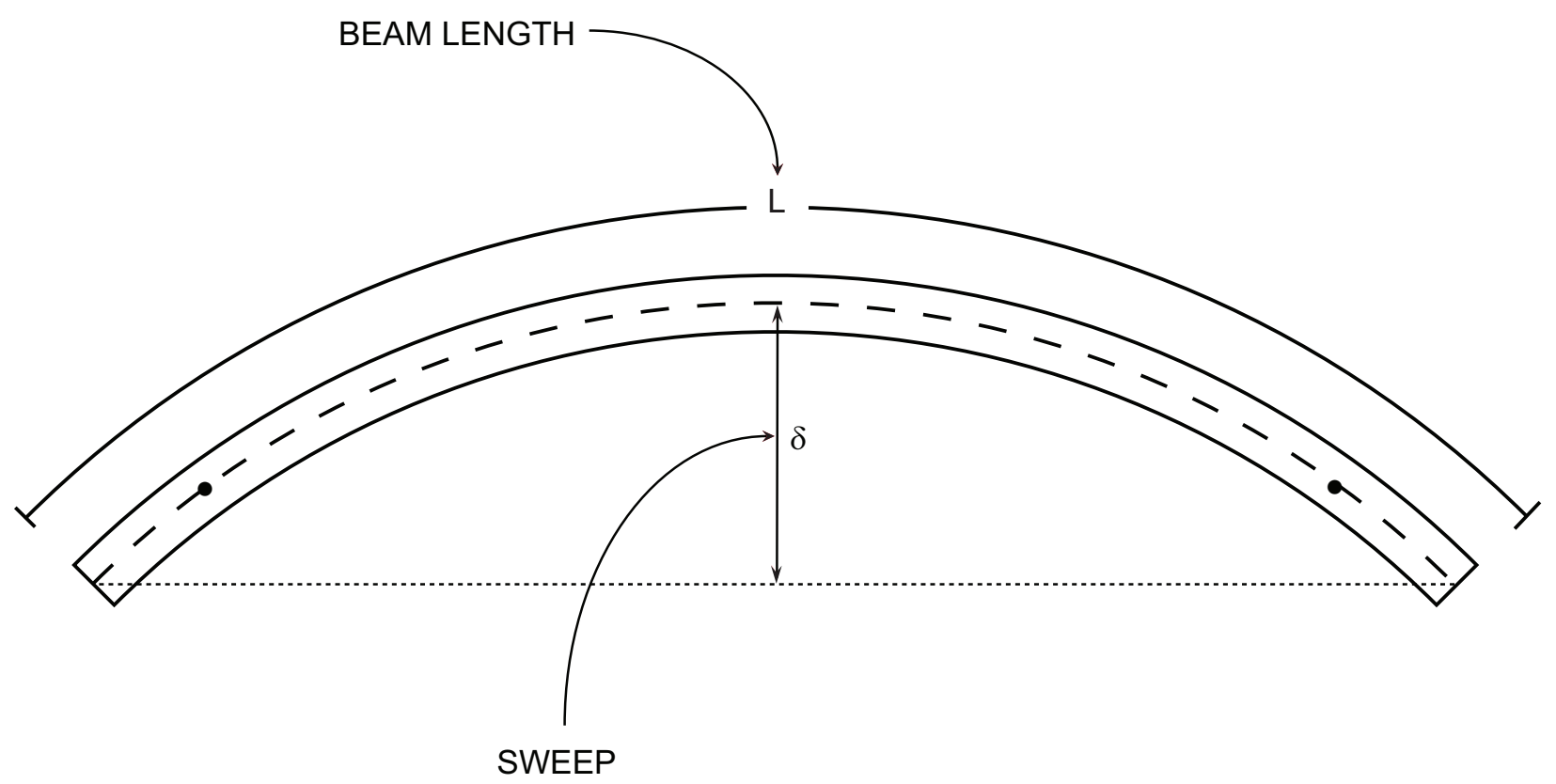

\section{PLAN VIEW}

Figure B3. Graphical representation of sweep 


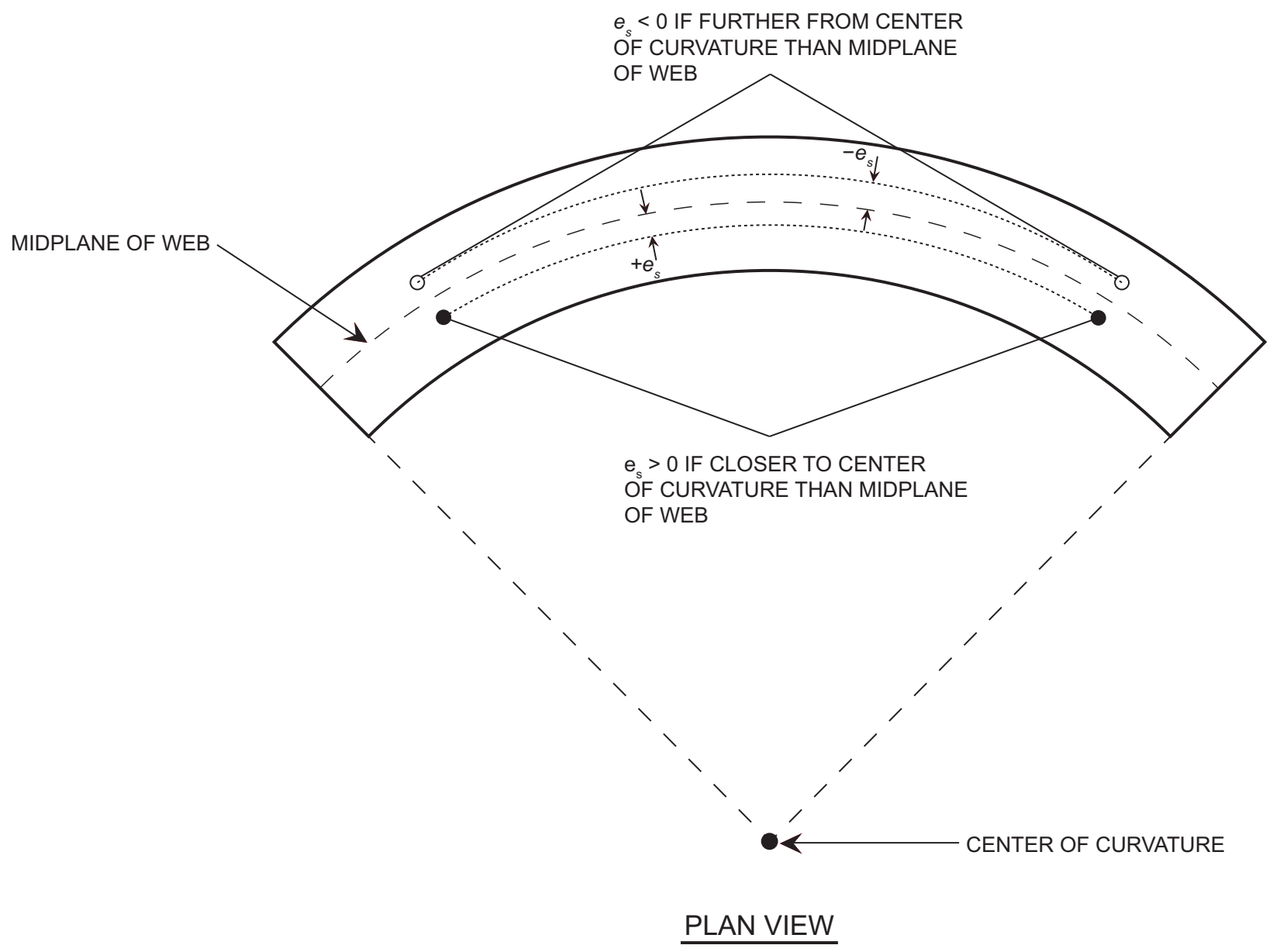

Figure B4. Lift supports eccentricity 


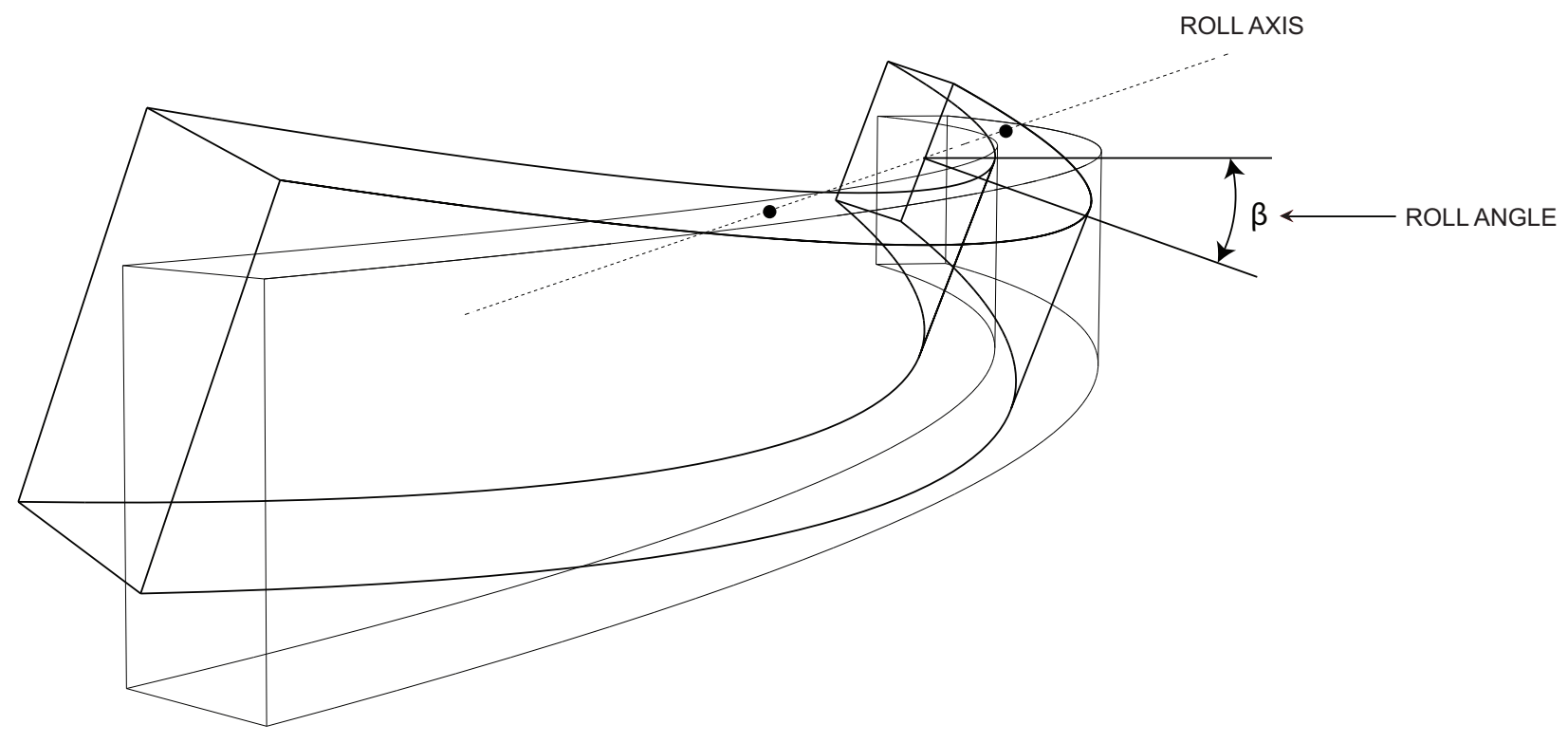

ISOMETRIC VIEW

Figure B5. Roll angle 


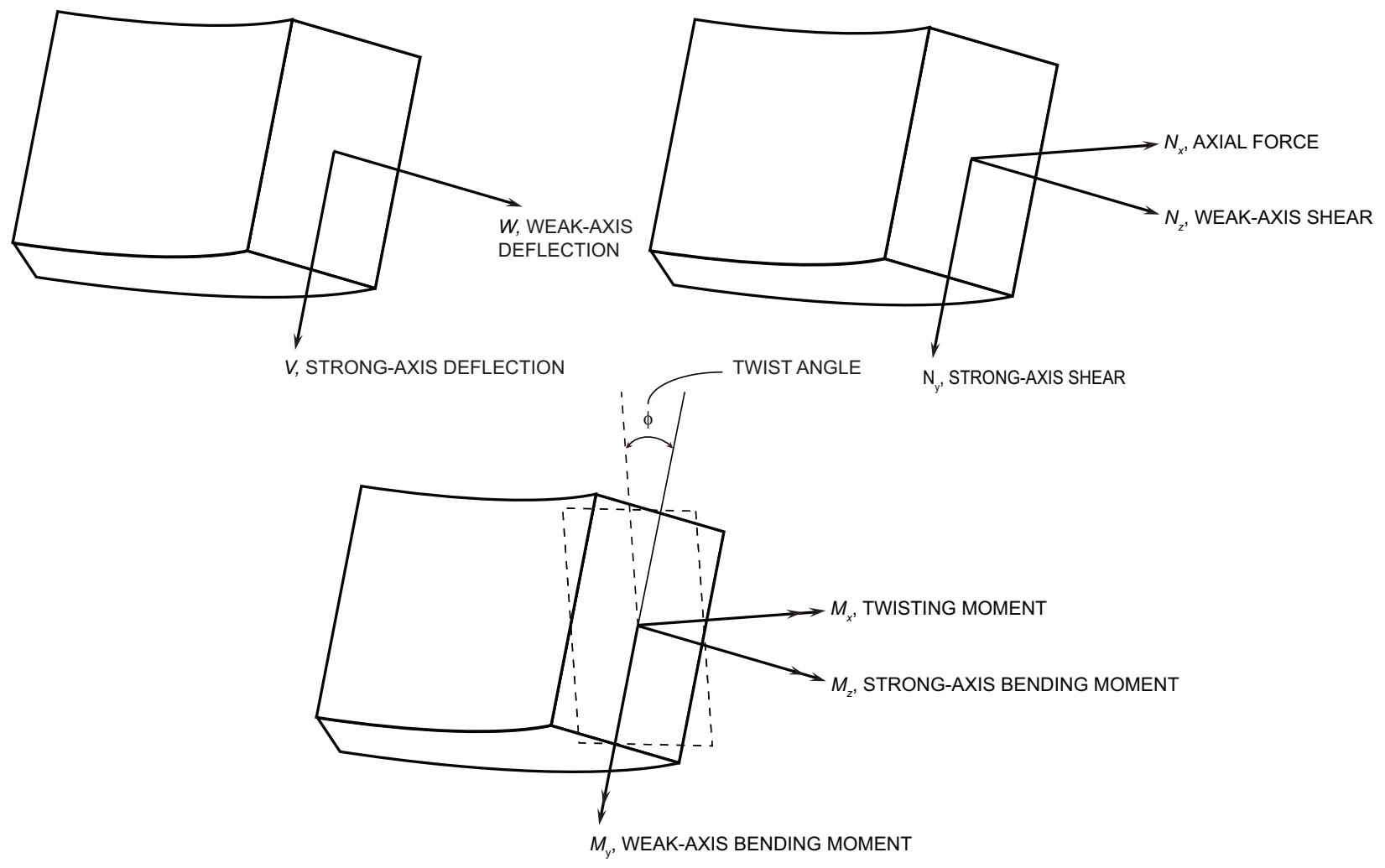

Figure B6. Deflections, shear, and moments 
Adapted from the original ABAQUS input file of Stratford and Burgoyne (1999) (with permission).

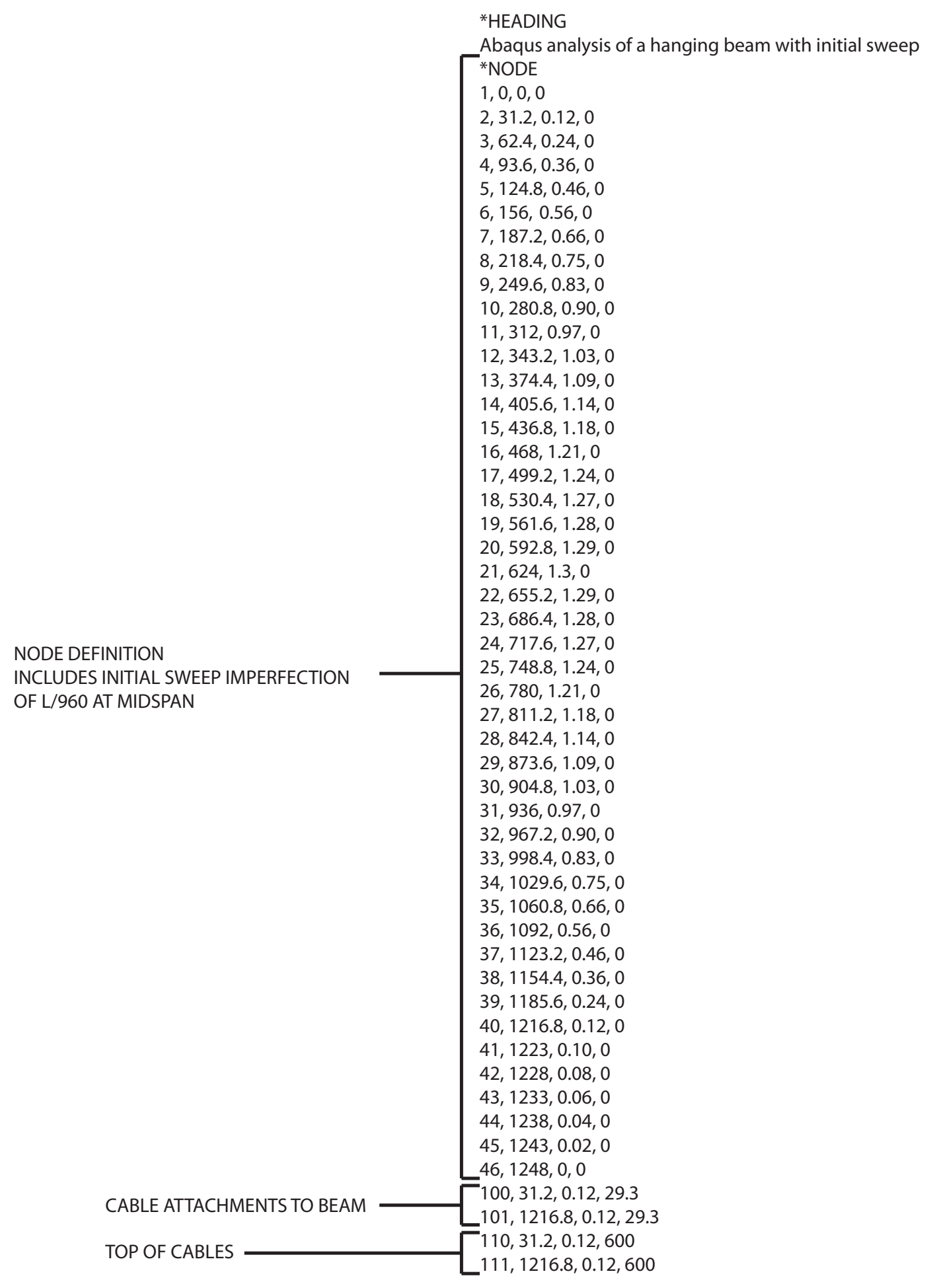




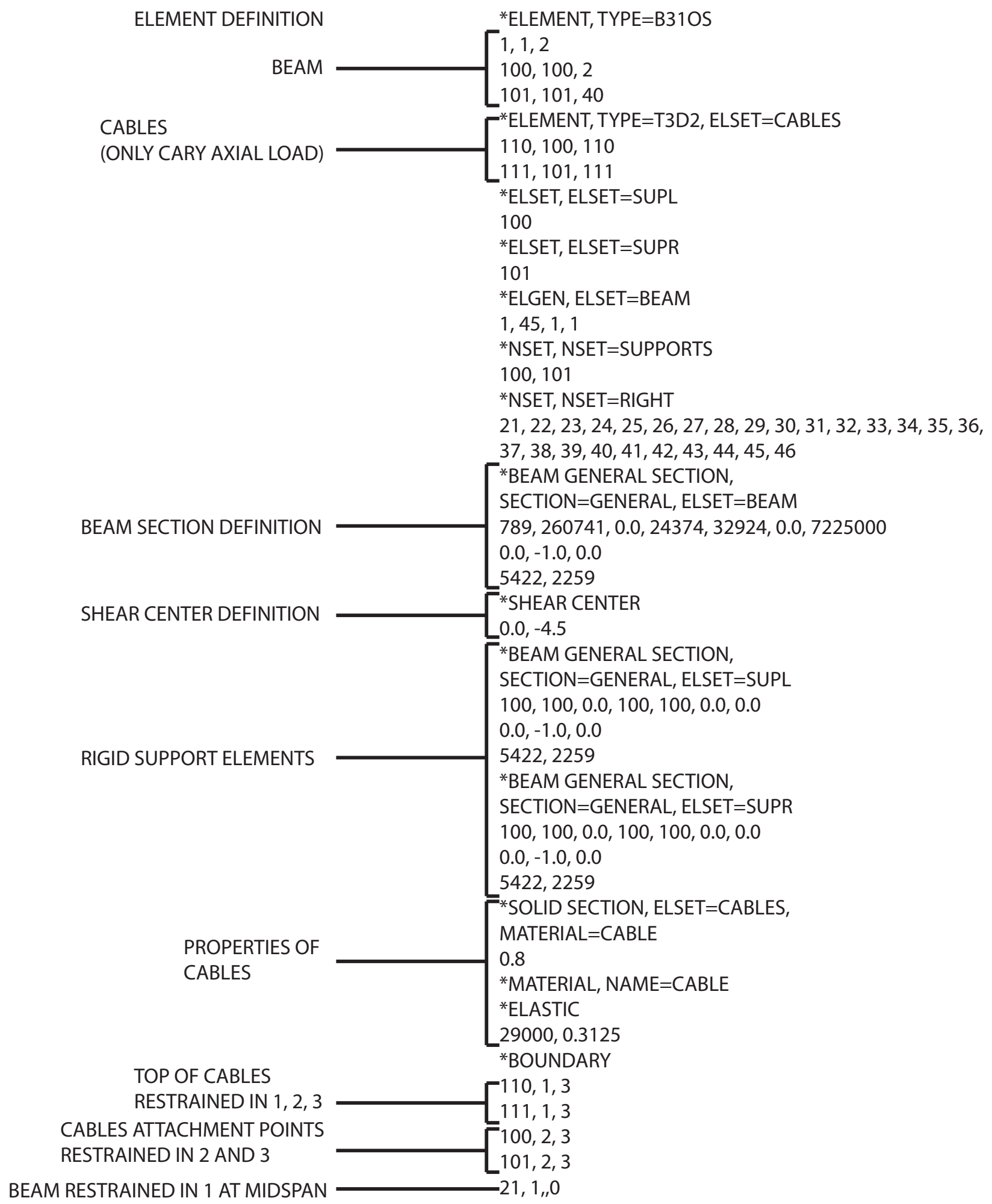









\section{APPENDIX D -MAST (1993) FS SAMPLE CALCULATIONS}

The calculation steps presented below are based on the procedure outlined in Appendix B of Mast (1993).

\section{Example 1: PCI BT77 beam}

\section{GIVEN}

Top flange width: $\mathrm{b}:=47 \cdot$ in

Weight of beam: $\quad w:=0.084 \frac{\text { kip }}{\text { in }}$

Area: $\quad A:=970.7 \cdot$ in $^{2}$

Length: $\mathrm{L}:=139 \mathrm{ft}$

Pickup points at distance: $\quad$ a $:=90 \cdot$ in $\quad$ from each end

Distance between pickup points: $\quad \mathrm{L}_{1}:=\mathrm{L}-2 \cdot \mathrm{a}=124 \mathrm{ft}$

Strong axis: $\quad \mathrm{I}_{\mathrm{X}}:=789500 \mathrm{in}^{4}$

$$
\begin{aligned}
& \mathrm{y}_{\text {top }}:=3 \cdot \mathrm{ft}+\left(3+\frac{5}{16}\right) \cdot \mathrm{in}=39.31 \cdot \mathrm{in} \\
& \mathrm{y}_{\text {bot }}:=3 \cdot \mathrm{ft}+\left(1+\frac{11}{16}\right) \cdot \mathrm{in}=37.69 \mathrm{in} \\
& \mathrm{S}_{\text {top }}:=\frac{\mathrm{I}_{\mathrm{x}}}{\mathrm{y}_{\text {top }}}=20083 \mathrm{in}^{3} \\
& \mathrm{~S}_{\text {bot }}:=\frac{\mathrm{I}_{\mathrm{x}}}{\mathrm{y}_{\text {bot }}}=20949 \mathrm{in}^{3}
\end{aligned}
$$

Weak axis: $\quad I_{y}:=63600$ in $^{4}$

Height of roll axis: $y_{r}:=39 \cdot$ in

Distance from center of gravity of bottom strands to the bottom fiber of the beam:

$\mathrm{y}_{\mathrm{bs}}:=\frac{14 \cdot 2+14 \cdot 4+12 \cdot 6+6 \cdot 8+4 \cdot 10+2 \cdot 12}{14+14+12+6+4+2} \cdot \mathrm{in}=5.15 \cdot \mathrm{in}$

Bottom strand eccentricity: $\quad \mathrm{e}_{\mathrm{bot}}:=\mathrm{y}_{\mathrm{bot}}-\mathrm{y}_{\mathrm{bs}}=32.53 \mathrm{in}$

Distance from center of gravity of top strands to the top fiber of the beam: 
$\mathrm{y}_{\mathrm{ts}}:=2 \cdot$ in

Top strand eccentricity: $\quad \mathrm{e}_{\text {top }}:=\mathrm{y}_{\mathrm{top}}-\mathrm{y}_{\mathrm{ts}}=37.31$ in

Total force due to prestress: $\quad P:=54.40 .83 \mathrm{kip}=2204.82 \mathrm{kip}$

Force in top strands: $\quad \mathrm{P}_{\text {top }}:=2.40 .83 \mathrm{kip}=81.66 \mathrm{kip}$

Force in bottom strands: $\quad \mathrm{P}_{\text {bot }}:=52.40 .83 \mathrm{kip}=2123.16 \mathrm{kip}$

Harp point location: $\quad \mathrm{x}:=0.5 \cdot \mathrm{L}-5 \cdot \mathrm{ft}=774$ in

Self-weight moment at harp point: $\quad \mathrm{M}_{\mathrm{Sw}}:=\frac{\mathrm{w} \cdot \mathrm{x}}{2} \cdot(\mathrm{L}-\mathrm{x})=29062 \mathrm{kip} \cdot \mathrm{in}$

\section{Stresses at harp points:}

Stresses due to prestress and self weight:

Top: $\quad f_{t}:=\frac{P}{A}-\frac{P_{\text {bot }} \cdot e_{\text {bot }}}{S_{\text {top }}}+\frac{P_{\text {top }} \cdot e_{\text {top }}}{S_{\text {top }}}+\frac{\mathrm{M}_{\text {sw }}}{S_{\text {top }}}=0.431 \cdot \mathrm{ksi} \quad$ COMPRESSIOP

Bottom: $\quad \mathrm{f}_{\mathrm{b}}:=\frac{\mathrm{P}}{\mathrm{A}}+\frac{\mathrm{P}_{\mathrm{bot}} \cdot \mathrm{e}_{\mathrm{bot}}}{\mathrm{S}_{\mathrm{bot}}}-\frac{\mathrm{P}_{\text {top }} \cdot \mathrm{e}_{\mathrm{top}}}{\mathrm{S}_{\mathrm{bot}}}-\frac{\mathrm{M}_{\mathrm{sw}}}{\mathrm{S}_{\mathrm{bot}}}=4.036 \mathrm{ksi} \quad$ COMPRESSIOr

\section{Find modulus of elasticity:}

Strength of concrete at release: $\quad \mathrm{f}_{\mathrm{ci}}^{\prime}:=6.5 \cdot \mathrm{ksi}$

$\mathrm{E}_{\mathrm{c}}:=33 \cdot 150^{1.5} \cdot \sqrt{\mathrm{f}_{\mathrm{ci}}^{\prime} \cdot \mathrm{psi}}=4888 \mathrm{ksi}$

\section{Compute initial eccentricity, $e_{i}$ :}

sweep $:=\frac{\mathrm{L}}{960}=1.74$ in

offset factor: $\quad$ offset $:=\left(\frac{\mathrm{L}_{1}}{\mathrm{~L}}\right)^{2}-\frac{1}{3}=0.462$

$\mathrm{e}_{\mathrm{i}}:=$ sweep $\cdot$ offset $=0.8 \cdot$ in

\section{Compute $z_{0}:$}

$\mathrm{z}_{0}:=\frac{\mathrm{w}}{12 \cdot \mathrm{E}_{\mathrm{c}} \cdot \mathrm{I}_{\mathrm{y}} \cdot \mathrm{L}} \cdot\left(0.1 \cdot \mathrm{L}_{1}^{5}-\mathrm{a}^{2} \cdot \mathrm{L}_{1}^{3}+3 \cdot \mathrm{a}^{4} \cdot \mathrm{L}_{1}+1.2 \cdot \mathrm{a}^{5}\right)=9.49$ in 


\section{Compute $\boldsymbol{\theta}_{\mathbf{i}}$ :}

$$
\theta_{\mathrm{i}}:=\frac{\mathrm{e}_{\mathrm{i}}}{\mathrm{y}_{\mathrm{r}}}=1.18 \cdot \mathrm{deg}
$$

Compute the tilt angle $\theta_{\text {max }}$ at cracking:

$$
\begin{aligned}
& \mathrm{f}_{\mathrm{r}}:=7.5 \cdot \sqrt{\mathrm{f}_{\mathrm{ci}} \cdot \mathrm{psi}}=0.605 \mathrm{ksi} \\
& \mathrm{M}_{\text {lat }}:=\frac{\left(\mathrm{f}_{\mathrm{r}}+\mathrm{f}_{\mathrm{t}}\right) \cdot \mathrm{I}_{\mathrm{y}}}{\frac{\mathrm{b}}{2}}=2802 \mathrm{kip} \cdot \mathrm{in} \\
& \theta_{\text {max }}:=\frac{\mathrm{M}_{\text {lat }}}{\mathrm{M}_{\mathrm{sw}}}=5.524 \mathrm{deg}
\end{aligned}
$$

\section{Factor of safety against cracking:}

$$
\mathrm{FS}:=\frac{1}{\frac{\mathrm{z}_{0}}{\mathrm{y}_{\mathrm{r}}}+\frac{\theta_{\mathrm{i}}}{\theta_{\max }}}=2.2
$$




\section{Example 2: AASHTO Type IV beam}

\section{GIVEN}

Top flange width: $\quad \mathrm{b}:=20$. in

Weight of beam: $\quad$ w $:=822$ plf $=0.07 \cdot \frac{\mathrm{kip}}{\text { in }}$

Area: $\quad$ A $:=789$ in $^{2}$

Length: $\quad \mathrm{L}:=104 \mathrm{ft}$

Pickup points at distance: $\quad a:=48 \cdot$ in $\quad$ from each end

Distance between pickup points: $\mathrm{L}_{1}:=\mathrm{L}-2 \cdot \mathrm{a}=96 \mathrm{ft}$

Strong axis: $\quad I_{x}:=260741$ in $^{4}$

$$
\begin{aligned}
& \mathrm{y}_{\text {top }}:=29.25 \mathrm{in} \\
& \mathrm{y}_{\text {bot }}:=24.75 \mathrm{in} \\
& \mathrm{S}_{\text {top }}:=8902.67 \mathrm{in}^{3} \\
& \mathrm{~S}_{\text {bot }}:=10521.33 \mathrm{in}^{3}
\end{aligned}
$$

Weak axis: $\mathrm{I}_{\mathrm{y}}:=24374 \mathrm{in}^{4}$

Height of roll axis: $y_{r}:=29.3$ in

Distance from center of gravity of bottom strands to the bottom fiber of the beam:

$\mathrm{y}_{\mathrm{bs}}:=\frac{36 \cdot 4+8 \cdot 8}{44} \cdot \mathrm{in}=4.73 \cdot \mathrm{in}$

Bottom strand eccentricity: $\quad \mathrm{e}_{\mathrm{bot}}:=\mathrm{y}_{\mathrm{bot}}-\mathrm{y}_{\mathrm{bs}}=20.02$ in

Distance from center of gravity of top strands to the top fiber of the beam:

$\mathrm{y}_{\mathrm{ts}}:=2 \cdot$ in

Top strand eccentricity: $\quad e_{\text {top }}:=y_{\text {top }}-y_{\text {ts }}=27.25$ in 
Total force due to prestress: $\mathrm{P}:=46 \cdot 40.88 \mathrm{kip}=1880 \mathrm{kip}$

Force in top strands: $\quad \mathrm{P}_{\text {top }}:=2 \cdot 40.88 \mathrm{kip}=81.76 \mathrm{kip}$

Force in bottom strands: $\quad \mathrm{P}_{\text {bot }}:=44.40 .88 \mathrm{kip}=1799 \mathrm{kip}$

Harp point location: $\quad \mathrm{x}:=.5 \cdot \mathrm{L}-5 \cdot \mathrm{ft}=564$ in

Self-weight moment at harp point: $\mathrm{M}_{\mathrm{Sw}}:=\frac{\mathrm{w} \cdot \mathrm{x} \cdot(\mathrm{L}-\mathrm{x})}{2}=13213 \mathrm{kip} \cdot \mathrm{in}$

\section{Stresses at harp points:}

Stresses due to prestress and self weight:

Top: $\quad f_{t}:=\frac{P}{A}-\frac{P_{\text {bot }} \cdot e_{\text {bot }}}{S_{\text {top }}}+\frac{\mathrm{P}_{\text {top }} \cdot e_{\text {top }}}{\mathrm{S}_{\text {top }}}+\frac{\mathrm{M}_{\text {sw }}}{S_{\text {top }}}=0.072 \mathrm{ksi} \quad$ COMPRESSIOr

Bottom: $\quad \mathrm{f}_{\mathrm{b}}:=\frac{\mathrm{P}}{\mathrm{A}}+\frac{\mathrm{P}_{\mathrm{bot}} \cdot \mathrm{e}_{\mathrm{bot}}}{\mathrm{S}_{\mathrm{bot}}}-\frac{\mathrm{P}_{\text {top }} \cdot \mathrm{e}_{\mathrm{top}}}{\mathrm{S}_{\mathrm{bot}}}-\frac{\mathrm{M}_{\mathrm{sw}}}{\mathrm{S}_{\mathrm{bot}}}=4.339 \mathrm{ksi} \quad$ COMPRESSIOr

\section{Find modulus of elasticity:}

Strength of concrete at release: $\quad \mathrm{f}_{\mathrm{ci}}^{\prime}:=8 \cdot \mathrm{ksi}$

$$
\mathrm{E}_{\mathrm{c}}:=33 \cdot 150^{1.5} \cdot \sqrt{\mathrm{f}_{\mathrm{ci}}^{\prime} \cdot \mathrm{psi}}=5422 \mathrm{ksi}
$$

\section{Compute initial eccentricity, $e_{i}$ :}

sweep $:=\frac{\mathrm{L}}{960}=1.3 \cdot$ in

offset factor: $\quad$ offset $:=\left(\frac{\mathrm{L}_{1}}{\mathrm{~L}}\right)^{2}-\frac{1}{3}=0.519$

$\mathrm{e}_{\mathrm{i}}:=$ sweep $\cdot$ offset $=0.67 \cdot$ in

\section{Compute $\mathrm{z}_{0}$ :}

$\mathrm{z}_{0}:=\frac{\mathrm{w}}{12 \cdot \mathrm{E}_{\mathrm{c}} \cdot \mathrm{I}_{\mathrm{y}} \cdot \mathrm{L}} \cdot\left(0.1 \cdot \mathrm{L}_{1}{ }^{5}-\mathrm{a}^{2} \cdot \mathrm{L}_{1}^{3}+3 \cdot \mathrm{a}^{4} \cdot \mathrm{L}_{1}+1.2 \cdot \mathrm{a}^{5}\right)=6.9 \cdot$ in

\section{Compute $\boldsymbol{\theta}_{\mathbf{i}}$ :}

$$
\theta_{\mathrm{i}}:=\frac{\mathrm{e}_{\mathrm{i}}}{\mathrm{y}_{\mathrm{r}}}=1.32 \cdot \mathrm{deg}
$$


Compute the tilt angle $\theta_{\text {max }}$ at cracking:

$$
\begin{aligned}
& \mathrm{f}_{\mathrm{r}}:=7.5 \cdot \sqrt{\mathrm{f}_{\mathrm{ci}} \cdot \mathrm{psi}}=0.671 \cdot \mathrm{ksi} \\
& \mathrm{M}_{\mathrm{lat}}:=\frac{\left(\mathrm{f}_{\mathrm{r}}+\mathrm{f}_{\mathrm{t}}\right) \cdot \mathrm{I}_{\mathrm{y}}}{\frac{\mathrm{b}}{2}}=1811 \cdot \mathrm{kip} \cdot \mathrm{in} \\
& \theta_{\max }:=\frac{\mathrm{M}_{\mathrm{lat}}}{\mathrm{M}_{\mathrm{sw}}}=7.85 \cdot \mathrm{deg}
\end{aligned}
$$

\section{Factor of safety against cracking:}

$$
\mathrm{FS}:=\frac{1}{\frac{\mathrm{z}_{0}}{\mathrm{y}_{\mathrm{r}}}+\frac{\theta_{\mathrm{i}}}{\theta_{\max }}}=2.5
$$


Table E1. Summary of sweep measurement results

\begin{tabular}{|c|c|c|c|c|}
\hline No. & Beam Type & $\begin{array}{c}\text { Length, } \\
\mathrm{ft}\end{array}$ & $\begin{array}{l}\text { Sweep } \delta, \\
\text { in. }\end{array}$ & $\begin{array}{c}\text { Sweep } \\
\text { (normalized) }\end{array}$ \\
\hline 1 & 77 in. Bulb Tee & 139 & 0.73 & $\mathrm{~L} / 2285$ \\
\hline 2 & 77 in. Bulb Tee & 139 & 0.38 & L/4389 \\
\hline 3 & 77 in. Bulb Tee & 139 & 1.25 & $\mathrm{~L} / 1334$ \\
\hline 4 & 77 in. Bulb Tee & 139 & 0.77 & L/2166 \\
\hline 5 & 77 in. Bulb Tee & 139 & 1.12 & $\mathrm{~L} / 1489$ \\
\hline 6 & 77 in. Bulb Tee & 139 & 0.83 & $\mathrm{~L} / 2010$ \\
\hline 7 & 74 in. Bulb Tee (Modified) & 124 & 0.44 & L/3369 \\
\hline 8 & 74 in. Bulb Tee (Modified) & 124 & 1.05 & $\mathrm{~L} / 1415$ \\
\hline 9 & 74 in. Bulb Tee (Modified) & 124 & 1.71 & $\mathrm{~L} / 872$ \\
\hline 10 & 74 in. Bulb Tee (Modified) & 124 & 0.92 & $\mathrm{~L} / 1611$ \\
\hline 11 & 74 in. Bulb Tee (Modified) & 124 & 2.21 & $\mathrm{~L} / 675$ \\
\hline 12 & 74 in. Bulb Tee (Modified) & 124 & 1.34 & $\mathrm{~L} / 1107$ \\
\hline 13 & 74 in. Bulb Tee (Modified) & 124 & 0.38 & $\mathrm{~L} / 3877$ \\
\hline 14 & 74 in. Bulb Tee (Modified) & 124 & 1.39 & $\mathrm{~L} / 1067$ \\
\hline 15 & 74 in. Bulb Tee (Modified) & 124 & 2.05 & $\mathrm{~L} / 725$ \\
\hline 16 & 74 in. Bulb Tee (Modified) & 124 & 0.51 & L/2905 \\
\hline 17 & 72 in. Bulb Tee & 122 & 1.18 & $\mathrm{~L} / 1242$ \\
\hline 18 & 72 in. Bulb Tee & 122 & 1.44 & $\mathrm{~L} / 1020$ \\
\hline 19 & 72 in. Bulb Tee & 122 & 1.57 & $\mathrm{~L} / 935$ \\
\hline 20 & 72 in. Bulb Tee & 122 & 0.52 & $\mathrm{~L} / 2813$ \\
\hline 21 & 72 in. Bulb Tee & 122 & 1.34 & L/1089 \\
\hline 22 & 72 in. Bulb Tee & 122 & 0.24 & $\mathrm{~L} / 6113$ \\
\hline 23 & 72 in. Bulb Tee & 124 & 0.98 & $\mathrm{~L} / 1520$ \\
\hline 24 & 72 in. Bulb Tee & 127 & 0.84 & $\mathrm{~L} / 1805$ \\
\hline 25 & 72 in. Bulb Tee & 127 & 1.47 & $\mathrm{~L} / 1038$ \\
\hline 26 & 72 in. Bulb Tee & 127 & 1.73 & $\mathrm{~L} / 881$ \\
\hline 27 & 72 in. Bulb Tee & 129 & 1.84 & $\mathrm{~L} / 841$ \\
\hline
\end{tabular}


Table E1. Summary of sweep measurement results, continued

\begin{tabular}{|c|c|c|c|c|}
\hline No. & Beam Type & $\begin{array}{c}\text { Length, } \\
\mathrm{ft}\end{array}$ & $\begin{array}{l}\text { Sweep } \delta, \\
\text { in. }\end{array}$ & $\begin{array}{c}\text { Sweep } \\
\text { (normalized) }\end{array}$ \\
\hline 28 & 72 in. Bulb Tee & 129 & 0.50 & L/3079 \\
\hline 29 & 72 in. Bulb Tee & 129 & 0.55 & L/2804 \\
\hline 30 & 72 in. Bulb Tee & 129 & 0.97 & L/1599 \\
\hline 31 & 72 in. Bulb Tee & 129 & 2.00 & $\mathrm{~L} / 774$ \\
\hline 32 & 72 in. Bulb Tee & 129 & 2.80 & $\mathrm{~L} / 552$ \\
\hline 33 & 72 in. Bulb Tee & 129 & 1.89 & $\mathrm{~L} / 821$ \\
\hline 34 & 72 in. Bulb Tee & 129 & 0.82 & L/1892 \\
\hline 35 & 72 in. Bulb Tee & 129 & 1.82 & $\mathrm{~L} / 851$ \\
\hline 36 & 72 in. Bulb Tee & 129 & 1.37 & $\mathrm{~L} / 1131$ \\
\hline 37 & 72 in. Bulb Tee & 129 & 3.28 & $\mathrm{~L} / 472$ \\
\hline 38 & 72 in. Bulb Tee & 129 & 0.57 & $\mathrm{~L} / 2714$ \\
\hline 39 & 72 in. Bulb Tee & 129 & 0.43 & $\mathrm{~L} / 3635$ \\
\hline 40 & 72 in. Bulb Tee & 129 & 2.92 & $\mathrm{~L} / 531$ \\
\hline 41 & 72 in. Bulb Tee & 129 & 0.84 & $\mathrm{~L} / 1832$ \\
\hline 42 & 72 in. Bulb Tee & 129 & 0.70 & $\mathrm{~L} / 2200$ \\
\hline 43 & 72 in. Bulb Tee & 129 & 1.75 & $\mathrm{~L} / 884$ \\
\hline 44 & 72 in. Bulb Tee & 129 & 1.38 & $\mathrm{~L} / 1122$ \\
\hline 45 & 72 in. Bulb Tee & 129 & 0.22 & $\mathrm{~L} / 7111$ \\
\hline 46 & 72 in. Bulb Tee & 129 & 1.18 & $\mathrm{~L} / 1312$ \\
\hline 47 & 72 in. Bulb Tee & 129 & 0.24 & $\mathrm{~L} / 6519$ \\
\hline 48 & 72 in. Bulb Tee & 129 & 0.48 & $\mathrm{~L} / 3246$ \\
\hline 49 & 72 in. Bulb Tee & 129 & 0.43 & $\mathrm{~L} / 3574$ \\
\hline 50 & 72 in. Bulb Tee & 129 & 0.99 & $\mathrm{~L} / 1558$ \\
\hline 51 & 72 in. Bulb Tee & 129 & 1.19 & $\mathrm{~L} / 1304$ \\
\hline 52 & 72 in. Bulb Tee & 129 & 0.74 & L/2094 \\
\hline 53 & 72 in. Bulb Tee & 129 & 2.06 & $\mathrm{~L} / 753$ \\
\hline 54 & 72 in. Bulb Tee & 129 & 1.17 & $\mathrm{~L} / 1320$ \\
\hline
\end{tabular}


Table E1. Summary of sweep measurement results, continued

\begin{tabular}{|c|c|c|c|c|}
\hline No. & Beam Type & $\begin{array}{c}\text { Length, } \\
\mathrm{ft}\end{array}$ & $\begin{array}{l}\text { Sweep } \delta, \\
\text { in. }\end{array}$ & $\begin{array}{c}\text { Sweep } \\
\text { (normalized) }\end{array}$ \\
\hline 55 & 72 in. Bulb Tee & 139 & 1.24 & $\mathrm{~L} / 1341$ \\
\hline 56 & 72 in. Bulb Tee & 139 & 2.08 & $\mathrm{~L} / 803$ \\
\hline 57 & 72 in. Bulb Tee & 139 & 1.07 & $\mathrm{~L} / 1557$ \\
\hline 58 & 72 in. Bulb Tee & 139 & 0.36 & L/4668 \\
\hline 59 & 72 in. Bulb Tee & 139 & 1.55 & $\mathrm{~L} / 1076$ \\
\hline 60 & 72 in. Bulb Tee & 139 & 1.71 & L/977 \\
\hline 61 & 72 in. Bulb Tee & 139 & 0.51 & $\mathrm{~L} / 3255$ \\
\hline 62 & 72 in. Bulb Tee & 139 & 1.81 & $\mathrm{~L} / 923$ \\
\hline 63 & 72 in. Bulb Tee & 139 & 1.92 & $\mathrm{~L} / 868$ \\
\hline 64 & 72 in. Bulb Tee & 139 & 0.45 & L/3707 \\
\hline 65 & 72 in. Bulb Tee & 139 & 2.48 & $\mathrm{~L} / 674$ \\
\hline 66 & 72 in. Bulb Tee & 139 & 1.28 & $\mathrm{~L} / 1304$ \\
\hline 67 & 72 in. Bulb Tee & 139 & 0.38 & L/4443 \\
\hline 68 & 72 in. Bulb Tee & 139 & 0.53 & $\mathrm{~L} / 3128$ \\
\hline 69 & 72 in. Bulb Tee & 139 & 0.88 & L/1902 \\
\hline 70 & 72 in. Bulb Tee & 139 & 1.14 & $\mathrm{~L} / 1459$ \\
\hline 71 & 72 in. Bulb Tee & 139 & 1.80 & L/926 \\
\hline 72 & 72 in. Bulb Tee & 139 & 1.03 & L/1626 \\
\hline 73 & 72 in. Bulb Tee & 139 & 1.22 & $\mathrm{~L} / 1369$ \\
\hline 74 & 72 in. Bulb Tee & 139 & 0.49 & $\mathrm{~L} / 3411$ \\
\hline 75 & 72 in. Bulb Tee & 139 & 0.95 & $\mathrm{~L} / 1757$ \\
\hline 76 & 72 in. Bulb Tee & 139 & 0.46 & $\mathrm{~L} / 3645$ \\
\hline 77 & 72 in. Bulb Tee & 139 & 0.74 & $\mathrm{~L} / 2253$ \\
\hline 78 & 72 in. Bulb Tee & 139 & 2.31 & $\mathrm{~L} / 722$ \\
\hline 79 & 72 in. Bulb Tee & 139 & 0.43 & L/3836 \\
\hline 80 & 72 in. Bulb Tee & 139 & 1.00 & L/1673 \\
\hline 81 & 72 in. Bulb Tee & 139 & 0.47 & L/3564 \\
\hline
\end{tabular}


Table E1. Summary of sweep measurement results, continued

\begin{tabular}{|c|c|c|c|c|}
\hline No. & Beam Type & $\begin{array}{c}\text { Length, } \\
\mathrm{ft}\end{array}$ & $\begin{array}{l}\text { Sweep } \delta, \\
\text { in. }\end{array}$ & $\begin{array}{c}\text { Sweep } \\
\text { (normalized) }\end{array}$ \\
\hline 82 & 72 in. Bulb Tee & 139 & 1.13 & $\mathrm{~L} / 1470$ \\
\hline 83 & 72 in. Bulb Tee & 139 & 1.00 & L/1664 \\
\hline 84 & 72 in. Bulb Tee & 139 & 0.48 & L/3464 \\
\hline 85 & 72 in. Bulb Tee & 139 & 0.97 & L/1719 \\
\hline 86 & 72 in. Bulb Tee & 139 & 0.92 & $\mathrm{~L} / 1813$ \\
\hline 87 & 72 in. Bulb Tee & 139 & 2.27 & $\mathrm{~L} / 735$ \\
\hline 88 & 72 in. Bulb Tee & 139 & 1.30 & $\mathrm{~L} / 1282$ \\
\hline 89 & 72 in. Bulb Tee & 139 & 2.30 & $\mathrm{~L} / 724$ \\
\hline 90 & 72 in. Bulb Tee & 139 & 1.40 & L/1188 \\
\hline 91 & 72 in. Bulb Tee & 139 & 0.82 & L/2039 \\
\hline 92 & 72 in. Bulb Tee & 139 & 0.40 & L/4216 \\
\hline 93 & 72 in. Bulb Tee & 139 & 0.77 & L/2179 \\
\hline 94 & 72 in. Bulb Tee & 139 & 1.00 & $\mathrm{~L} / 1662$ \\
\hline 95 & 72 in. Bulb Tee & 139 & 0.53 & $\mathrm{~L} / 3157$ \\
\hline 96 & 72 in. Bulb Tee & 139 & 1.10 & $\mathrm{~L} / 1512$ \\
\hline 97 & 72 in. Bulb Tee & 139 & 1.60 & $\mathrm{~L} / 1039$ \\
\hline 98 & 72 in. Bulb Tee & 139 & 1.25 & $\mathrm{~L} / 1336$ \\
\hline 99 & 72 in. Bulb Tee & 139 & 0.94 & $\mathrm{~L} / 1778$ \\
\hline 100 & 72 in. Bulb Tee & 139 & 0.30 & $\mathrm{~L} / 5551$ \\
\hline 101 & 72 in. Bulb Tee & 139 & 0.33 & $\mathrm{~L} / 5120$ \\
\hline 102 & 72 in. Bulb Tee & 139 & 0.64 & $\mathrm{~L} / 2624$ \\
\hline 103 & 72 in. Bulb Tee & 139 & 0.56 & L/2993 \\
\hline 104 & 72 in. Bulb Tee & 139 & 1.82 & L/919 \\
\hline 105 & 72 in. Bulb Tee & 139 & 0.53 & L/3155 \\
\hline 106 & 72 in. Bulb Tee & 139 & 2.23 & $\mathrm{~L} / 749$ \\
\hline 107 & 72 in. Bulb Tee & 139 & 0.87 & $\mathrm{~L} / 1916$ \\
\hline 108 & 72 in. Bulb Tee & 139 & 1.33 & $\mathrm{~L} / 1253$ \\
\hline
\end{tabular}


Table E1. Summary of sweep measurement results, continued

\begin{tabular}{|c|c|c|c|c|}
\hline No. & Beam Type & $\begin{array}{c}\text { Length, } \\
\mathrm{ft}\end{array}$ & $\begin{array}{l}\text { Sweep } \delta, \\
\text { in. }\end{array}$ & $\begin{array}{c}\text { Sweep } \\
\text { (normalized) }\end{array}$ \\
\hline 109 & 72 in. Bulb Tee & 139 & 1.14 & $\mathrm{~L} / 1458$ \\
\hline 110 & 72 in. Bulb Tee & 139 & 0.50 & $\mathrm{~L} / 3316$ \\
\hline 111 & 72 in. Bulb Tee (Modified) & 121 & 0.34 & $\mathrm{~L} / 4249$ \\
\hline 112 & 72 in. Bulb Tee (Modified) & 121 & 0.55 & $\mathrm{~L} / 2628$ \\
\hline 113 & 72 in. Bulb Tee (Modified) & 121 & 0.61 & $\mathrm{~L} / 2364$ \\
\hline 114 & 72 in. Bulb Tee (Modified) & 121 & 0.98 & $\mathrm{~L} / 1483$ \\
\hline 115 & 72 in. Bulb Tee (Modified) & 121 & 0.91 & $\mathrm{~L} / 1601$ \\
\hline 116 & 72 in. Bulb Tee (Modified) & 121 & 0.87 & $\mathrm{~L} / 1669$ \\
\hline 117 & 72 in. Bulb Tee (Modified) & 121 & 0.46 & $\mathrm{~L} / 3162$ \\
\hline 118 & 72 in. Bulb Tee (Modified) & 121 & 0.44 & L/3293 \\
\hline 119 & 72 in. Bulb Tee (Modified) & 121 & 0.36 & $\mathrm{~L} / 4050$ \\
\hline 120 & 72 in. Bulb Tee (Modified) & 121 & 0.65 & $\mathrm{~L} / 2235$ \\
\hline 121 & 72 in. Bulb Tee (Modified) & 121 & 0.42 & $\mathrm{~L} / 3464$ \\
\hline 122 & 72 in. Bulb Tee (Modified) & 121 & 0.73 & L/1992 \\
\hline 123 & 72 in. Bulb Tee (Modified) & 121 & 0.95 & $\mathrm{~L} / 1524$ \\
\hline 124 & 72 in. Bulb Tee (Modified) & 121 & 0.30 & $\mathrm{~L} / 4815$ \\
\hline 125 & 72 in. Bulb Tee (Modified) & 121 & 0.36 & $\mathrm{~L} / 4078$ \\
\hline 126 & 72 in. Bulb Tee (Modified) & 121 & 0.33 & L/4335 \\
\hline 127 & 72 in. Bulb Tee (Modified) & 121 & 0.36 & $\mathrm{~L} / 4078$ \\
\hline 128 & 72 in. Bulb Tee (Modified) & 121 & 0.77 & $\mathrm{~L} / 1890$ \\
\hline
\end{tabular}

